Portland State University

PDXScholar

$1-1-1987$

\title{
A Study of Ability to Choose Appropriate Conflict Behavior Determined by the Relationship Between Locus of Control and Conflict Behavior Styles
}

Mary H. Zinkin

Portland State University

Follow this and additional works at: https://pdxscholar.library.pdx.edu/open_access_etds Let us know how access to this document benefits you.

\section{Recommended Citation}

Zinkin, Mary H., "A Study of Ability to Choose Appropriate Conflict Behavior Determined by the Relationship Between Locus of Control and Conflict Behavior Styles" (1987). Dissertations and Theses. Paper 335.

https://doi.org/10.15760/etd.335

This Dissertation is brought to you for free and open access. It has been accepted for inclusion in Dissertations and Theses by an authorized administrator of PDXScholar. Please contact us if we can make this document more accessible: pdxscholar@pdx.edu. 
A STUDY OF ABILITY TO CHOOSE APPROPRIATE CONFLICT BEHAVIOR

DETERMINED BY THE RELATIONSHIP BETWEEN

LOCUS OF CONTROL AND CONPLICT

BEHAVIOR STYLES

by

MARY H. ZINKIN

A dissertation submitted in partial fulfillment of the requirements for the degree of

\footnotetext{
DOCTOR OF PHILOSOPHY

in

URBAN STUDIES
}

Portland State University

(C) 1987 
TO THE OFFICE OF GRADUATE STUDIES AND RESEARCH:

The members of the Committee approve the dissertation of Mary $\mathrm{g}$. Zinkin presented November 6, 1987.

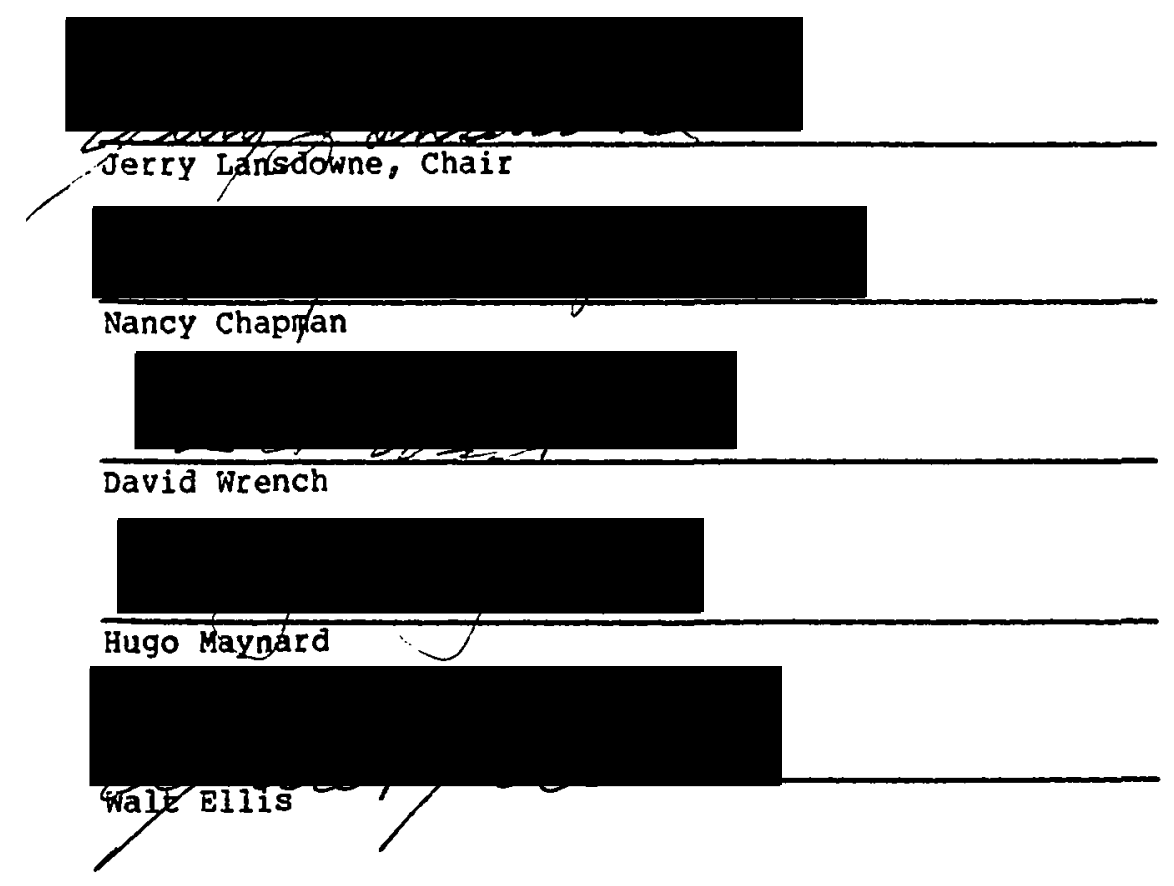

APPROVED :

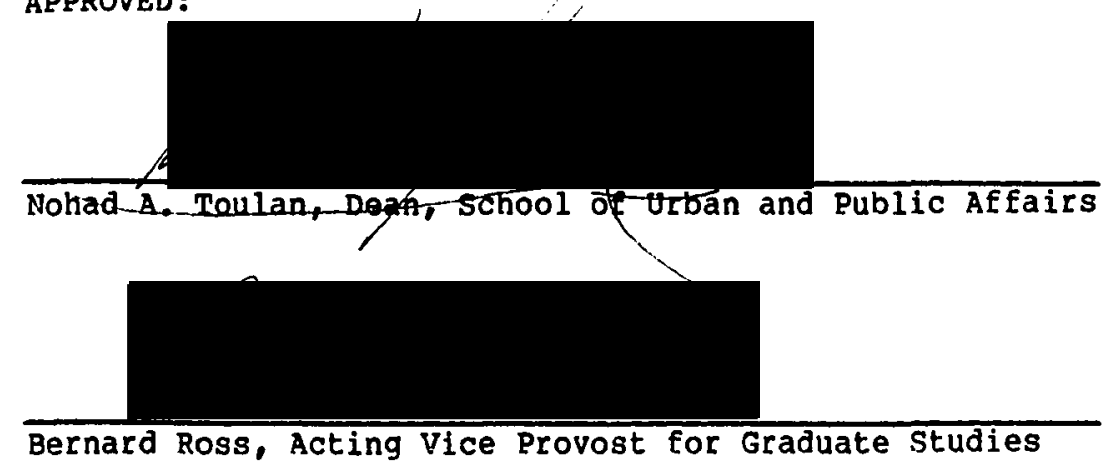


AN ABSTRACT OF THE DISSERTATION OF Mary H. Zinkin for the Doctor of

Philosophy in Urban Studies presented November 6, 1987.

Title: A Study of Ability to Choose Appropriate Conflict Behavior Determined by the Relationship Between Locus of Control and Conflict Behavior styles.

APPROVED BY MEMBERS OF THE DISSERTATION COMMITTEE:

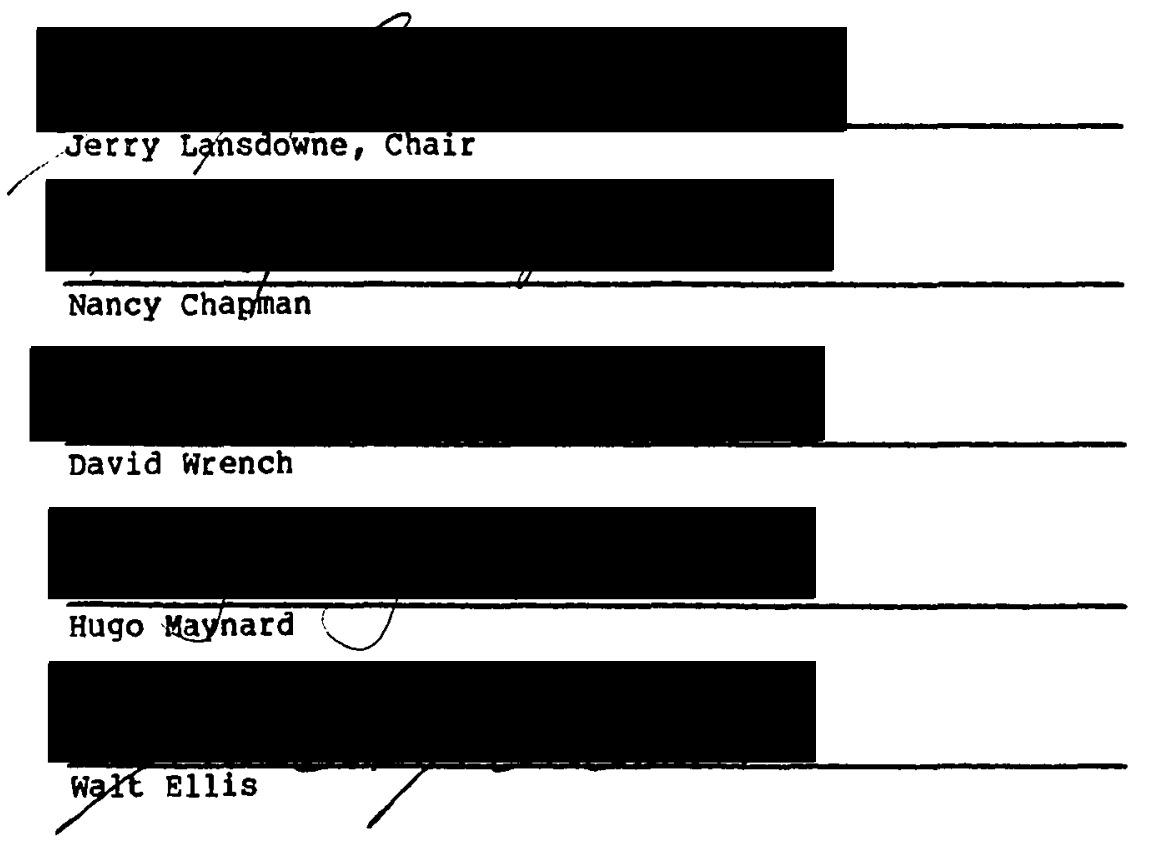

This study addressed two major theoretical controversies in the literature: 1) whether conflict behavior can best be explained by personal characteristics or by situational characteristics and 2) whether there is one best way to handle conflict or several effective ways depending on the situation. Specifically, it explored the relationship between locus of control (internal, powerful others, chance) and conflict behavior (non-confrontation, solution-orientation, 
control) in situations where choosing each of these strategies was regarded most appropriate. The study gathered data relevant to four questions:

1. Is there a relationship between an individual's conflict behavior style and personal characteristics such as feelings of power and control?

2. If there is a relationship, does it affect one's choice of conflict behavior in particular situations?

3. Can situations be defined so that a particular conflict behavior could be considered effective and therefore most appropriate?

4. Are all individuals equally disposed to choose the effective conflict behavior in the situation?

Using the results of previous studies exploring the effectiveness of conflict behavior strategies in various situations, characteristics were defined by this researcher forming the basis for regarding choice of a particular strategy as most appropriate. Conflict situations incorporating those characteristics were then developed and pretested for use in administering the organizational Communication Conflict Instrument (OCCI) (Putnam and Wilson, 1982). Pour conflict situations were used. Situation 1 described a conflict with a lover/intimate friend - no predictions were made as to a particular behavior being effective. The situation was intended to reflect one's characteristic response to conflict. Situation 2 described a conflict with a co-worker and solution-orientation was predicted to be most effective. Situation 3 described a conflict with an assistant where control behavior was predicted to be most effective. Situation 4 described a conflict with a 
professor. Non-confrontation was considered the most effective strategy choice in the situation.

Levenson's I, P, and C Locus of Control scale (1973) and Putnam and Wilson's OCCI (1982) were administered to 163 undergraduates at Portland State University. In addition, subjects completed a questionnaire developed by the researcher to obtain information to evaluate the validity of each situation as well as gather demographic information on each subject. Each subject signed an informed consent form. Pemales comprised 638 of the sample, males - 37\%. The age range for the sample was $16-45$ years, 74.28 were between the ages of 18-21, 19.68 between the ages of $22-31$. Results of canonical correlations indicated that "powerful others" locus of control was related to choice of non-confrontation conflict behavior. Multivariate analysis of variance results indicated that the situation, sex, and locus of control variables account significantly for differences in choice of conflict behavior. Using the Newman-Keuls procedure resulted in an unexpected outcome; al1 subjects reflected a significant tendency to choose the appropriate behavior in the situation.

The findings of this study suggest that conflict behavior can be explained by both personal characteristics and situational characteristics. The study also provides evidence that there is not one best way to handle conflict across all situations, supporting a contingency approach to interpersonal conflict. 


\section{ACRNOWLEDGMENTS}

The style manual for dissertations 1 ists an acknowledgement page (if applicable); in my case there needs to be more than one acknowledgment page. Although a dissertation is one of the only true individual endeavors, I have been greatly encouraged, supported, and challenged by others which has enriched this experience.

I first want to thank Jerry Lansdowne, Nancy Chapman, David Wrench, Hugo Maynard, and Walt Ellis for being the best dissertation committee. They have, individually and as a group, asked the hard questions, paid rigorous attention to details, spent hours with me designing the questionnaires and evaluating the results, provided tremendous support and encouragement, and made me feel so special and worthwhile.

A special acknowledgement is due Jim Paulsen, not an official member of my committee, but an honorary one. The month of February was spent, day after day, in Jim's office with computer printouts strewn about, literally with our heads together analyzing the data. Others who made this dissertation possible are steve Rildahl and Iynn Godat who provided me with a large sample; Multnomah county and the National Institute for Dispute Resolution for fellowship funds; and Robert Kopp for assisting me with the computer and statistical analysis. Thanks to Chris Arthur, I discovered Locus of Control. Bobby Weinstock 1 istened to and challenged my original thoughts and supported me through every stage in this process. I'm grateful for all my friends 
who were interested in me and this journey, particularly Peggy, Sharon, Dennis, Ray, Erica, and Marcia.

Without Chris Parley I fear I never could have accomplished this goal. She has been a great source of love, support, and understanding; she helped edit chapters; she patiently reminded me to pay attention to the mundane necessities of life (eating and sleeping) as I needed constant reminders.

I thank Georgia Baylis for her help in typing several drafts. Words cannot express how grateful I am for Mary Dozark's competent assistance in preparing this dissertation for defense and final submission.

Lastly, I dedicate this to my family of origin, for the roots of my theories come from analyzing and obtaining an adult understanding of my experiences with them. 
TABLE OF CONTENTS

PAGE

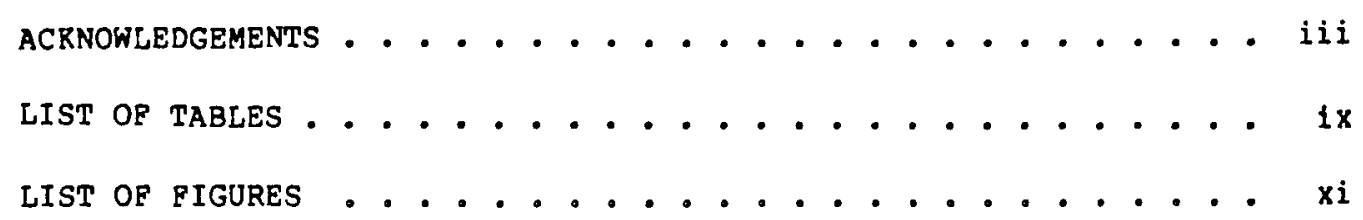

CHAPTER

I INTRODOCTION . . . . . . . . . . . . . . . I

LIMITS ON CONELICT RESOLUTION . . . . . . . . . . 1

CONFLICT BEHAVIOR STYLES AND LOCUS OF CONTROL . . . . 3

EFPECTIVE CONPLICT BEHAVIOR IN PARTICULAR SITUATIONS . - 6

II THEORETICAL CONTROVERSIES-REVIEW OP THE LITERATURE . . - 9

OVERVIEW .......................... 9

THE NATURE OF CONFLICT BEHAVIOR . . . . . . . . . 9

Classifying Conflict Behavior . . . . . . . . 9

Conflict Behavior as an Aspect of Personality . . . 10

Situational Factors in Conflict Behavior . . . . 13

DEVELOPING A CONTINGENCY MODEL . . . . . . . . . . . 14

Effective Conflict Management . . . . . . . . 14

Situation Characteristics ........... 16

Personal Characterlstics . . . . . . . . 17

SUMMARY . . . . . . . . . . . . . . . . . 19

II METHODS .......................... 21

SUBJECTS ......................... 21

MATERIALS . . . . . . . . . . . . . . . . 21 
vii

PAGE

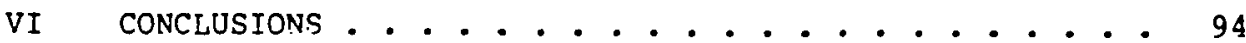

AFTERTORD ....................... 97

REFERENCES . . . . . . . . . . . . . . . . . . . . . 99

APPENDIX

A INFORMED CONSENT FORM .................. 107

B LOCUS OF CONTROL SCALE . . . . . . . . . . . 110

C CONFLict InStruments . . . . . . . . . . . . 115

D AdDITIONAL QUESTIONNAIRE . . . . . . . . . 130 
LIST OF TABLES

I Effective conflict strategy in various Situations . . . . 26

II Strategy Choices in Three Situations . . . . . . . . . 38

II Subject Responses to Measurements . . . . . . . . . . 43

IV Content Analysis of subject Responses . . . . . . . . . 43

$v$ Subject Ratings of Reality of situations . . . . . . . . . 44

VI Subject Ratings of Validity of situations . . . . . . . . 47

VII Cause of Conflict-Responses . . . . . . . . . . . 48

VIII Distribution of versions of OCCI . . . . . . . . . 49

IX OCCI Score Ranges for Normalized population . . . . . . 51

X OCCI Score Ranges from Sample population ......... 51

XI Correlation Coefficients for Variables . . . . . . . . 53

XII Canonical Correlations for Locus of Control, sex, and Conflict Behavior . . . . . . . . . . . 55

XIII Regression Analysis for Within Cell .......... 55

XIV Canonical Correlations for Conflict Behavior in Pour Situations with Locus of Control and sex ....... 59

XV Regression Analysis for Within Cell -

Non-Confrontation ............. 60

XVI Regression Analysis for Within Cell - Solution-

orientation .................. 60

XVII Regression Analysis for within Cell - control . . . . 60

XVIII Locus of Control Median Split Scores . . . . . . . . . 61 
XIX Anova Procedure Results . . . . . . . . . . 63

XX Combinations of Locus of Control . . . . . . . . . . 64

XXI Number of Cases Locus of Control by Sex . . . . . . . 72

XXII Mean Scores of Conflict Behavior Across Situations . . . 80 
LIST OF PIGURES

FIGURE

PAGE

1. Contingency Model of Conflict Behavior . . . . . . . 7

2. Conflict Behavior Modes . . . . . . . . . . . 11

3. OCCI Scores for Locus of Control Combinations . . . . 37

4. Mean Scores Non-Confrontation - Female . . . . . . . 66

5. Mean Scores Non-Confrontation - Male ......... 67

6. Mean Scores Solution-orientation - Pemale ........ 68

7. Mean Scores Solution-orientation - Male . . . . . 69

8. Mean Scores Control - Pemale . . . . . . . . . 70

9. Mean Scores Control - Male ............. 71

10. Locus of control by sex with solution-orientation scores from Situation 4 (155 cases) ......... 72

11. Relationship between LOCP and Non-Confrontation Behavior ................ 73

12. Interaction of Sex Across situation and Non-Confrontation Behavior . . . . . . . 73

13. Relationship Between sex and Solution-orientation Behavior .................... 74

14. Pour Way Interaction: LOCP $x$ LOCC $\times$ Sex $x$ Situation for Solution-orientation Behavior . . . . . . 76

15. Interaction of LOCI and situation for control Behavior . . . . . . . . . . . . . 77

16. Interaction of LOCI and Sex for Control Behavior . . . 77 
17. Interaction of LOCC and Sex for Control Behavior . . . 78

18. Interaction of LOC? and LOCC and sex for Control

Behavior ....................

19. Four Way Interaction: LOCP x LOCC x Sex x Situation

for Control Behavior . . . . . . . . . . 79 
The body of knowledge regarding the study of conflict is diverse and dispersed in several academic disciplines: sociology, economics, business administration, organizational development, communication and psychology. The study of conflict has been laden with values--conflict can be a productive process, it can be a destructive process; current theory proposes that whether conflict is a productive or destructive process depends on how it is managed. How conflict is managed is determined by many factors; one significant factor is conflict behavior style. Understanding conflict behavior styles, therefore, increases our knowledge of conflict management. Ultimately, this knowledge can be applied to ensure that conflict is a productive process.

\section{LIMITS ON CONELICT RESOLUTION}

When a group of people, in a classroom or workshop, are asked to call out their automatic response to the word "conflict", words such as the following are heard:

$\begin{array}{llllll}\text { powerless } & \text { struggle fight destroy anger cry } \\ \text { challenge } & \text { scary } & \text { war } & \text { yell } & \text { hostile hurt }\end{array}$

As suggested by these associations, definitions of conflict are usually laden with a negative value. Examples of definitions and assumptions about conflict as presented in the literature are: incompatible goals, scarce rewards or resources, incompatible interests, disagreements, competition. A commonly accepted definition of conflict is: 
Conflict is an expressed struggle between at least two interdependent parties who perceive incompatible goals, scarce rewards, and interference from the other party in achieving their goals. (Hocker \& Wilmot, 1985, p.23)

This definition seems to represent accurately most people's experience in a conflict situation. This study offers an explanation for why associations and experiences with conflict seem to be negative.

In order to build a more neutral association with conflict it is important for the definition to be relatively neutral as well. For the purposes of this study, the definition of conflict will be "a natural tension arising from differences".

When the same group of people, after calling out their automatic response to conflict, are asked what skills are needed to resolve conflict they can list easily the necessary elements of successful conflict resolution. However, knowledge of skills needed to resolve conflict does not necessarily translate into actual successful conflict resolution. As is true for any skill, practice is required to master the resolution of conflict. In addition, the ability to utilize conflict resolution skilis may be limited by the negative feelings associated with conflict.

As evidenced by the automatic response to the word "conflict" as listed on page 1 , our practice with conflict has been and is an extremely negative experience. This may impair our ability to use our knowledge. As Lawrence and Lorsch noted:

Managers in all the organizations we studied almost unanimously saw confrontation as the most desirable mode of conflict resolution. Yet our findings indicate it is used much less than it is recommended. This is most commonly explained by the assumption that people have the requisite knowledge, but have a personality-based aversion to confronting differences sharply. (Lawrence \& Lorsch, 1967, p. 222) 
One of the purposes of this study is to investigate further that assumption that people have a personality-based aversion which affects use of a particular conflict behavior. To understand more about individual conflict behavior, a system of classifying behavior into styles has been developed.

CONETICT BEHAVIOR STYLES AND LOCUS OF CONTROL

This dissertation is based on the premise that our first experience with conflict, where we develop our response to it, is in the family of origin. The family is a system of interdependent parties. Most often in the event of incompatible goals or scarce rewards, the children (or least powerful parties) experience interference from the parents (or more powerful parties) in achieving their goals. It, therefore, appears that we usually develop and learn a response to conflict in a situation where we have less power. This pattern of interaction can easily lead to the development of an underlying belief system that progresses as:

1. I won't get what I want if it is different from what the other party wants.

2. I shouldn't want it at all.

3. I don't know what I want.

Resolving conflict involves some level of asserting one's own needs and cooperating to satisfy the other's needs at the same time. However, in the family of origin one is more likely to "cooperate" than to "assert" if given the opportunity to work on resolving conflicts. What occurs most often is the parent (other) asserting her/his need. 
A basic determinant of one's conflict style is, therefore, the particular response to the above mentioned pattern of interaction, particularly 1 . In order to understand more how this pattern of interaction affects the development of one's conflict behavior style it seems that it would be helpful to focus on the individual's perceptions of power and control.

A concept that has been developed to capture one's expectations of the relationship between behavior and its results or outcomes is locus of control.

The term locus of control refers to whether people believe that outcomes are controllable, in other words whether outcomes are believed to be contingent upon behavior. (Deci \& Ryan, 1985, p. 1131

Rotter (1966) developed the first scale to measure locus of control, the Rotter Internal-External Locus of Control Scale. Simply stated, internal locus of control refers to an individual who believes that the outcome is contingent upon his/her behavior. External locus of control refers to an individual who believes that outcomes are not contingent upon his/her behavior. As decharms (1981) explains, the feeling that getting what you want is in your hands is reflective of an internal locus of control. Peeling that getting what you want is in the hands of others is an external locus of control.

If conflict behavior styles originally develop in response to feelings of "how I get what I want", then locus of control orientations should help distinguish the differences in various styles. Since locus of control also involves one's feelings and expectations in regards to getting things in relation to others, it can offer critical insight when applied to understanding the development of conflict behavior styles. 
Feelings and expectations of control in conflict situations may generate many of the tensions felt in conflict situations.

Conflict behavior styles reflect an individual's patterned response to conflict. If the individual has beliefs that what is desired is not within her/his control, going back to family experiences, then that "external" orientation would be expected to generate negative feelings and limit ability to choose appropriate strategies for dealing with conflict. Therefore, the more control one feels in conflict, the more one would be expected to be able to use the most effective/ appropriate behaviors in each situation:

The effective conflict manager preserves a harmonious relationship with others as they solve problems. Ineffective conflict management is characterized by behavior that tries to defeat or avoid the issues that bring people into conflict. (Yelsma \& Brown, 1985, p. 734)

Whether each individual has a certain characteristic style of conflict behavior, or whether an individual typically chooses different styles in different contexts has been researched and discussed in the literature. The purpose of this study is to explore a third possibility--that choice of conflict behavior is based on an orientation to conflict determined by feelings of power and control; and that one's ability to choose the most appropriate behavior is limited by these personality factors.

First, the study will determine relationships between locus of control and conflict behavior styles, to document the contribution those feelings of power and control make to the development of styles of conflict behavior. 
Second, it w1ll examine how the ability to choose appropriate conflict behavior in different situations is affected by the relationship between locus of control and conflict behavior style. Finally, the study will develop conflict theory further by offering a contingency model of conflict behavior. This model, simply stated, assumes that one can define appropriate conflict behavior in a particular situation and asserts that some individuals have more ability than others to choose that effective conflict behavior style. This ability is determined by the intervening factors in Figure 1.

EFFECTIVE CONFLICT BEHAVIOR IN PARTICULAR SITUATIONS

Effective conflict behavior is commonly defined as a match between the conflict behavior style and the situation. Following Blake and Mouton (1964), there have been a number of attempts to classify the different ways in which an individual may deal with conflict. Although five different conflict behavior modes have been described by a number of researchers (Thomas, 1976; Rahim Bonoma, 1979), a factor analytic study by Putnam and wilson (1982) suggests that these represent only three dimensions of behavior. These are:

1. Non-confrontation - avoiding or accommodating, including failure to take a position, withdrawal from conflict, sidestepping situations, soothing the other and seeking harmony, playing down differences.

2. Solution-orientation - compromising and collaborating, including proposing middle ground positions, integrating, 


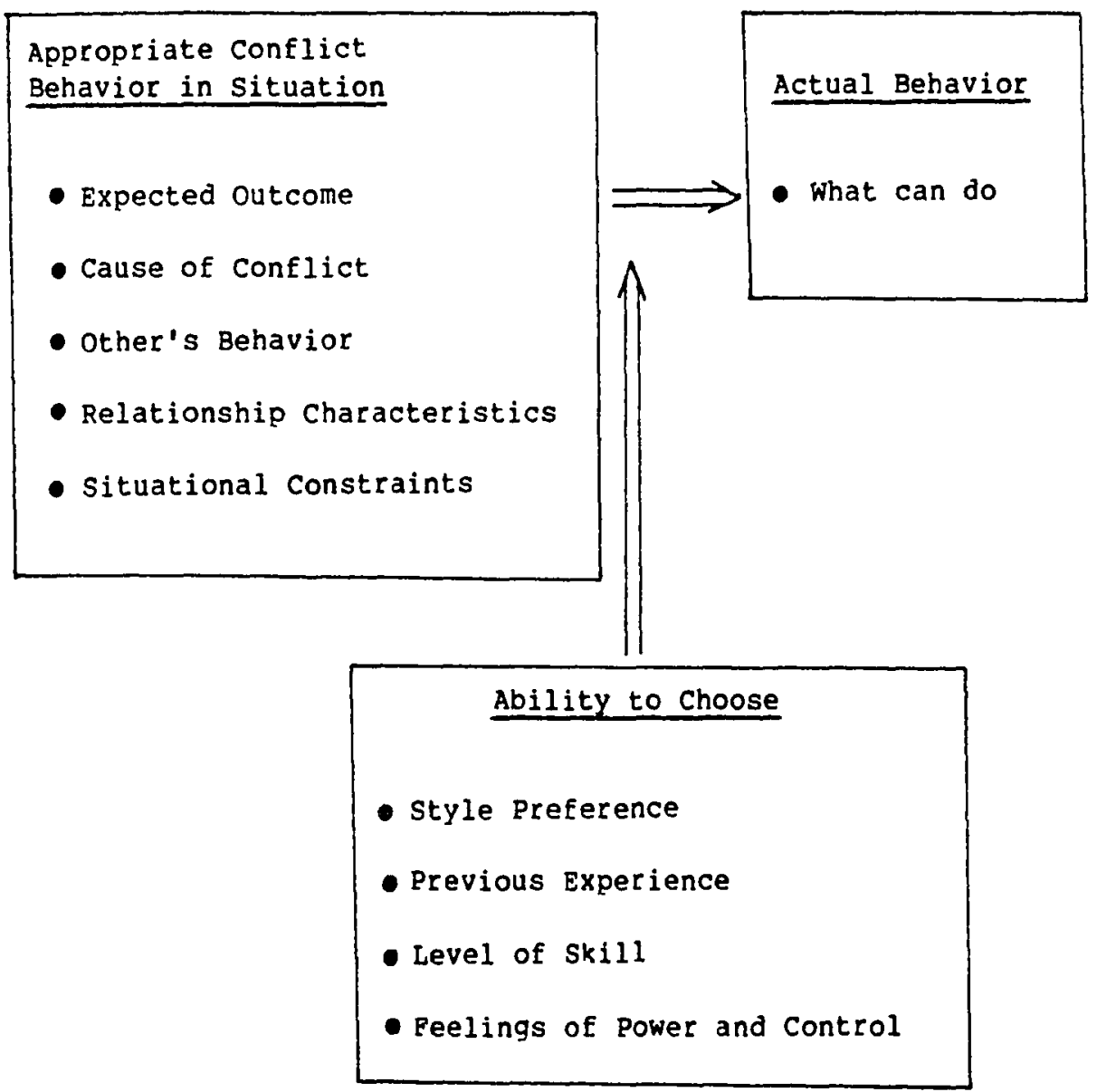

Figure 1. Contingency model of conflict behavior. 
confronting disagreements and problem solving to find solutions.

3. Control - competing, including dominating, forcing behavior and win-lose arguing.

Prom previous studies it is possible to get some idea of what strategies are most appropriate in each situation. In some situations non-confrontation is the best approach, in others solution-orientation is the best approach, and in still others control is the most effective behavior to manage the conflict.

Since effective conflict management requires a match between the situation and the conflict behavior, once an individual assesses the situation to determine the behavior that will be most effective, all that remains is the ability to behave in that way. Yet, conflict management resulting in a productive process seems to be the exception rather than the rule. One can assume, therefore, that the ability to choose the effective strategy and behave accordingly in a particular situation is not guaranteed by the requisite knowledge.

There is much interest in understanding conflict and how to be effective in conflict management. This study will focus on the relationship between conflict behavior styles and locus of control as a means of understanding one's ability to choose appropriate/effective conflict behavior in particular situations. 
CHAPTER II

THEORETICAL CONTROVERSIES-REVIEW OF THE LITERATURE

OVERVIEW

Although there is apparent agreement in the literature that conflict behavior can be categorized, there is not agreement as to the nature of the categories. Some researchers argue that each individual has a predisposition to a particular conflict behavior style, and that this is associated with personality variables. Regardless of the situation, these researchers argue, a given individual will behave in a consistent manner. Other researchers argue that effective conflict managers will choose the most appropriate mode depending on the context and situation. These researchers assert that the situation is the key to understanding conflict management and that any individual can behave as dictated by the situation, utilizing a range of conflict behaviors.

A third possibility has been presented in the previous chapter. It may be that personal characteristics, such as, personality variables and past experience influence the extent to which the individual is able to select the most appropriate behavior in a particular situation. This may have different implications from either of the other theories.

THE NATURE OF CONFLICT BEHAVIOR

Classifying Conflict Behavior

Pive modes of conflict behavior were initially proposed by Blake \& Mouton (1964). Thomas (1976) modified the original model, resulting in 
the following scheme for classifying conflict behavior (Figure 2).

As operationalized in the interpersonal context by Blake \& Mouton (1964) and later researchers, competing has been identified with forcing behavior and win-lose arguing; collaborating has been identified with confronting disagreements and problem solving to find solutions; avoiding has been identified with withdrawal and failure to take a position; accommodating has been identified with attempting to soothe the other person and seek harmony; and compromising has been identified with the proposal of middle ground positions. (Rilmann \& Thomas, 1975, p. 971)

Rahim and Bonoma (1979) modified this scheme slightly by differentiating the styles of handing conflict on two basic dimensions, concern for self and concern for others. Their dimensions reflect an individual's motivation orientation resulting in five styles. Compared with Thomas' modes (in parentheses), they are avoiding (avoidance), dominating (competition), obliging (accommodation), compromising (compromise) and integrating (collaboration).

Researchers have reached contrasting conclusions, using tests developed to identify preference for conflict behavior style (Rilmann \& Thomas, 1977; Lawrence \& Lorsch, 1967; Ball, 1969; Putnam \& Wilson, 1982; Rahim, 1983), as to what factors cause an individual to adopt a particular style.

\section{Conflict Behavior As An Aspect of Personality}

Many researchers interpret styles as stable aspects of individual personality, which will be adopted regardless of the situation. Terhune (1970) concludes after reviewing studies of cooperation and conflict that personality variables do influence behavior and that more research is needed to focus on the personality and less on the situation. In the following studies, some researchers have used terminology which differs 


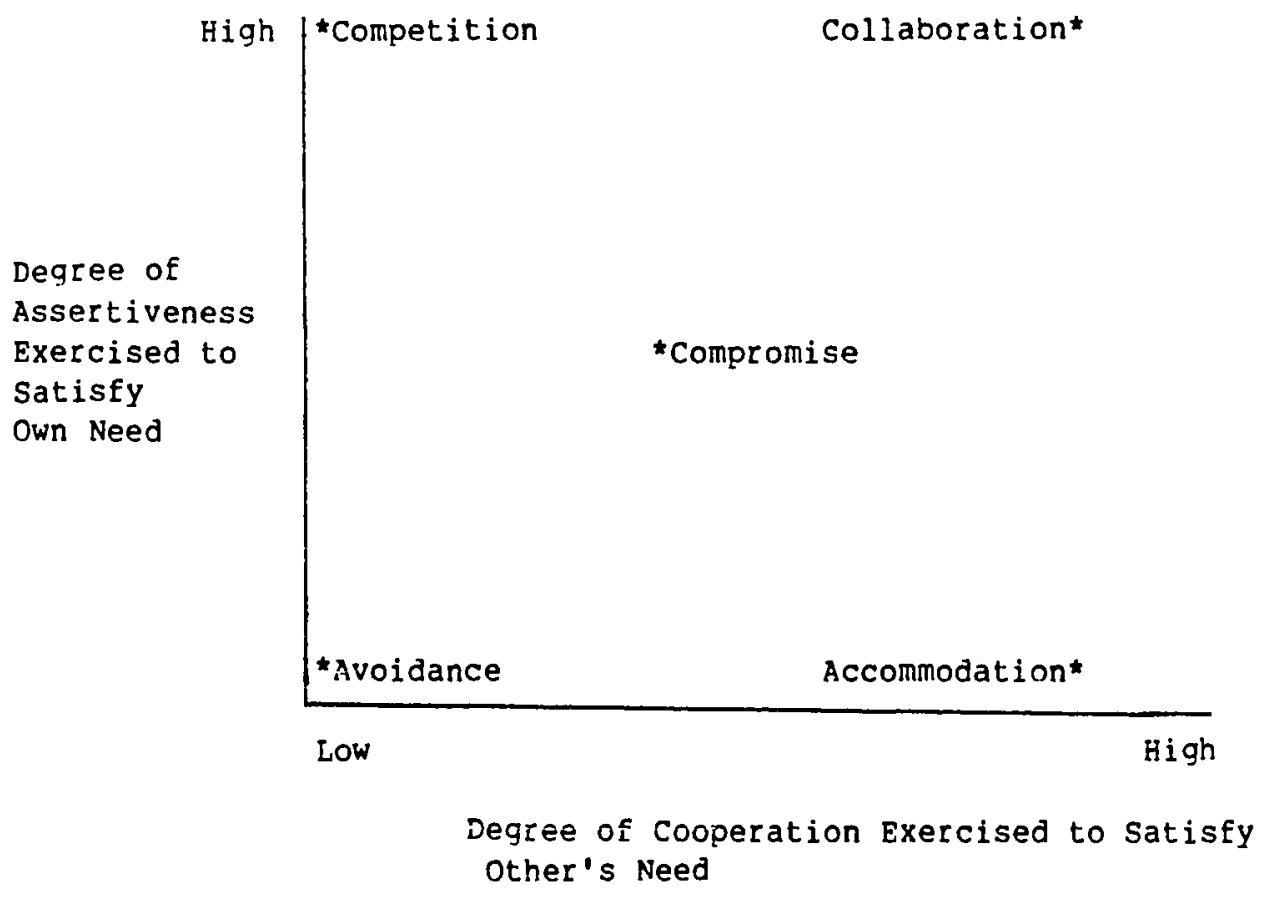

Figure 2. Conflict behavior modes.

slightly from the definition of conflict behaviors as presented by Thomas (1976). In these studies smoothing incorporates both avoidance and accommodation; forcing includes competition; and confronting incorporates both collaboration and compromise. Bell \& Blakeny (1977) studied relationships among conflict resolution modes and four personality variables (achievement, dominance, aggression, affiliation) resulting in a single significant correlation between achievement scores and the confronting mode. Jones \& Melcher (1982) developed eleven hypotheses relating nine personality variables - achievement, dominance, aggression, affiliation, deference, succorance, nurturance, dogmatism, 
and Machiavellianism - to the preference for smoothing, forcing, and confronting. All significant correlation coefficients were low, explaining only a small amount of the variance in mode preference. Rilmann \& Thomas (1975) investigated the Jungian psychological correlates of an individual's choice of five different conflict handling modes: competing, collaborating, compromising, avoiding, and accommodating; with significant findings that suggest basic psychological predispositions may influence the choice of conflict handling modes. Brown, Yelsma, \& Reller (1981) conceived of six predispositions that contribute to the way human beings handle conflict. These six dynamic constructs of personality are range of feelings, task energy, respect for community, respect for others, desire for control, and concern for one's own self uniqueness.

The researchers in this school of thought have arrived at similar conclusions. While studies in this group have resulted in several significant correlations, the correlations have been fairly low explaining only small amounts of variance.

Thomas (1976) proposed that individuals possess a hierarchy of responses to conflict, with a dominant style being shaped by motives and abilities. If the dominant style fails to work, then other responses-"back up styles" may be tried.

This is not to say that party has inflexible traits and that his behavior does not vary from situation. Rather, party is assumed to have some tendencies in his behavior. (Thomas, 1976, p. 913)

The failure of research to find large relationships between personality factors and conflict behavior suggests the advisability of investigating contingent relationships. 
Situational Pactors In Conflict Behavior

Other researchers propose that conflict behavior is contingent on the situation and that people are able to choose different styles in different contexts. Folger \& Poole (1984) argue that the most useful position defines styles as orientations people can take toward conflict -- a general expectation of how conflict should be approached. They continue that "choosing an orientation is making a decision about the principles that will guide one through the conflict; it is choosing the degree to which parties will be cooperative and/or assertive". (Folger \& Poole, 1984, p.44)

Researchers in this group oppose the personality-trait model of conflict hehavior and have conducted studies focusing on the effectiveness of the behavior in the situation rather than on the individual style of behavior. These studies introduce the concept of choice of behavior as opposed to predisposition, and evaluate the use of particular choices in various situations. The evidence these researchers present is indirect. Burke (1970) reported that supervisors who used forcing and avoiding were rated least constructive in their approach to conflict management, while those who confronted or smoothed over problems were perceived as most constructive. This finding differed from earlier reports by Lawrence \& Lorsch (1967) who stated that forcing was an effective back-up method to confrontation, rather than smoothing. Burke (1970) explains the difference by proposing that humans will feel conflict as constructive if they are given some degree of consideration in its resolution. 
In sum, these researchers have attempted to shift the focus of research away from personality and on to aspects of the situation.

DEVELOPING A CONTINGENCY MODEL

\section{Effective Conflict Management}

While there is an underlying assumption that individuals do possess, and differ in, interpersonal conflict styles, it is also assumed that effective modes of conflict resolution can be identified and exercised by anyone - regardless of their predisposition or tendencies. Other studies of conflict behavior (Phillips \& Cheston, 1979) have shown that people change in response to their situation, and that more effective people are more flexible. In fact, within the last ten years, several researchers have attempted to define under what circumstances a particular conflict management behavior will be most effective. As Thomas, Jamieson, \& Moore (1978) report, long range objectives are to provide conflict parties with a repertoire of different conflict handling modes and to progress toward a contingency theory to enable individuals to make informed, rational choices of modes on the basis of their usefulness in specific situations.

Phillips Cheston (1979) identified the characteristics that determine when problem solving, forcing, and avoiding were most appropriate as: the conflict issue, the power relationship, the climate for resolution, the existing procedures, and long-term potential for recurrence. Renwick (1975) investigated the impact that the topic and the source of the disagreement had on choices of conflict behavior in organizational settings. She found that while the nature of the 
disagreement did have an impact, behavioral predispositions also played a major role in shaping responses to conflict. Robbins (1978) defined three sources of conflict: communication, structure, and personal behavior factors. He evaluated the strength and weaknesses of the various conflict resolution techniques, in an attempt at defining appropriateness to various situations.

Collaboration is often regarded as the ideal means to manage conflict, however, none of the conflict modes are regarded as appropriate for every contingency.

Essentially, the collaborationists argue that theirs is the most preferred strategy for the good of the enterprise because: (1) open and honest interaction promotes authentic interpersonal relations; (2) conflict is used as a creative force for innovation and improvement; (3) the process enhances feedback and information flow; and (4) the solving of disputes has a way of improving the climate of the organization so that there is more openness, trust, risk taking, and feelings of integrity. (Derr, 1978, p. 78)

Derr further defines the conditions required for collaboration and the skills required, and the considerations that suggest when power-play is an appropriate method.

Filley (1978) reports that collaboration/problem solving is underlearned, while power-oriented methods of dominance and submission are learned and practiced. He also considers the mutuality of dependence, the requirement of reaching an agreement, and the importance of the use of creativity as essential in the choice of problem solving in manaing conflict.

Hocker \& wilmot (1985) provide examples of appropriate and inappropriate situations for employing the five styles, depending on the goals desired. 
Rahim (1985) studied how managers handle conflict with supervisors, subordinates, and peers and found a difference; that is managers were primarily obliging with superiors, integrating with subordinates, and compromising with peers. Rahim then gives examples of when one style may be more appropriate than another.

Musser (1982) in an attempt to balance the perspective in the 1iterature studied the subordinate's choices of conflict management strategy in high-stakes conflicts. In organizational conflict the manager and the subordinate utilize conflict strategies. Musser adds to the analysis of effective conflict management the fit of both parties respective strategies as an important element to analyze.

\section{Situation Characteristics}

The model developed by Hocker wilmot (1985) based on Thomas (1977), Phillips \& Cheston (1979), and their own experiences with people in workshops and seminars provides a foundation for defining appropriateness of each conflict strategy. The other studies cited in the previous section support and in some cases contribute additional aspects to the Hocker \& Wilmot (1985) model.

The Hocker Wilmot (1985) model suggests the following situational characteristics to determine appropriateness: the power relationship, the degree of interdependence, the time factor, the desired goals, and the nature of the situation in terms of being temporary or lasting. Both Derr (1978) and Robbins (1978) concur with these characteristics and in addition cite a value or ideological difference as an important consideration. Filley's (1978) description 
of the requirements for successful use of collaboration support the mode1.

The contingency model proposed by theorists thus far states there is no one best way to handle conflicts in all situations, rather different approaches are effective in different situations. This study expands upon that by offering characteristics of situations to help determine when a particular approach would be most effective.

\section{Personal Characteristics}

Given that there may be appropriate conflict behavior in particular situations, this study proposes that personal characteristics influence an individual's ability to choose that appropriate behavior. This study also is based on the premise that there is a relationship between personal characteristics and conflict behavior.

In reviewing the literature regarding conflict behavior as an aspect of personality previously cited, it was apparent that research had not been conducted using locus of control as the personality variable.

Locus of control was selected for this study because of its hypothesized relationship to the development of conflict behavior styles.

Since Rotter's (1966) study of the internal-external control variable was published, substantial research has been conducted. As reported in Throop \& MacDonald (1971), by 1971 there were already 339 articles on the internal-external control dimension.

A review of the locus of control literature to substantiate its applicability to this study and to select the most reliable measure was 
conducted.

Rotter (1966) developed from social learning theory the concept of internal-external control of reinforcement. Internal control refers to those who believe reinforcements are contingent upon their own behavior. External control refers to those who believe that reinforcements are not under their own personal control but rather are under the control of powerful others, luck, chance, fate, etc.

One of the greatest difficulties in research with the internalexternal dimension lies in the different definitions given to the construct (Palenzuela, 1984). While there is great variation in definition, support can be found (Gurin et al, 1969; Palenzuela, 1984; Paulhus \& Christie, 1981; Wallston \& Wallston, 1981; Worell et al, 1981) for the term locus of control to be identified as perceived power or control. It is this definition that is used in this study.

As reported in Joe (1971) studies have been conducted relating locus of control to other personality characteristics, to ethnic group and social class differences, to anxiety, to efforts to attain goals, to achievement motivation, to preferences for learning, to reactions to threat, and to psychological adjustment. He concludes:

The most significant evidence for the construct validity of the internal-external control variable lies in the area of personality functioning. While findings are not remarkably consistent, generally, data tend to support Rotter's contention that the internal-external control concept is a generalized expectancy operating across many situations. (Joe, 1971, p.634).

Nowicki \& Duke (1974) concur that the construct taps generalized perceptions of control, rather than specific control in specific situations. Individuals possess locus of control orientations. 
These broad and enduring orientations influence the way an individual perceives, interprets and responds to situations. Palenzuela (1984) summarizes the difficulties that have been experienced by researchers with the measurement of locus of control. The multidimensionality of the construct has been questioned (Rotter, 1975) and proposed (Levenson, 1973; Paulhus, 1983; Palenzuela, 1984). Much of the research throughout the years reflects efforts to validate and to improve the measurement of locus of control. The relevant research supporting the scale to be used in this study will be cited when the methodology is presented in the next chapter.

SUMMARY

This study is an attempt to make a significant contribution to the literature by investigating in a unique way several relevant questions pertaining to conflict behavior:

1. Is there a relationship between an individual's conflict behavior style and personal characteristics such as feelings of power and control?

2. If there is a relationship, does it affect one's choice of conflict behavior in particular situations?

3. Can situations be clearly defined so that a particular conflict behavior could be considered effective and therefore most appropriate?

4. Are all individuals equally disposed to choose the effective conflict behavior in the particular situation? 
Those who argue that conflict behavior is predetermined by personal characteristics would expect that individuals would adopt the same approach in the different conflict situations. Those who argue that conflict behavior is predetermined by situational characteristics would expect individuals to vary their conflict behavior in the different situations.

This study addresses some of the questions present in the longstanding person vs. situation controversy. It asks to what extent individuals are consistent or varied in their approach to conflict behavior in different situations, with the expectation that support will be found for both arguments. 
CHAPTER III

METHODS

SUBJECTS

Undergraduates in two Introductory Psychology classes, Fall term, 1986 at Portland State University were offered extra credit for voluntarily participating in this study. Each student signed an informed consent form (see Appendix A): 163 students participated. Women comprised 638 of the sample; men, 378. The age range for the sample was $16-45$ years; 74.28 were between the ages of $18-21,19.68$ between the ages of $22-31$.

\section{MATERIALS}

Three instruments were used for data collection: one to measure conflict strategy choices, one to measure locus of control orientations, and one to obtain information to evaluate the validity of each situation as well as to gather demographic information on each subject. They are located in Appendices $B, C$, and $D$.

\section{Measuring Conflict strategy Choices}

Several researchers have created instruments to measure one's preferred mode of dealing with conflict, or conflict behavior style (Rilmann \& Thomas, 1975; Lawrence \& Lorsch, 1967; Hall, 1969; Rahim, 1983). 
Putnam and Wilson (1982) developed the Organizational

Communication conflict Instrument (OCCI) to measure interpersonal

strategies of conflict management. According to Putnam and Wilson,

Conflict strategies represent the behavioral choices that people make rather than a person's characteristic style. (Putnam \& Wilson, 1982, p. 633)

In developing their scale, Putnam and Wilson first critically analyzed existing scales. As was reported by Rilmann \& Thomas (1977), previous scales had the following deficiencies: failure to measure psychometric properties of the scales, nonipsative scoring for the Lawrence and Lorsch scale, low internal reliabilities and unstable scores for some of the five styles, inconsistencies in defining the smoothing mode, and potential social desirability effects for all scales. Kilmann and Thomas developed the MODE instrument (Management of Differences Exercise) (1975) which improved reliability and social desirability, but still, according to Putnam and Wilson (1982) presented researchers with other critical problems.

First, no efforts were made to verify the existence of five distinct styles of conflict management; that is, no efforts were made to analyze the item structure of the scale. Second, internal reliabilities of the five modes did not meet the .80 standard of acceptability as established by Nunnally (1978). Third, information on item analysis is non-existent. Since each item contributed different amounts of variance to all five subscales, paired comparisons confounded the measurement of any one style, particularly since subjects were forced to choose among alternatives that might not reflect their own behavior. In effect, the content validity, item information, and factor structure of the MODE instrument were problematic. (Putnam \& wilson, 1982, pp. 634-635)

The OCCI Porm A consisted of 30 items designed to tap the communicative dimensions of the five styles of conflict behavior as originally conceptualized by Blake and Mouton (1964). However, Putnam \& 
Wilson found that form A did not meet standards of item consistency, discriminatory power, and internal reliability; so Form $\mathrm{B}$ was developed. Factor analysis of Form $B$ with an orthogonal varimax rotation resulted in a three factor solution.

A five-factor solution, while desirable to support Blake and Mouton's model, resulted in low-level loadings on the fourth and Fifth dimensions, made little conceptual sense, and accounted for only an additional nine percent of the total variance; hence a three-factor solution was adopted. (Putnam \& Wilson, 1982, p. 635)

The three factors are non-confrontation (avoiding and smoothingindirect strategies); solution-orientation (direct confrontation, compromises); and control (direct confrontation by persistent arguing and nonverbal forcing).

Examples of items from Form $B$ of the occr are noted below (putnam \& Wilson, 1982, pp. 636-637):

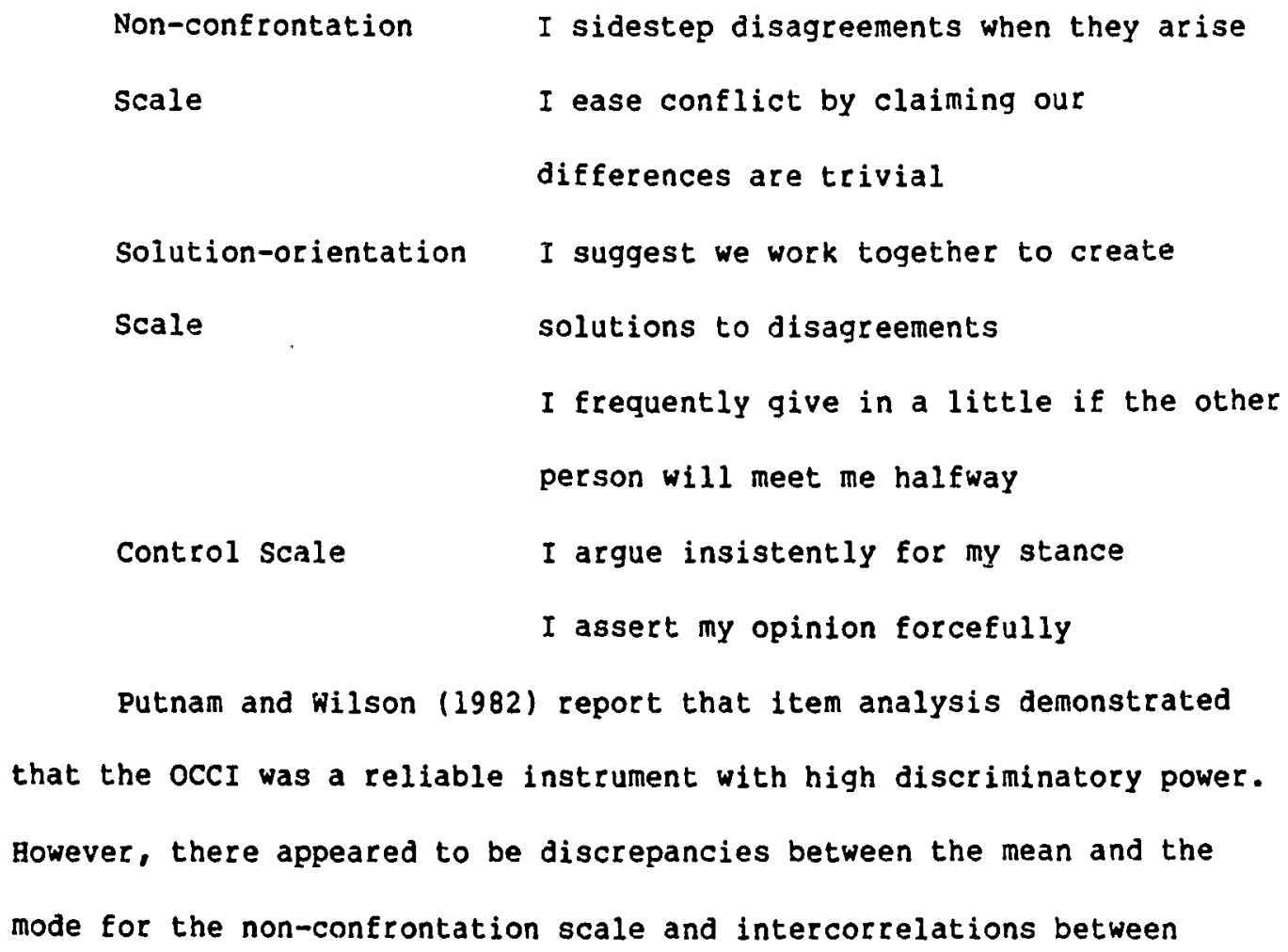


non-confrontation and control led them to believe there was a response bias in the measurement. Therefore, they developed Porm Bx of the ocCI to minimize social desirability of the non-confrontation scale.

While some social desirability continued to influence item responses, it did not account for 80 percent of the variance found in previous questionnaires (Thomas \& Rilmann, 1975). (Putnam \& Wilson, 1982, p. 639)

Putnam and Wilson report that their testing of the occI resulted in moderate construct validity; and three predictive validity studies supported the strong power of the OCCI. The OCCI measures to what extent one chooses the three different conflict behavior strategies: non-confrontation, solution-orientation, or control. Individuals receive scores on each scale; the lower the score the more the use of the strategy. The non-confrontation scale consists of 12 items, the solution-orientation of 11 and the control scale consists of 7 items, each item scored on a Likert-scale $(1-7)$. The possible range of scores on each scale is non-confrontation 12-84, solution-orientation 11-77, and control 7-49. Since the Form BX of the Putnam \& Wilson OCCI seemed superior in measuring choices of conflict strategies, it was the most appropriate instrument to use in this study.

In administering the OCCI, Putnam and Wilson encourage researchers to describe a conflict situation, specifying a context and a target. Using the results of previous studies exploring the effectiveness of conflict behavior strategies in various situations (Burke, 1970; Derr, 1978; Hocker \& Wilmot, 1985; Phillips \& Cheston, 1979; Rahim, 1983, 1985; Renwlck, 1975; Robbins, 1978; Thomas, et al, 1978) characteristics were defined by this researcher forming the basis for regarding choice 
of a particular strategy as most appropriate. These characteristics are outlined in TABLE I.

Conflict situations were developed reflecting these characteristics and pre-testing was conducted to ensure that the situation descriptions conveyed real situations.

Pretesting. Undergraduate students in three psychology classes and one Urban studies class were the subjects of the pre-test or pilot study. A total of twenty-nine students participated; 18 females and 11 males. Each subject completed an informed consent form and the questionnaire developed by the researcher (see Appendix D).

The purposes of the pilot study were:

1. to ensure that the situation descriptions were realistic

2. to ensure that the situation descriptions distinguished accurately the characteristics as described in Table I

3. to obtain a sense of the time requirements for participation in this study

4. to determine whether additional demographic information could be obtained within the time constraints

5. to ensure that the purpose of the study was not detectable or obvious (protection against response bias)

6. to obtain suggestions for improving the study

7. to establish that the measurements used (Locus of Control and OCCI) were considered by subjects to be distinct and different in purpose and content. 
TABLE I

EFFECTIVE CONRLICT STRATEGY IN VARIOUS SITUATIONS

\begin{tabular}{|c|c|}
\hline Conflict strategy & Characteristics of situation \\
\hline Non-confrontation & $\begin{array}{l}\text { * one has less power than other } \\
\text { * maintaining relationship is more } \\
\text { important than achieving goal in } \\
\text { conflict } \\
\text { * temporary situation }\end{array}$ \\
\hline Solution-orientation & $\begin{array}{l}\text { * equal power } \\
\text { * relationship and goal are equally } \\
\text { important } \\
\text { * not a temporary situation } \\
\text { * high degree of interdependence }\end{array}$ \\
\hline Control & $\begin{array}{l}\text { * one has more power than the other } \\
\text { * achieving goal more important } \\
\text { than maintaining relationship } \\
\text { * need to reach a decision quickly } \\
\text { * cause of conflict is value } \\
\text { differences }\end{array}$ \\
\hline
\end{tabular}


After analyzing the results of the pre-test, four different versions of the OCCI were created, and questionnaire packets were developed (see Appendices B, C, and D).

The situation descriptions for the four versions of the occI that were used were:

Situation 1: Imagine you are discussing where to go on vacation this summer with your lover or best friend, someone you feel intimate with. You are in a meaningful and important relationship. You disagree on where to go. You feel very strongly about where you go for a vacation.

No predictions were made as to a particular behavior being effective. The situation was intended to reflect one's typical response to conflict, because it did not reflect the particular situation characteristics portrayed in Table I.

Situation 2: Imagine you are working on a project for a class. Your co-worker on the project is someone you want to stay friends with. Your grade in the class is based on the joint grade you and your co-worker get on this project. You disagree on the format for the class presentation, a major component of the grade.

Solution-orientation behavior was predicted to be most effective.

Situation 3: Imagine you are one of the reporters for the student newspaper. In a staff meeting the Editor asks you and an assistant to cover a rally that's taking place this evening. The assistant, under you, disapproves of the rally and doesn't think the paper should produce an article. You disagree with that idea and think the paper should cover the rally. 
Control behavior was predicted to be most effective in this situation.

Situation 4: Imagine you are in the last few weeks of class with an eminent professor. You admire this professor although many students have experienced problems in the course. The professor has made an assignment which you feel is unfair. You disagree with completion of this particular assignment being one of the requirements for receiving an $\mathbf{A}$ grade.

Non-confrontation was considered the most effective strategy choice in this situation.

\section{Measuring Locus of Control orientations}

Although Rotter's I-E Locus of Control Scale (1966) is the instrument that has been used most widely, for the purposes of this study the scale developed by Hanna Levenson (1973) seems more appropriate. Levenson questioned the validity of combining under external control of expectancies, the variables of fate, chance, and powerful others. Rather, she differentiates between two types of external locus of control: 1) belief in the unordered and random nature of the world and 2) belief in an ordered and predictable world with powerful others in control. This distinction would seem to have important implications for conflict resolution style and behavior. Levenson separated Rotter's unidimensional I-E scale into three dimensions of expectancy: Internal (I scale), Powerful others (P Scale), and Chance (C Scale). The Levenson I, P, and C scales are composed both of items adapted from Rotter's scale and of additional statements written specifically for measuring belief in personal control 
(Internal scale), powerful others (Powerful others Scale), and chance or façe (Chance Scale).

The final form is comprised of three eight-item subscales, in a seven-point likert format $(0-6)$ presented as a unified 24 item scale. According to Levenson the $I, P$, and $C$ Scales differ from Rotter's I-E Scale in five ways:

1. They are presented as a Likert Scale, instead of in a forced choice format, so that their three dimensions are more statistically independent of one another than are the two dimensions of Rotter's scale.

2. The I, P, and C Scales make a personal-1deological distinction. All statements are phrased so as to pertain only to the person answering. They measure the degree to which an individual feels he or she has control over what happens, not what the person feels is the case for "people in general".

3. The items in the scales contain no wording that might imply modifiability of the specific issues. Both the factors of personal versus ideological control and system modifiability were found by Gurin, et al (1969) to be contaminating factors in Rotter's I-E scale.

4. The $I, P$, and $C$ scales are constructed in such a way that there is a high degree of parallelism in every 3 -item set.

5. Correlations between items on the new scales and the Marlowe-Crowne Social Desirability scale are negligible and nonsignificant. (Levenson, 1981, pp. 17-18)

The Spearman-Brown reliabilities are $.62, .66$ and .64 for the I, P, and c Scales.

Test-retest reliabilities for a 1-week period are in the $.60-.79$ range (Levenson, 1973a), and Lee (1976) found comparable correlations with a 7 -week test-retest interval $(.66, .62$, and .73) (Levenson, 1981, p. 23)

There have been many studies since the development of the scale that demonstrate the validity of the measure.

The three scales permit a separate assessment of three major sources of control over the individual's reinforcements. The scales have been found useful in a number of research 
applications (Levenson, 1973a, 1973b, 1974; Levenson \& Mahler, 1976; Levenson \& Miller, 1976; Prociuk \& Breen, 1975, 1976;

Wallston, 1978). (Paulhus \& Christie, 1981, p. 163)

In addition, the scales have been used to examine the relationship of locus of control to socioeconomic status and ethnicity (Garcia \& Levenson, 1975), racial differences with an adult felon sample (Shearer \& Moore, 1978), consistent home environment (MacDonald, 1971 and Reimanis, 1971), life cycle changes (Ryckman Malikioski, 1975 and Reinsch, 1979), life satisfaction in the elderly (zukotynski \& Levenson, 1976), psychological adjustment in a hospital setting (Martin, 1979), adjustment in a non-psychiatric setting (Morelli, Rrotinger, \& Moore, 1979), relationship to psychopathology (Molinari, 1979), psychological adjustment for semirural women (Marsha11, 1979), treatment outcomes of alcoholics (Castor \& Parsons, 1977), concept formation (Beck, 1979) hypnotic susceptibility (Burger, 1979), and antipollution behavior (Trigg, Perlman, Perry, Janisse, 1976). The possible score on each of the three scales ranges from $0-48$. A person can score high or low on all three dimensions. Eight questions comprise each of the three scales. The scores on each scale are interpreted as follows (Levenson, 1981, p. 59):

Internal scale -

Powerful others scale -
High score indicates that the subject expects to have control over his/her own Iife. Low score indicates that the subject does not expect to have control over his/her own life.

High score indicates that the subject expects powerful others have control over his/her life. Low score indicates that the subject expects powerful others do not have control over his/her life. 
Chance Scale -

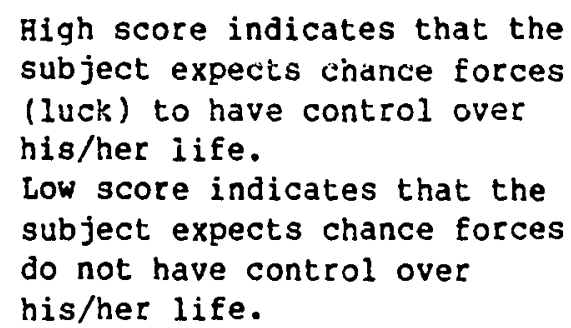

It seems for purposes of this study that this instrument measures expectations that relate directly to one's natural response when in a conflict situation.

The Additional Questionnaire Developed by Researcher

Pre-test results indicated that subjects would have adequate time to complete an additional questionnaire. All of the information obtained in the pre-test was collected on all subjects participating in the study. In addition questions regarding subject's sex, age, family composition, and general feelings about conflict were answered by all subjects (see Appendix D). The family information and general perceptions/feelings about conflict were not analyzed and thus will not be included within the scope of this dissertation.

The last question answered by each subject was " Do you have any comments you'd like to make about your experience participating in this research?" A content analysis of the answers obtained from this question will be included in the results chapter.

PROCEDURES

Data were collected from two different introductory psychology classes; the first resulted in 96 subjects participating - the second in 67 subjects for a total of 163 subjects participating. 
An informed consent form was distributed, signed by subjects, and collected prior to participation in the study (see Appendix A). Each subject then received two packets of questionnaires which were numbered to ensure subject confidentiality. The first packet contained the locus of control inventory and the four versions of the OCCI. The locus of control inventory and situation 1 of the occI preceded, in that order, the other three versions of the OCCI. The order of the ocCI for Situations 2,3 , and 4 was permutated to control for order effect in the following manner: $234,243,324,342,423,432$. Each version of the OCCI was on a different color paper and items within versions 2,3 , and 4 of the OCCI were re-ordered to reduce the tedious and repetitive nature of answering the same 30-item test four times. Verbal instructions were given by the researcher, and subjects were asked not to discuss their participation until all data were collected. After the subjects completed the locus of control and OCCI questionnaires (5 total), they responded to the additional questionnaire developed by the researcher. Total time spent ranged from 20 to 45 minutes.

\section{STATISTICAL ANALYSIS PROCEDURES}

Hypothesis Testing - Canonical Correlation Procedures

Through the use of canonical correlation procedures, scores from Situation l only ( the lover/friend version) were used to determine how much the choice of conflict behavior strategy could be predicted by the three locus of control orientations. Canonical correlation is the extension of multiple linear regressicn to the case of multiple 
criterion variables. Levenson (1981) argued that multiple regression equations are the most effective and appropriate way to analyze scores on the three locus of control scales, particularly since they utilize the full multidimensional complexity of the instruments, helping to avoid typological thinking. Canonical correlation allows for sets of variables to be examined for relationships with other sets of variables. Specific predictions were hypothesized in answering the question:

Is there a relationship between an individual's conflict behavior style and personal characteristics such as feelings of power and control?

If conflict behavior choices are related to locus of control orientations, the canonical correlations would result in significant correlation coefficients. However, unlike in simple correlational analysis, the relationships are not between just two variables. The canonical correlation technique is used when sets of variables need to be analyzed. In this study there are two sets of variables: conflict behavior strategy scores (non-confrontation, solution-orientation, control) and locus of control scores (internal, powerful others, chance). The canonical correlation procedure will, by weighting the combinations within each variable, search for linear relationships with the other weighted combination of variables.

Predictions were made only for what canonical correlations would reveal from using the scores from situation 1 of the occr. Situation 1 was designed to elicit an individual's natural, patterned response to conflict. Any behavior is appropriate in situation 1, unlike in the other three situations. Therefore situation 1 is appropriate to use in a test for the relationship between conflict behavior and feelings of 
power and control; specifically in a test of how much the choice of conflict behavior strategy could be predicted by the three locus of control orientations. Using the locus of control scores and the scores from Situation 1 of the OCCI, canonical correlations were expected to result in the following relationships: Al: The Internal Locus of Control orientation would predict the choice of solution-orientation behavior, H2: The Powerful Others and Chance Locus of Control orientations would preaict the choice of non-confrontation behavior, H3: The Powerful Others Locus of Control orientation would predict the choice of control behavior.

If $\mathrm{Hl}$ is true, a significant canonical correlation would be due to the relationship between internal locus of control and solutionorientation behavior. If $\mathrm{K2}$ is true, a significant canonical correlation would be due to the relationship between powerful others and chance locus of control and non-confrontation behavior. If H 3 is true, a significant canonical correlation would be due to the relationship between powerful others locus of control and control behavior.

These would appear in the canonical correlation results through the numerical weights (coefficients) given both sets of variables. Por example, if $\mathrm{HI}$ is true, the largest weights will be given to internal locus of control and solution-orientation behavior. If these three hypotheses are true, there will be three functions; one for each signiflcant canonical correlation.

These predictions are based in the proposed theory that conflict behavior choices in conflict situations with an intimate friend/lover reflect the individual's automatic, patterned response; reflecting the 
family experience with conflict and how much one feels "getting what I want is in my hands".

If one believes getting what $s /$ he wants is in her/his hands, then direct communication about the conflict and trying to find solutions, (particularly ones that integrate the needs of both parties), is likely to be the chosen strategy. (HI)

If one believes that getting what $s /$ he wants is not in her/his hands, but rather in the hands of powerful others, chance, or fate, one is likely to be indirect, avoid or withdraw from disagreements, gloss over differences and conceal ill feelings; identified by a nonconfrontation approach. (H2)

If one believes that getting what $s /$ he wants is not in her/his hands but clearly in the hands of powerful others, one is likely to argue persistently and advocate one's position, as reflected in the control strategy. (H3)

Although gender was considered an important factor no predictions were made.

Hypothesis Testing - Multivariate Analysis of Variance Procedures

In order to answer the other questions raised in this study -those that pertain to the ability to choose different conflict behaviors depending on the situation -- a complex multivariate analysis of variance with repeated measures was used. This technique generated Information on how much of the variance in choice of conflict behavior was attributed to the person (locus of control profile), the situation (the four situations), and the interactions between the person and the situation. 
The data available for this analysis were scores on the I, P, and $C$ Locus of Control scale and scores on the OCCI for four different situations (Figure 3). Again, situations 2, 3, and 4 were designed to predict that a particular conflict behavior strategy would be most effective. All high and low groups were formed by median splits. Cells contained three variables: scores on the three strategies of the oCCI. Although eight combinations of locus of control scores on choice of strategies under conditions of the four situations were available, predictions were made specifically to only three combinations. The eight combinations were:

$\begin{array}{lr}\text { Hi I Hi P Hi C } & \text { LO I Hi P Hi C } \\ \text { Hi I LO P Hi C } & \text { to I LO P Hi C } \\ \text { Hi I Hi P LO C } & \text { LO I Hi P LO C } \\ \text { * Hi I LO P LO C } & \text { LO I LO P LO C }\end{array}$

**The three combinations for which predictions were made

These combinations were considered relatively "pure" types on locus of control (i.e., high on one dimension, and low on both others) and were predicted to show the following characteristic patterns of strategy choice in the three situations (Table II).

Only situations 2,3 , and 4 were used because they specifically assume a particular use of conflict behavior is more effective than another. These predictions are based on the theory that having an Internal Locus of Control orientation will result in the ability to choose the most effective conflict behavior in the situation with the most flexibility. Having a Powerful others Locus of Control orientation 


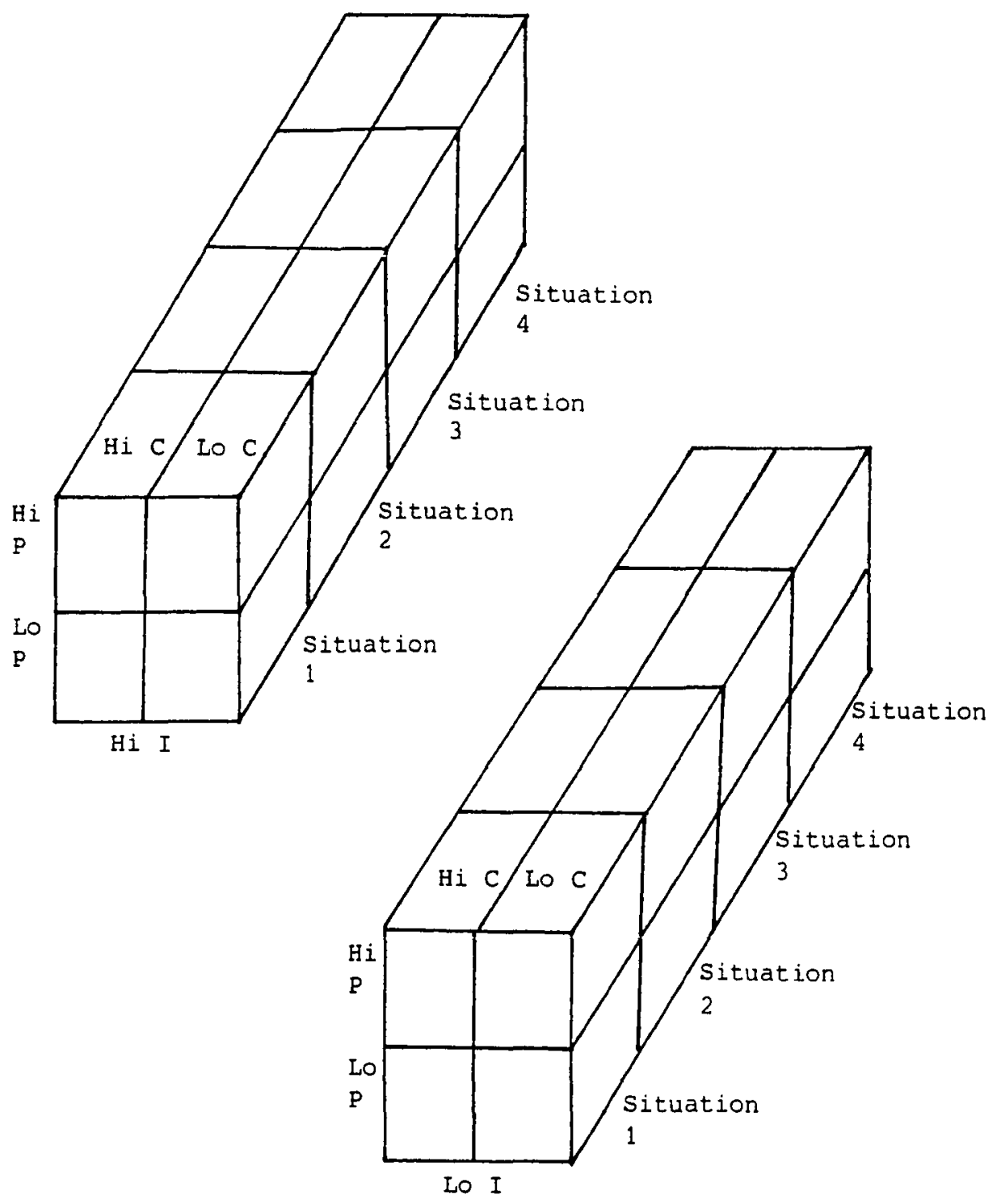

Figure 3. OCCI scores for each locus of control combination. 
TABLE II

STRATEGY CHOICES IN THREE SITUATIONS

\begin{tabular}{|c|c|c|c|c|c|c|c|c|c|c|c|}
\hline \multicolumn{4}{|c|}{$\begin{array}{c}\text { SOLUTION-ORIENTATI } \\
\text { SCORES }\end{array}$} & \multicolumn{4}{|c|}{$\begin{array}{r}\text { CONTROL } \\
\text { SCORES } \\
\end{array}$} & \multicolumn{4}{|c|}{$\begin{array}{l}\text { NON-CONPRONTATION } \\
\text { SCORES }\end{array}$} \\
\hline & \multicolumn{3}{|c|}{ Situation } & \multicolumn{4}{|c|}{ situation } & & \multicolumn{3}{|c|}{ situation } \\
\hline & 2 & 3 & 4 & & 2 & 3 & 4 & & 2 & 3 & 4 \\
\hline $\mathrm{Hi} \mathrm{I}$ & Lo & Hi & $\mathrm{Hi}$ & $\mathrm{Hi} \mathrm{I}$ & $\mathrm{Hi}$ & Lo & $\mathrm{Hi}$ & $\mathrm{Hi} I$ & $\mathrm{Hi}$ & $\mathrm{Hi}$ & Lo \\
\hline Bi $P$ & $\mathrm{Bi}$ & $\mathrm{Hi}$ & $\mathrm{Hi}$ & $\mathrm{HI} \quad \mathrm{P}$ & Lo & Lo & Lo & $\mathrm{Hi} P$ & $\mathrm{Hi}$ & $\mathrm{Hi}$ & $\mathrm{Hi}$ \\
\hline $\mathrm{BiC}$ & Hi & $\mathrm{Hi}$ & $\mathrm{Hi}$ & Hi C & $\mathrm{Hi}$ & $\mathrm{Hi}$ & $\mathrm{Hi}$ & $\mathrm{Hi} \mathrm{C}$ & Lo & Lo & Lo \\
\hline
\end{tabular}

is expected to result in the use of control behavior in every situation, including the one (Situation 3) where it is most appropriate. It is expected that a Chance Locus of Control orientation will result in the use of non-confrontation in every situation, including situation 4 where it is most appropriate.

These predictions were hypothesized to answer the questions, restated from Chapter II:

1. Is there a relationship between an individual's conflict behavior style and personal characteristics such as feelings of power and control?

2. If there is a relationship, does it affect choice of conflict behavior in particular situations?

3. Are all individuals equally disposed to choose the effective conflict behavior in the particular situation? 
The other question stated in Chapter II is:

Can situations be clearly defined so that a particular conflict behavior could be considered effective and therefore most appropriate?

In this study it is assumed, on the basis of previous research, that is is possible to identify particular strategies as most appropriate for certain conflict situations. The extent to which subjects actually choose those strategies in those situations will be taken as evidence as to the validity of that assumption. 
In addition to the three locus of control scores and the twelve conflict behavior scores ( 3 conflict scores $x 4$ situations) additional data were collected. Prior to conducting the canonical correlations and the multivariate analysis of variances, the additional data were analyzed. This preliminary analysis was conducted to determine that the data collected were valid and free of bias or confounding effects.

\section{PRELIMINARY ANALYSTS}

\section{Subject Effect}

If subjects correctly guess the hypotheses of a study, the results can be biased. Subjects might respond as they believe they are expected to rather than as they really feel or think. To ensure against this effect each subject was asked to respond to the following questions:

1. Did you have any hunches about the purpose of the study? Yes__ No

2. If yes, what did you think it was investigating?

Analysis of the responses indicates that of the 163 participants, 528 (84) did have a hunch about the purpose of the study and 488 (79) did not. Analysis was then conducted on the responses received from the 528 of the subjects who had a hunch as to what the purpose of the study was. Only three subjects were considered to have guessed the purpose of the study; i.e., 
I think it may be investigating the varied responses one has to a disagreement and conflict as a result of the relationship one has to the person he is disagreeing with and the extent to which he feels he is the one in control of his life.

Since only a little more than half the sample had any hunch about the purpose of the study, and of those only three were good at guessing the hypotheses - results were considered not affected by subject Effect. All respondents were included in the analysis.

\section{Instrumentation Effects}

Subjects were asked what they thought the first questionnaire was measuring (locus of control) and what the other four questionnaires were measuring (the four OCCI). These questions were asked to ensure that subjects considered the locus of control and the OCCI as different so that results could not be interpreted as merely reporting reliability. Subjects' responses were coded in one of four ways as listed below:

$1=$ Reversed, that is locus of control was considered a behavioral measure and OCCI as attitudinal.

$2=$ Same, that is whatever subjects considered the locus of control as measuring, it was the same as what they perceived the OCCI to be measuring.

3 = Irrelevant, answers to one or both questions were unintelligible or blank or irrelevant to issues at hand. 
4 = Correct, subjects correctly identified the locus of control as an attitudinal, opinion measure and the OCCI as behavioral.

See Table III on the following page for a tabulation of the responses.

A strong majority of the subjects responses (818) correctly identified the measures or were unable to identify the measures at all and only 1.88 of the responses were clearly incorrect. This provides some evidence that the OCCI was tapping behavior intentions while the locus of control was measuring attitudes.

\section{Valid Data/Self Report}

Subjects were asked to comment on their experience participating in this research so that the face validity of responses overall could be verified. Depending on the nature of the comments, various conclusions could be reached as to the validity of the data generated by their participation in the study.

Thirty percent (49) of the subjects wrote comments, with 708 (114) either not responding or writing "No" in the comments section. The content of the forty-nine written comments was analyzed and is displayed in Table IV on the following page.

As may be seen from Table IV, few subjects saw the study as artificial or unrelated to their lives. It is especially interesting that over 308 of the responses indicated that increased self-awareness resulted from participation in the study. 
TABLE III

SUBJECT RESPONSES TO MEASUREMENTS

\begin{tabular}{lcc}
\hline Code & Cases & 8 of Total \\
\hline Reversed & 3 & 1.8 \\
Same & 28 & 17.2 \\
Irrelevant & 61 & 37.4 \\
Correct & 71 & 43.6 \\
$\quad$ TotaL & 163 & 100.0 \\
\hline
\end{tabular}

TABLE IV

CONTENT ANALYSIS OF SUBJECT RESPONSES

\begin{tabular}{lcc}
\hline Type of Comment & Number & Percent \\
\hline $\begin{array}{l}\text { Good study, important, interesting } \\
\text { good experience }\end{array}$ & 16 & 32.7 \\
$\begin{array}{l}\text { Increased awareness of how handle } \\
\text { conflict }\end{array}$ & 6 & 12.2 \\
Insight, analysis into self and & 9 & 18.4 \\
relationships & 7 & 14.3 \\
Like to see results \\
Difficult, hard to grasp, boring \\
Didn't reflect real behavior \\
Toral
\end{tabular}




\section{Validity of situations}

The results of this study depended greatly on participants choosing behavior in different situations (see pp. 27-28); thus the situations needed to be real to the subject and needed to reflect accurately the different characteristics that determine appropriateness. Data on how the subjects perceived the situations were collected through the additional questionnaire. Each subject was asked to respond to seven questions pertaining to each of the four situations (See Appendix D). They were also asked not to refer to the situations in answering the questions.

Reality. The first question asked for each situation was: "Was this situation real to you?" The response format was a Likert Scale; $1=$ Not very real to $5=$ Very real. The percentages of response in each category are displayed in Table $v$.

TABLE $V$

SUBJECT RATINGS OF REALITY OR SITUATIONS

\begin{tabular}{|c|c|c|c|c|c|}
\hline & $\begin{array}{c}\text { Not Very } \\
\text { Real } \\
1\end{array}$ & 2 & $\begin{array}{c}\text { Not } \\
\text { Sure } \\
3\end{array}$ & 4 & $\begin{array}{c}\text { Very } \\
\text { Real } \\
5\end{array}$ \\
\hline situation 1 & 6.1 & 24.5 & 10.4 & 42.3 & 16.6 \\
\hline situation 2 & 7.4 & 11.7 & 20.9 & 42.3 & 17.8 \\
\hline situation 3 & 21.5 & 25.2 & 17.2 & 27.6 & 8.6 \\
\hline situation 4 & 11.7 & 8.0 & 18.4 & 44.8 & 17.2 \\
\hline
\end{tabular}


In both the pre-test and the actual study situation 3 was considered as less real than the other three situations. Situation 3 is the one in which the subject has more power than the other party. Several different versions of that situation were tested in the pre-test; and the one that was considered most realistic was used in the main study.

Over 808 of the responses in both situation 2 and situation 4 fell within the range from Not sure to very Real. Situation 1 scored a little less realistic with 69.38 of the responses falling in those categories. Situation 3 had only 53.48. Despite those variations from situation to situation the results generally indicated that subjects felt the situations were quite realistic.

Validity. The other questions regarding the situations were designed to verify that they accurately reflected the intended conditions. This was important because those conditions were the basis for certain conflict behaviors being considered most appropriate. For Situation 1, the only intended conditions were that the decision did not necessarily need to be reached quickly and that it was not a temporary situation. The characteristics situation 2 was designed to reflect were equal power, the goal and the relationship being equally important, the situation needing to be resolved somewhat quickly, both people's ideas contributing to the resolution, and it being a very temporary situation. In situation 3 the subject was supposed to feel that $s /$ he was in a position of power, that the goal was more important than the relationship, that a decision was needed very quickly, that only the subject's ideas would contribute to the 
resolution, and that it was not a temporary situation. Situation 4 was designed for the subject to feel that s/he had less power, that the relationship was more important, that a decision was not needed quickly, that only the other's ideas would contribute to the resolution, and that it was very temporary.

Subjects were asked to answer questions that were used to analyze how well the situations reflected the intended conditions. For example, the second question asked for each situation was: "Did you feel you had a position of power over the other party?" The response was a likert Scale; $1=$ Less Power to 5 = More Power. Questions 3-6 also asked about the intended conditions.

A validity score was obtained for each situation in the following manner:

a. Given the intended conditions, a value was assigned to the subject's response $(5$ points for the intended condition, 2 , 3 , or 4 points for the intermediary response, and 1 point for the "wrong" response) for questions 1-6 for situations 2, 3, and 4. For example, in the case of question $\$ 2$, for Situation 2, 5 points were assigned when the subject circled response 3-Equal Power; 3 points were assigned when the subject circled either 2 or 4; and 1 point was assigned for answers 1 or 5 . In the case of situation 3 , the scale accurately reflected the condition so responses received the value as circled. In Situation 4 the scale is reversed, so the values assigned were reversed: response 1 received 5 points, response 5 received 1 point. 
b. A total score was computed for each situation, ranging from 6-30 points.

c. The total score was divided by the number of items (6); therefore, the range of validity scores was $1.0-5.0$.

d. In computing the validity score for situation 1 , only 3 items were used since it was not designed to reflect as many intended conditions. Items $\$ 1,4$, and 6 were used. Total scores ranged from 3-15 points. The total score was divided by 3 so that validity scores could be compared. However, scores for situation 1 contain less information than the other three situations.

The higher the validity score, the more subjects indicated that the situation accurately reflected the desired characteristics. The results are displayed in Table VI.

TABLE VI

SUBJECT RATINGS OF VALIDITY OF SITUATIONS

\begin{tabular}{|c|c|c|c|}
\hline & $\begin{array}{c}\text { Range of } \\
\text { Scores }\end{array}$ & Average & $\begin{array}{l}\text { \& } 3.0 \text { or } \\
\text { Greater }\end{array}$ \\
\hline Situation 1 & $\begin{array}{l}1.3 \text { to } 4.3 \\
(3.0-3.7=608)\end{array}$ & 3.1 & 658 \\
\hline Situation 2 & $\begin{array}{l}2.0 \text { to } 4.8 \\
(3.2-4.2=778)\end{array}$ & 4.0 & 948 \\
\hline Situation 3 & $\begin{array}{l}1.7 \text { to } 4.5 \\
(3.0-3.7=638)\end{array}$ & 3.3 & 798 \\
\hline Situation 4 & $\begin{array}{l}2.3 \text { to } 4.7 \\
(3.0-3.8=798)\end{array}$ & 3.3 & 838 \\
\hline
\end{tabular}


Using these validity scores, situation 3 is not substantially less valid than the other situations, that is, although considered less real it still accurately reflects the characteristics intended.

In addition, Question 17, "What would you describe the cause of the conflict to be?" was included for two purposes. Pirst, was to verify that the cause of conflict in situation 3 was value differences, thereby determining that control is the appropriate behavior. Second, was to discover if any interesting relationships could be discovered between cause of conflict and situation characteristics (Table VII).

TABLE VII

CAUSE OF CONFLICT - RESPONSES

\begin{tabular}{lccc}
\hline & $\begin{array}{c}\text { Value } \\
\text { Differences }\end{array}$ & Communication & other \\
\hline Situation 1 & 378 & 268 & 328 \\
Situation 2 & 248 & 488 & 208 \\
Situation 3 & 698 & 188 & 88 \\
Situation 4 & 318 & 338 & 308 \\
\hline
\end{tabular}

These percentages indic: te that as was intended, the cause of conflict in situation 3 strongly was considered value differences. Communication received just a little less than half of the responses in Situation 2, and indeed the cause of conflict in that situation was intended to be communication. Neither of the other two situations was written to convey an intended cause of conflict. 


\section{Order Effect}

The order in which subjects answered the Locus of control and OCCI questionnaires was permutated to control for order effect. The Locus of Control and OCCI Situation 1 preceded, in that order, the other three versions of the OCCI. Each permutation was equally distributed in the sample as reflected in Table VIII.

\section{Selection}

Students volunteered for participation in this study, and were offered extra credit for doing so. Students were told by the researcher that the study pertained to how people deal with conflict. Conditions In each of the two classrooms were similar; data were maintained separately in the event analysis would be necessary. However, there seemed to be no selection bias to require separate analysis. This

TABLE VIII

DISTRIBUTION OF VERSIONS OF OCCI

\begin{tabular}{lll}
\hline Permutation & of sample \\
\hline Situation: & $2,3,4$ & 17.2 \\
$2,4,3$ & 16.6 \\
$3,2,4$ & 17.2 \\
$3,4,2$ & 16.6 \\
$4,2,3$ & 16.6 \\
$4,3,2$ & 16.0 \\
\hline
\end{tabular}


conclusion was reached since the results of the previously discussed preliminary analysis were similar for both classrooms.

\section{STATISTICAL ANALYSIS}

Bor each subject, fifteen scores were obtained for analysis: three Locus of Control scores, and twelve OCCI scores (three for each of the four situations). Missing data reduced the number of cases; depending on the variables included in the analysis the number of cases ranged from a low of 146 to a high of 155. For all discussion the following abbreviations will be used:

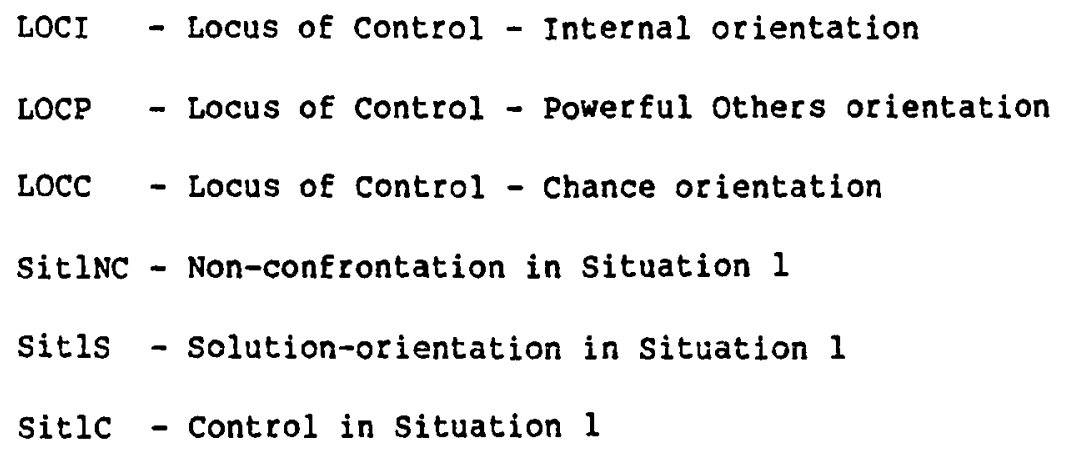
sit4)

\section{Sample Characteristics}

A comparison was made between the sample population and the normalized population reported in Putnam and Wilson (1982). They report an upper and a lower third range of scores (Table IX).

The sample used in this study, $N=163$, reflected similar means, but the range of scores differed slightly, as shown in Table $x$. 
TABLE IX

OCCI SCORE RANGES POR NORMALIZED POPULATION

\begin{tabular}{lccc}
\hline & Non-Confrontation & $\begin{array}{c}\text { Solution- } \\
\text { Orientation }\end{array}$ & Control \\
\hline $\begin{array}{l}\text { High scores }= \\
\text { (Infrequent use) }\end{array}$ & $73-84$ & $45-73$ & $40-49$ \\
$\begin{array}{l}\text { Low Scores }= \\
\text { (Frequent use) }\end{array}$ & $10-37$ & $16-26$ & $10-23$ \\
$\begin{array}{l}\text { Mean } \\
\text { Standard Deviation }\end{array}$ & 17.7 & 36 & 32 \\
\hline $\mathrm{N}=360$ & & 10.1 & 8.7 \\
\hline
\end{tabular}

This sample was more uniform in response given that standard deviations were smaller. Also, subjects did not use non-confrontation as consistently as the most extreme subjects in their sample.

TABLE $X$

OCCI SCORE RANGES PROM SAMPLE POPOLATION

\begin{tabular}{lccc}
\hline & Non-Confrontation & $\begin{array}{c}\text { Solution- } \\
\text { Orientation }\end{array}$ & Control \\
\hline $\begin{array}{l}\text { High scores }= \\
\text { (Infrequent use) }\end{array}$ & $63-84$ & $38-68$ & $32-48$ \\
$\begin{array}{l}\text { Low scores }= \\
\text { (Frequent use) }\end{array}$ & $26-52$ & $13-31$ & $10-25$ \\
Mean & 58 & 35 & 29 \\
Standard Deviation & 10.7 & 8.4 & 6.9 \\
\hline
\end{tabular}

$N=163$ 
Intercorrelation Analysis

A correlation matrix of Pearson's $r$ 's was computed among the fifteen variables (Locus of Control and OCCI scores) to determine if there were significant intercorrelations. The correlation coefficients are reported in Table $\mathrm{XI}$.

The first set of correlations presented is for the locus of control variables. The powerful others scale is somewhat correlated to the chance scale. This may present a limitation in interpreting data, since the scales are not completely independent.

The remainder of Table XI displays the correlations on the OCCI scales. These results indicate that control and non-confrontation are not opposites, rather they are slightly negatively correlated. Although the correlations are significant they are quite small, and would not be expected to have any important effect on results.

\section{Canonical Correlations}

Hypothesis Testing. The relationship between locus of control and one's natural response to conflict was expected to be found through canonical correlations of those variables. In particular, predictions were made for relationships between the locus of control scores and the OCCI scores for situation 1. Situation 1 was designed to elicit an individual's natural, patterned response to conflict. Any behavior was appropriate in Situation 1.

Given the hypotheses to be tested by this statistical procedure, three significant correlations (functions) were expected: one due to the relationship between internal locus of control and solutionorientation behavior; one due to the relationship between powerful 
TABLE XI

CORRELATION COEPFICIENTS FOR VARIABLES

\begin{tabular}{lccc} 
& LOCI & LOCP & LOCC \\
LOCI & 1.00 & -.012 & -.04 \\
LOCP & -.012 & 1.00 & $.527 * \star$ \\
LOCC & -.04 & $.527 * \star *$ & 1.00 \\
\hline
\end{tabular}

t** x significant at $p<.001$

\begin{tabular}{lccc} 
& SitlNC & Sitls & Sit1C \\
SitlNC & 1.00 & -.024 & $-.239 * \star \star$ \\
Sitis & -.024 & 1.00 & -.015 \\
Sitic & $-.239 \star \star \star$ & -.015 & 1.00 \\
\hline
\end{tabular}

*** = significant at $p<.001$

\begin{tabular}{lccc} 
& Sit2NC & Sit2S & Sit2C \\
Sit2NC & 1.00 & -.112 & $-.227^{\star *}$ \\
Sit2S & -.112 & 1.00 & -.007 \\
Sit2C & $-.227^{\star \pm}$ & -.007 & 1.00 \\
\hline
\end{tabular}

$\star *=$ significant at $\mathrm{p}<.01$

\begin{tabular}{lccc} 
& Sit3NC & Sit3S & Sit3C \\
Sit3NC & 1.00 & -.005 & $-.188^{*}$ \\
Sit3S & -.005 & 1.00 & $-.129 *$ \\
Sit3C & $-.188^{* *}$ & $-.129 *$ & 1.00 \\
\hline
\end{tabular}

** = significant at $p<.01$

* = significant at $p<.05$

\begin{tabular}{lccc} 
& Sit4NC & Sit4S & Sit4C \\
Sit4NC & 1.00 & -.053 & $-.44^{\star *}$ \\
Sit4S & -.053 & 1.00 & $.194^{\star *}$ \\
Sit4C & $-.44^{\star \star}$ & $.194^{\star *}$ & 1.00 \\
\hline
\end{tabular}

** = significant at $p<.01$ 
others and chance locus of control and non-confrontation behavior; and one due to the relationship between powerful others locus of control and control behavior.

The results of the canonical correlation procedure using the locus of control variables and the OCCI scores for situation 1 was one significant correlation (function) of $.34, p<.006$ due to the relationship between powerful others locus of control and nonconfrontation behavior. Being high on the powerful others locus of control orientation resulted in more use of nonconfrontation behavior.

Since the locus of control variables did not possess the expected level of explanatory power regarding conflict behavior, supplementary analyses were conducted.

Supplementary Analyses. Canonical correlations were run for the other three situations and sex was added as an independent variable. It was hypothesized that sex was related to choice of conflict behavior and therefore might have been obscuring the expected relationships.

The results are displayed in Tables XII and Table XIII. For all of the canonical correlations, the dependent variables were the three different conflict strategies (NC $=$ non-confrontation, $s=$ solutionorientation, $C=$ control); independent variables were the three locus of control orientations - LOCP, LOCI, and LOCC - and sex.

Table XII displays the weighted combination of scores producing the correlation, the size of the correlation and level of significance, as well as the direction of the relationship (same sign indicating similar direction, different sign indicating opposite direction). 
TABLE XII

CANONICAL CORRELATIONS FOR LOCUS OF CONTROL, SEX AND CONFLICT BEHAVIOR

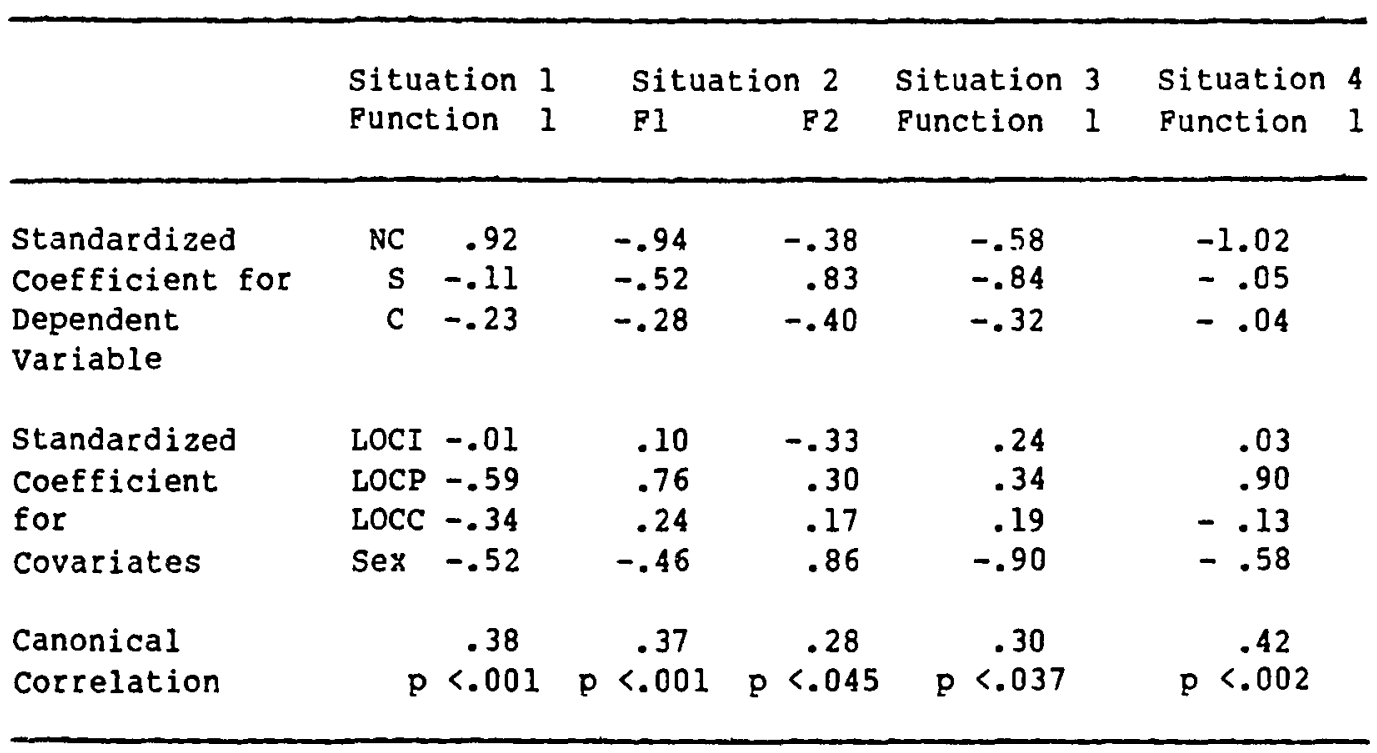

TABLE XIII

REGRESSION ANALYSIS FOR WITHIN CELL

\begin{tabular}{|c|c|c|c|c|}
\hline Covariate & situation 1 & situation 2 & situation 3 & Situation 4 \\
\hline LOCI & & & & \\
\hline $\begin{array}{l}\text { LOCP } \\
\text { LOCC }\end{array}$ & NC $p<.01$ & NC $\mathrm{p}<.01$ & & NC $p<.001$ \\
\hline Sex & $\begin{aligned} N C p & <.05 \\
C p & <.01\end{aligned}$ & $s p<.001$ & $s p<.001$ & NC $p<.002$ \\
\hline
\end{tabular}


To interpret the results in Table XII knowing how the various scales are scored is important. The conflict behavior scale is scored such that low = more use of the strategy and high = less use of the strategy. The locus of control scale is scored such that low = less orientation and high = more orientation. The sex scale is scored such that low = female and high = male.

In addition Table XIII can be used to enhance interpretation of the results displayed in Table XII. Table XIII reports tests of specific relationships producing the significant correlations as displayed in Table XII.

Adding sex to the analysis for situation 1 changed the weighted scores and resulted in a larger correlation.

Obtaining the additional canonical correlations for situations 2, 3, and 4, while not included as part of the original hypothesis testing procedure, were done to help interpret results from the Multivariate Analyses of Variance to be reported in the next section.

As indicated in both Table XII and Table XII significant overall canonical correlations appear to be due to the following relationships:

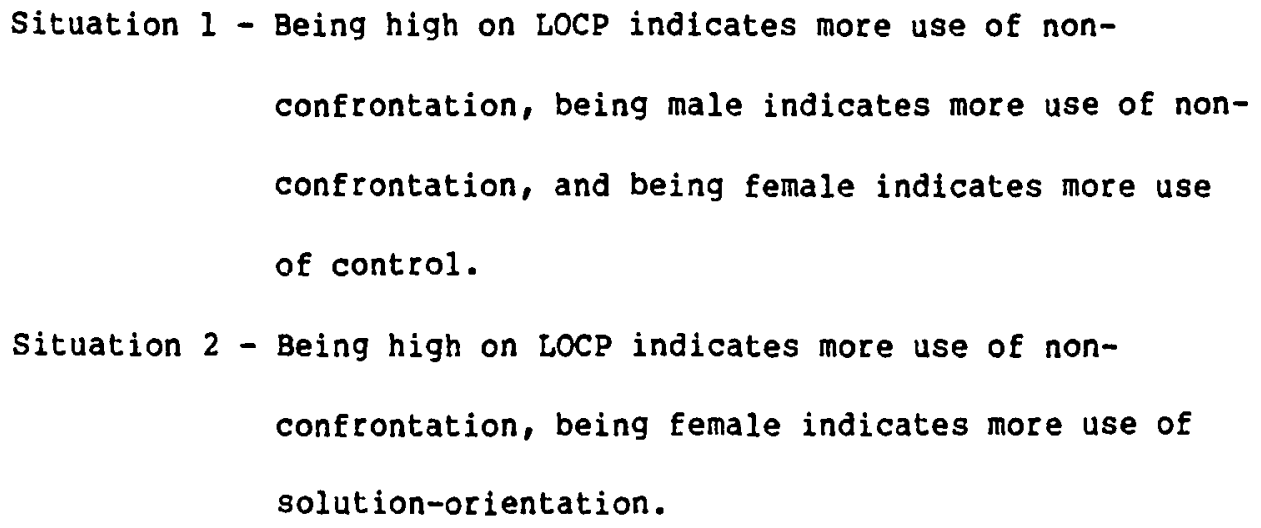


Situation 3 - Being female indicates more use of solutionorientation.

Situation 4 - Being high on LOCP indicates more use of nonconfrontation and being female indicates more use of non-confrontation.

Additional canonical correlations were obtained to conduct a different analysis. The independent variables remained the locus of control orientations and sex, but the dependent variable changed. Rather than have the dependent variable be the three different conflict behaviors in each situation, correlations were obtained for the three different conflict behaviors across all four situations. As can be seen in Tables XIV-XVII, obtaining canonical correlation results in this manner further clarifies the relationships discovered in the previous analysis. For each conflict strategy, it is possible to determine which variable (locus of control orientation, sex) helps predict the behavior (and if so, in which situation).

As indicated in Tables XIV-XVII significant overall correlations appear to be due to the following relationships:

Non-confrontation - Being high on LOCP and being male indicate more use of this strategy in situation 1 , being high on LOCP and being female indicate more use of this strategy in situation 4.

Solution-orientation - Being female indicates more use of this strategy in both situations 2 and 3 . 
Control

- Being female indicates more use of this

strategy in situation 1.

Again, these results aid interpretation of other results as well as substantiate the strength of relationships discovered. Referring to these tables will be helpful when results of Multivariate Analyses of Variances are reported.

\section{Multivariate Analysis of Variance (ANOVA)}

Hypothesis Testing. The ability to choose appropriate conflict behavior in various situations was expected to be tested through multivariate analyses of variance procedures (ANOVA). It was predicted that having an internal locus of control orientation would result in the ability to choose the most appropriate conflict behavior in each situation, having a powerful others locus of control orientation would result in the use of control behavior in every situation (including Situation 3 where it was most appropriate), and having a chance locus of control orientation would result in the use of non-confrontation in every situation (including Situation 4 where it was most appropriate).

To test these hypotheses, three unidimensional repeated measure ANOVAs were run on the three conflict strategies, using median splits on the locus of control variables. The median splits for the locus of control variables are displayed in Table XVIII.

The ANOVAs were run with OCCI scores from situations 2, 3, and 4 for each conflict strategy as the dependent variable, and locus of control as the independent variable. Situations 2, 3, and 4 predicted a 
TABLE XIV

CANONICAL CORRELATIONS FOR CONFLICT BEHAVIOR IN FOUR SITUATIONS WITH LOCUS OF CONTROL AND SEX

\begin{tabular}{|c|c|c|c|c|c|c|c|}
\hline & \multicolumn{3}{|c|}{$\begin{array}{r}\text { Non-confrontation } \\
\text { F1 F2 }\end{array}$} & \multicolumn{2}{|c|}{$\begin{array}{l}\text { Solution-orientation } \\
\text { Function } 1\end{array}$} & \multicolumn{2}{|c|}{$\begin{array}{l}\text { Control } \\
\text { Punction } 1\end{array}$} \\
\hline Standardized & SitINC & -.28 & -1.03 & Sitls & .42 & SitlC & 1.08 \\
\hline Coefficient & sit2NC & .19 & -.58 & Sit2s & -.95 & sit $2 C$ & -.86 \\
\hline for Dependent & sit3NC & -.16 & .49 & Sit3s & -.75 & sit $3 C$ & -.09 \\
\hline Variable & Sit $4 \mathrm{NC}$ & 1.03 & .30 & Sit $4 S$ & .53 & Sit $4 \mathrm{C}$ & .22 \\
\hline Standardized & LOCI & .04 & .14 & LOCI & .17 & LOCI & .14 \\
\hline Coefficient & LOCP & -.79 & .48 & LOCP & .04 & LOCP & .59 \\
\hline for & LOCC & .16 & .39 & LOCC & .24 & LOCC & -.18 \\
\hline Covariates & $\operatorname{sex}$ & .72 & .58 & Sex & -.98 & $\operatorname{sex}$ & .81 \\
\hline Canonical & & .43 & .37 & & .37 & & .32 \\
\hline Correlation & $p$ & $<.001$ & $p<.004$ & & $p<.02$ & & $p<.08$ \\
\hline
\end{tabular}


TABLE XV

REGRESSION ANALYSIS FOR WITHIN CELI: NON-CONERONTATION

\begin{tabular}{|c|c|c|c|c|}
\hline Covariate & SitlNC & Sit $2 N C$ & sit $3 N C$ & sit 4 NC \\
\hline LOCI & & & & \\
\hline LOCP & $p<.01$ & $p<.01$ & $p<.07$ & $p<.001$ \\
\hline LOCC & & & & \\
\hline Sex & $p<.04$ & & & $p<.001$ \\
\hline
\end{tabular}

TABLE XVI

REGRESSION ANALYSIS POR WITHIN CELL: SOLUTION-ORIENTATION

Covariate sitls sit2s sit3s sit4s

LOCI

LOCP

LOCC

Sex $\quad p<.001 \quad p<.001$

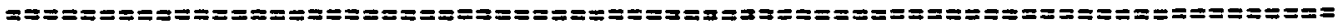

TABLE XVII

REGRESSION ANALYSIS POR WITHIN CELL: CONTROL

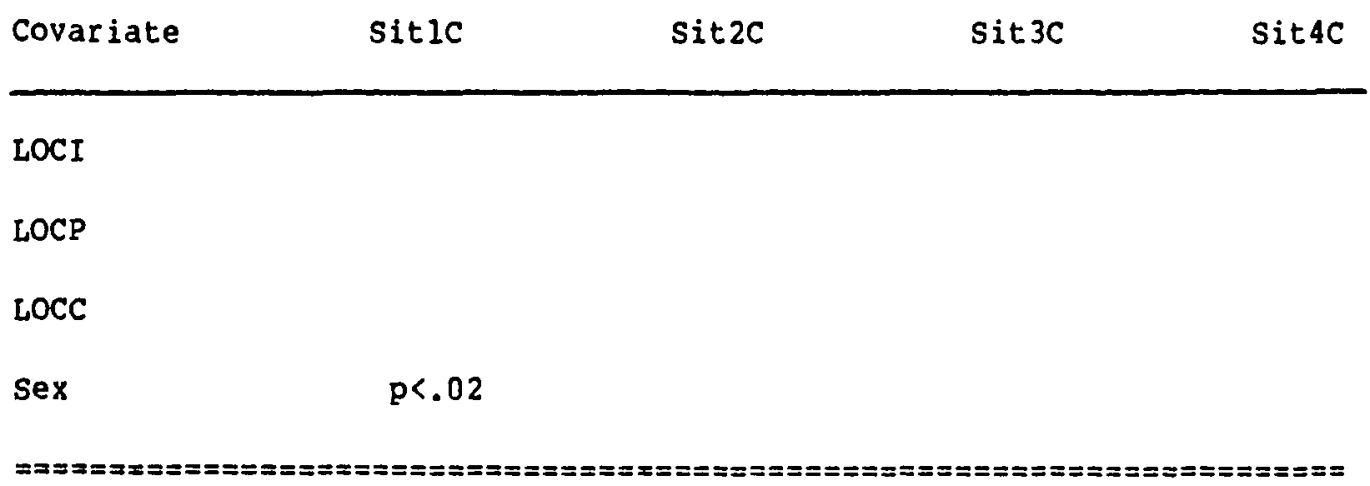


TABLE XVIII

LOCUS OF CONTROL MEDIAN SPLIT SCORES

\begin{tabular}{lrrr}
\hline & LOCI & LOCP & LOCC \\
\hline Hi & $35-48$ & $17-48$ & $17-48$ \\
LO & $0-34$ & $0-16$ & $0-16$ \\
\hline
\end{tabular}

particular cholce of behavior as most appropriate: situation 2 solution-orientation, situation 3 - control, situation 4 - nonconfrontation.

The results that were expected to indicate support for the hypotheses were significant interactions between the locus of control variables and situation for each ANOvA. A main effect for situation in each ANOVA was also expected.

As displayed in Table XIX, a significant main effect for situation was obtained. However, none of the hypothesized locus of control and situation interactions appeared in the results. A main effect for LOCP in the non-confrontation ANOVA was obtained, indicating that the high powerful others locus of control orientation chooses non-confrontation more often.

Supplementary Analyses. ANOVAs were run with scores from Situation 1 added to allow further interpretation of the canonical correlation results. The independent variable remained locus of control orientations. One additional result was obtained, as displayed in Table XIX. The interaction of LOCI and situation in the control ANOVA was not significant, but near enough to warrant further investigation. 
Since it appeared in the canonical correlation analysis that sex was related to conflict behavior choices, it was added as an independent variable. This would also allow for consistent comparison of results from both analyses. Therefore ANOVAs were run with scores from all four situations for each conflict strategy as the dependent variable and locus of control oriencations and sex as the independent variables. The results are displayed in Table XIX and will be reported in detail in the section headed "ANOVA FINDINGS".

In analyzing the results from the ANOVAs for each conflict strategy, plots were made for males and females separately for each of the eight cells of the design. These eight cells are displayed in Table $\mathrm{XX}$.

The number of cases in each situation will vary due to missing cases.

Because the ANOVA results did not indicate the particular interaction relationships that were predicted, it was inappropriate to single out combinations numbers $2,3, \& 5$ for separate analysis (high on one dimension and low on the other two).

The specific plots follow in Figures 4-9. The mean scores for each conflict strategy are displayed across the 4 situations for each combination of locus of control. The number of cases in each combination is displayed as well.

Before reporting the ANOVA findings in more detail, it is important to discuss the number of cases in each cell by sex to ensure that results are not due to some factor relating to the unbalanced design. Note that on the bottom of each plot (pages 66 to 71 ) the 
TABLE XIX

ANOVA PROCEDURE RESULTS

\begin{tabular}{|c|c|}
\hline Variables & Non-confrontation \\
\hline $\begin{array}{l}\text { Sit } 2,3,4 \\
\text { LOC }\end{array}$ & $\begin{array}{l}\text { main effect - situation } p<.001 \\
\text { main effect - LOCP } p<.004\end{array}$ \\
\hline $\begin{array}{l}\text { Sit } 1,2,3,4 \\
\text { LOC }\end{array}$ & $\begin{array}{l}\text { main effect - situation } p<.001 \\
\text { main effect - LOCP } p<.004\end{array}$ \\
\hline $\begin{array}{l}\text { Sit } 1,2,3,4 \\
\text { LOC and } \\
\text { Sex }\end{array}$ & $\begin{array}{l}\text { main effect - situation p<.001 } \\
\text { main effect - Locp p<.01 } \\
\text { interaction - sex x situation } p<.01\end{array}$ \\
\hline Variables & Solution-orientation \\
\hline $\begin{array}{l}\text { Sit } 2,3,4 \\
\text { LOC }\end{array}$ & main effect - situation $p<.001$ \\
\hline $\begin{array}{l}\text { Sit } 1,2,3,4 \\
\text { LOC }\end{array}$ & main effect - situation p<.001 \\
\hline $\begin{array}{l}\text { Sit } 1,2,3,4 \\
\text { Loc and } \\
\text { Sex }\end{array}$ & $\begin{aligned} \text { main effect }- \text { situation } p<.001 \\
\text { main effect - sex } p<.01 \\
\text { interaction - LOCP X LOCC X sex X situation } \\
\text { p<.05 }\end{aligned}$ \\
\hline Variables & Control \\
\hline $\begin{array}{l}\text { Sit } 2,3,4 \\
\text { LOC }\end{array}$ & main effect - situation $p<.001$ \\
\hline $\begin{array}{l}\text { Sit } 1,2,3,4 \\
\text { LOC }\end{array}$ & $\begin{array}{l}\text { main effect - situation } p<.001 \\
\text { interaction - LOCI X situation } p<.127\end{array}$ \\
\hline $\begin{array}{l}\text { Sit } 1,2,3,4 \\
\text { Loc and } \\
\text { Sex }\end{array}$ & $\begin{array}{l}\text { main effect - situation p<.001 } \\
\text { interaction - LOCI X situation } p<.04 \\
\text { interaction - LOCI X sex p<.03 } \\
\text { interaction - LOCC X seX } p<.03 \\
\text { interaction - LOCP X LOCC X sex } p<.02 \\
\text { interaction - LOCP X LOCC X sex X situation } \\
\text { p<.013 }\end{array}$ \\
\hline
\end{tabular}


TABLE XX

COMBINATIONS OP LOCUS OF CONTROL

\begin{tabular}{llll}
\hline Cel1 & \multicolumn{3}{c}{ Locus of Control } \\
\hline 1 & LO P & LO C & LO I \\
2 & LO P & LO C & Hi I \\
3 & LO P & Hi C & LO I \\
4 & LO P & Hi C & Hi I \\
5 & Hi P & LO C & LO I \\
6 & Hi P & LO C & Hi I \\
7 & Hi P & Hi C & LO I \\
8 & Hi P & Hi C & Hi I \\
\hline
\end{tabular}

number of cases is listed. In addition, Table XXI and Pigure 10 summarize this information.

While 638 of the total cases were female and 378 male, the distribution of scores on some of the locus of control orientations does not exactly reflect that breakdown. On locus of control internal orientation, the HiI's were split $50 / 50$ female/male. However, females represent 768 of the LOI scores. For the other locus of control orientations, the split between females and males reflects the same percentage difference in number of cases. Therefore, the median split on locus of control internal is comprised of a disproportionate split on sex, which potentially confounds the results. 
ANOVA PINDINGS

Non-Confrontation

The main effect for Locus of control $p$ in the non-confrontation conflict strategy is reflected in Figure 11.

Being high on LOCP indicates more use of the non-confrontation behavior strategy. Non-confrontation is the most effective behavior strategy to choose in situation 4 , and indeed both $\mathrm{Hi}$ and Lo $\mathrm{P}$ reflect that choice (low score indicates more use), although the difference between $\mathrm{HI}$ and Lo on LOCP is significantly more marked in situation 4 than in the other three.

The other result of the ANOVA for non-confrontation is the interaction of sex $x$ situation, reflected in Figure 12 .

Females choose non-confrontation behavior more than males although this difference is not significant as indicated by the lack of a significant main effect for sex in the non-confrontation ANOVA. However, the interaction occurs in the first situation compared to the other three. That is, males chose non-confrontation more than females in that situation only. This is the situation involving a conflict with an intimate friend/lover. Females are relatively consistent in their use of non-confrontation until involved in a conflict with a professor; an authority figure; one who is in a position of power. In that situation they use non-confrontation more than in the other three.

\section{Solution-orientation}

The main effect for sex in the solution-orientation behavior strategy ANOVA is reported in Figure 13. 


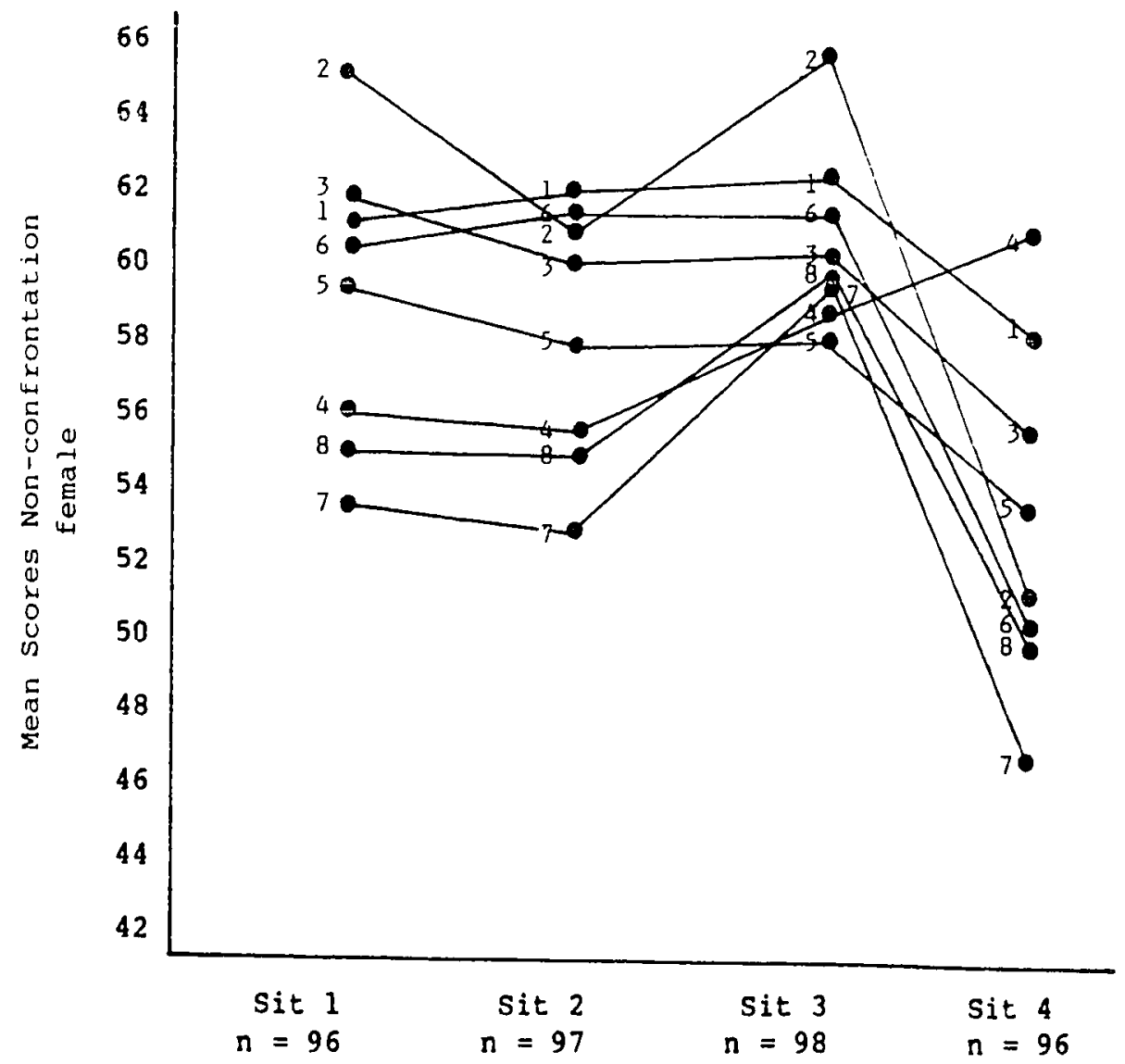

$1=$ LOP LOC LOI

20

21

21

21

$2=$ LOP LOC HII

13

13

13

13

3 = LOP HiC LOI

13

13

13

13

4 = LOP HiC HiI

7

7

7

$5=$ HIP LOC LOI

8

8

8

$6=\mathrm{HiP}$ LOC HiI

8

8

7

7 = HiP HiC LOI

16

15

16

15

$8=\mathrm{HiP} H i C \mathrm{HiI}$

11

12

12

12

$\mathrm{n}$ of cases

Pigure 4. Mean scores non-confrontation - female. 


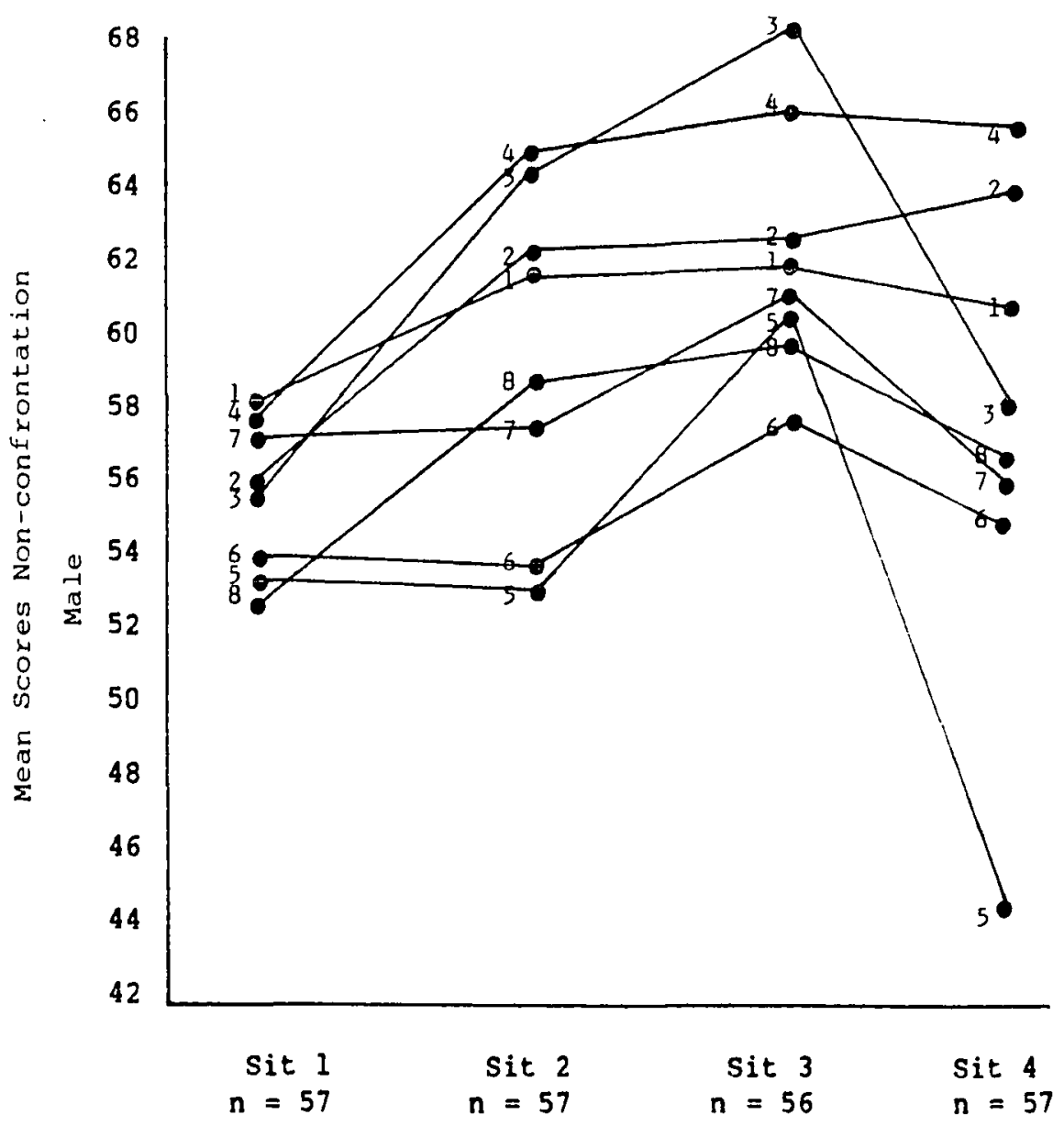

$1=$ LOP LOC LOI

7

7

7

7

$2=$ LOP LOC HiI

10

10

10

10

$3=$ LOP HiC LOI

2

2

2

$4=\operatorname{LOP} \mathrm{HiC} \mathrm{HiI}$

7

7

7

5 = HiP LOC LOI

1

1

1

$6=$ HiP LOC HiI

7

7

7

7 = Hip HiC LoI

8

8

8

8 = HiP HiC HiI

15

15

15

$\mathrm{n}$ of cases

Pigure 5. Mean scores non-confrontation - male. 


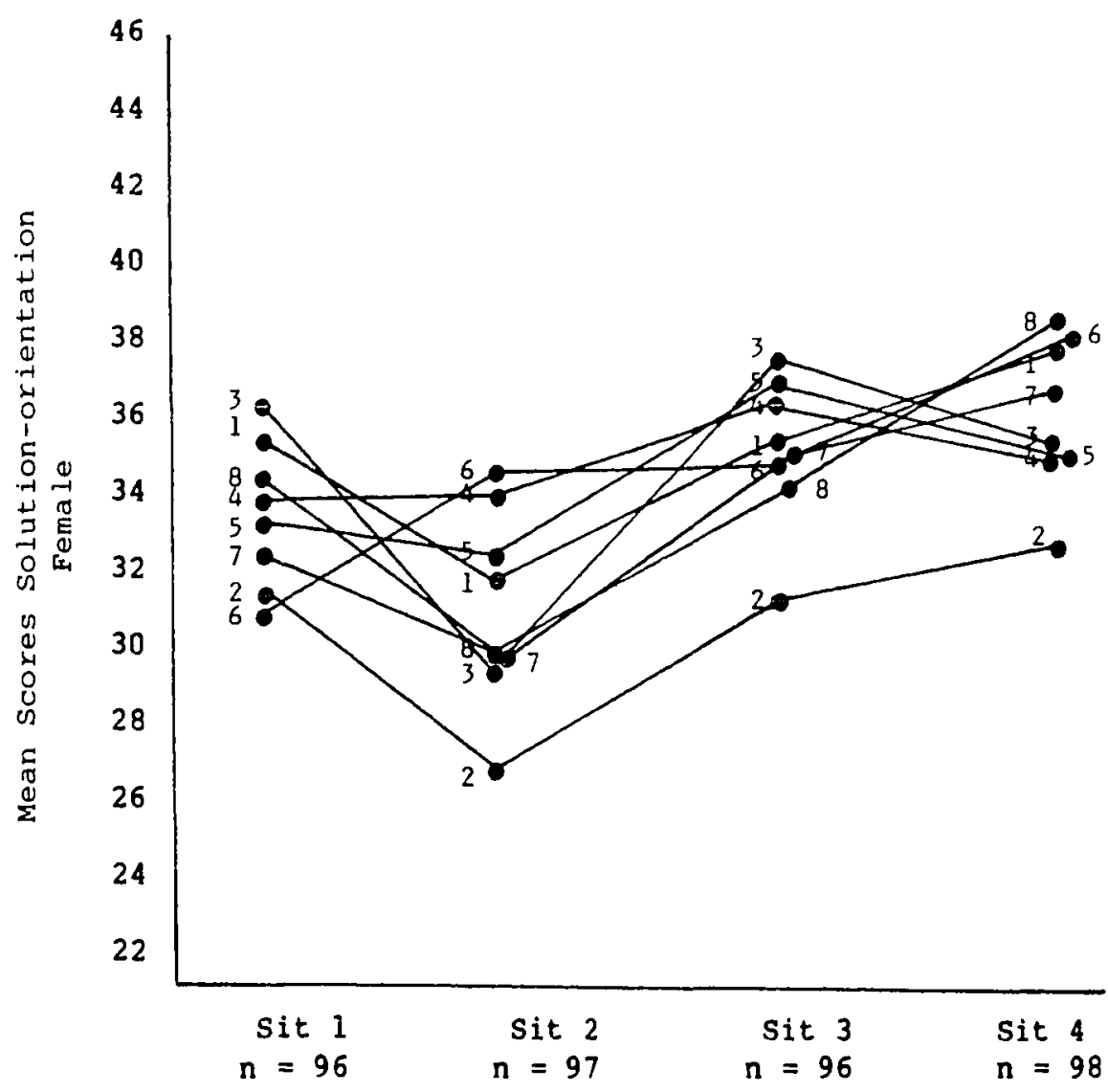

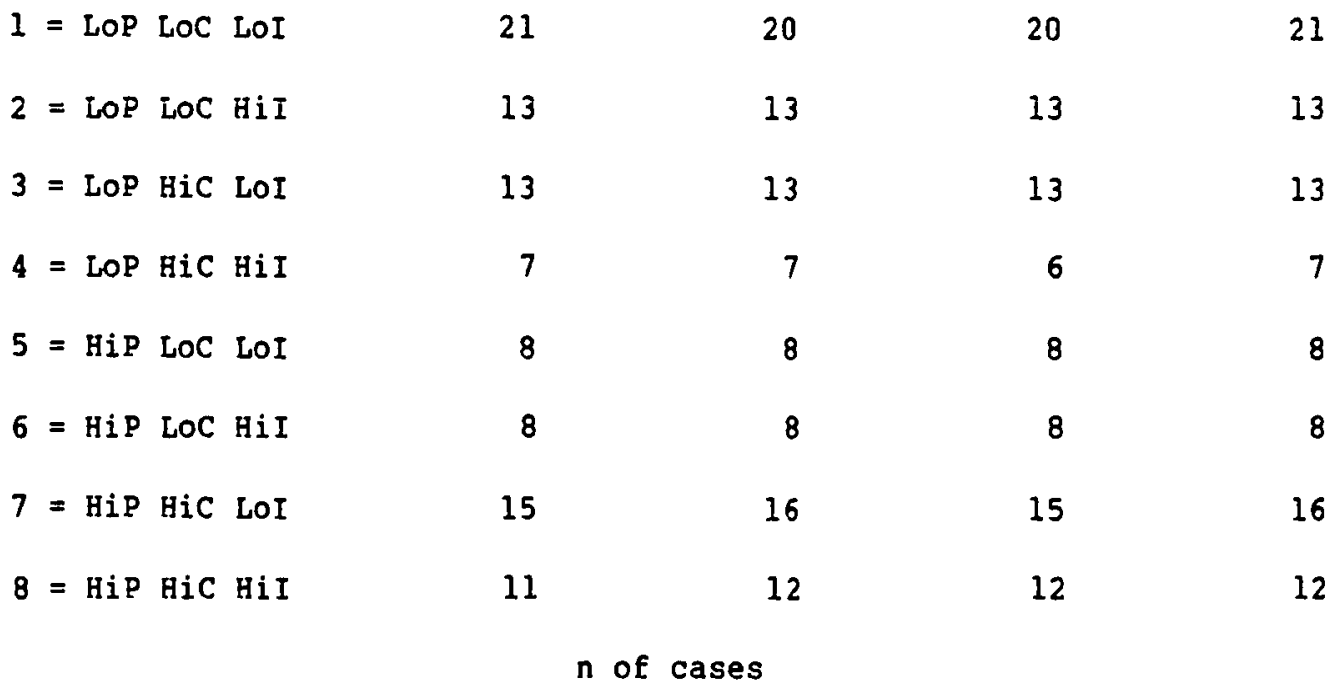

Figure 6. Mean scores solution-orientation - female. 


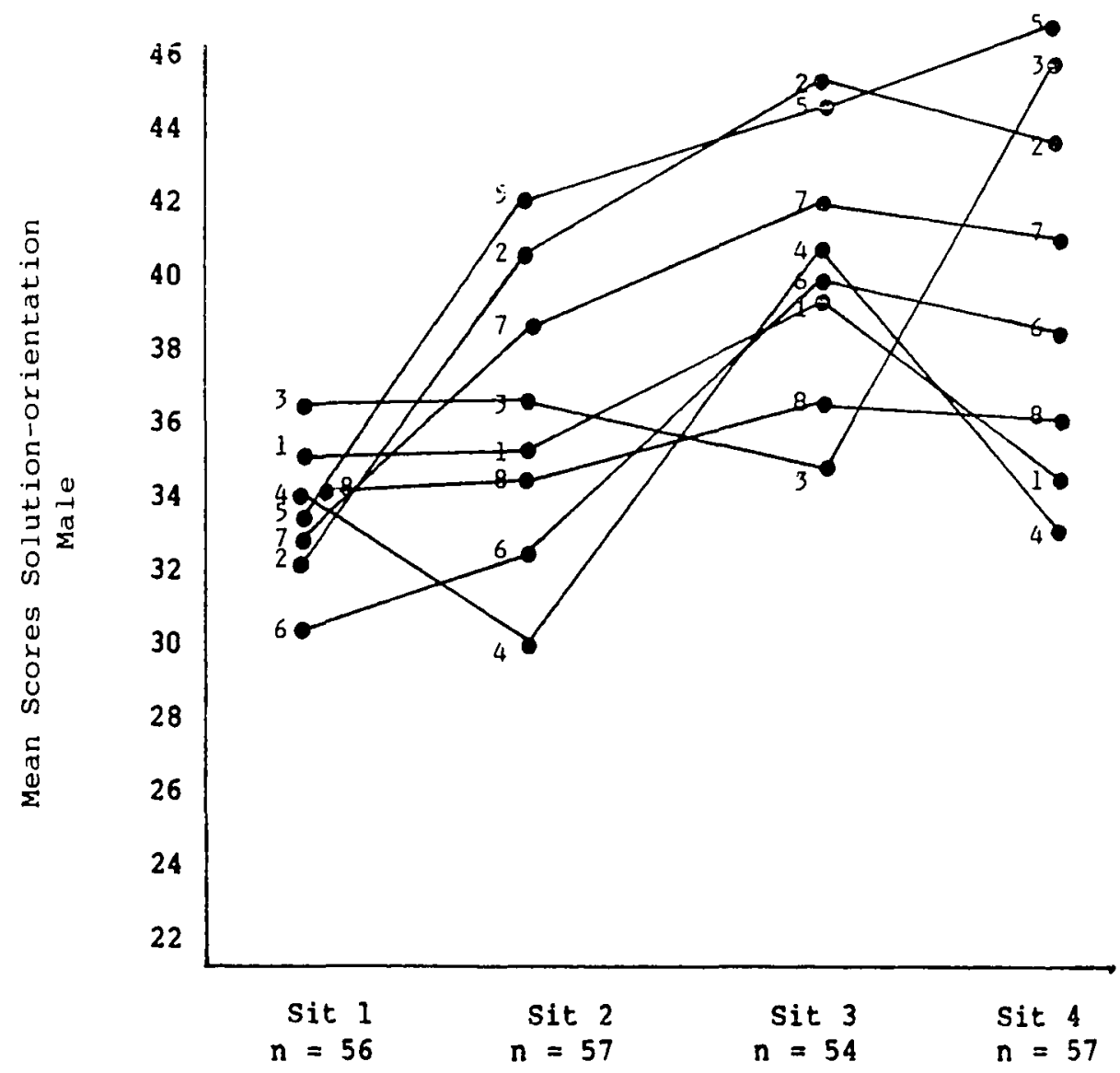

$1=$ LOP LOC LOI

$2=$ LOP LOC HiI

$3=$ LOP HiC LOI

$4=$ LOP HiC HiI

$5=$ HiP LOC LOI

$6=\operatorname{HiP}$ LOC HiI

7 = HiP HiC LOI

$8=$ HiP HiC HiI
7

9

2

7

1

7

8

15

7
10
2
7
1
8

15
6

10

2

6

1

6

7

15

$\mathrm{n}$ of cases
Sit 4

$n=57$ 


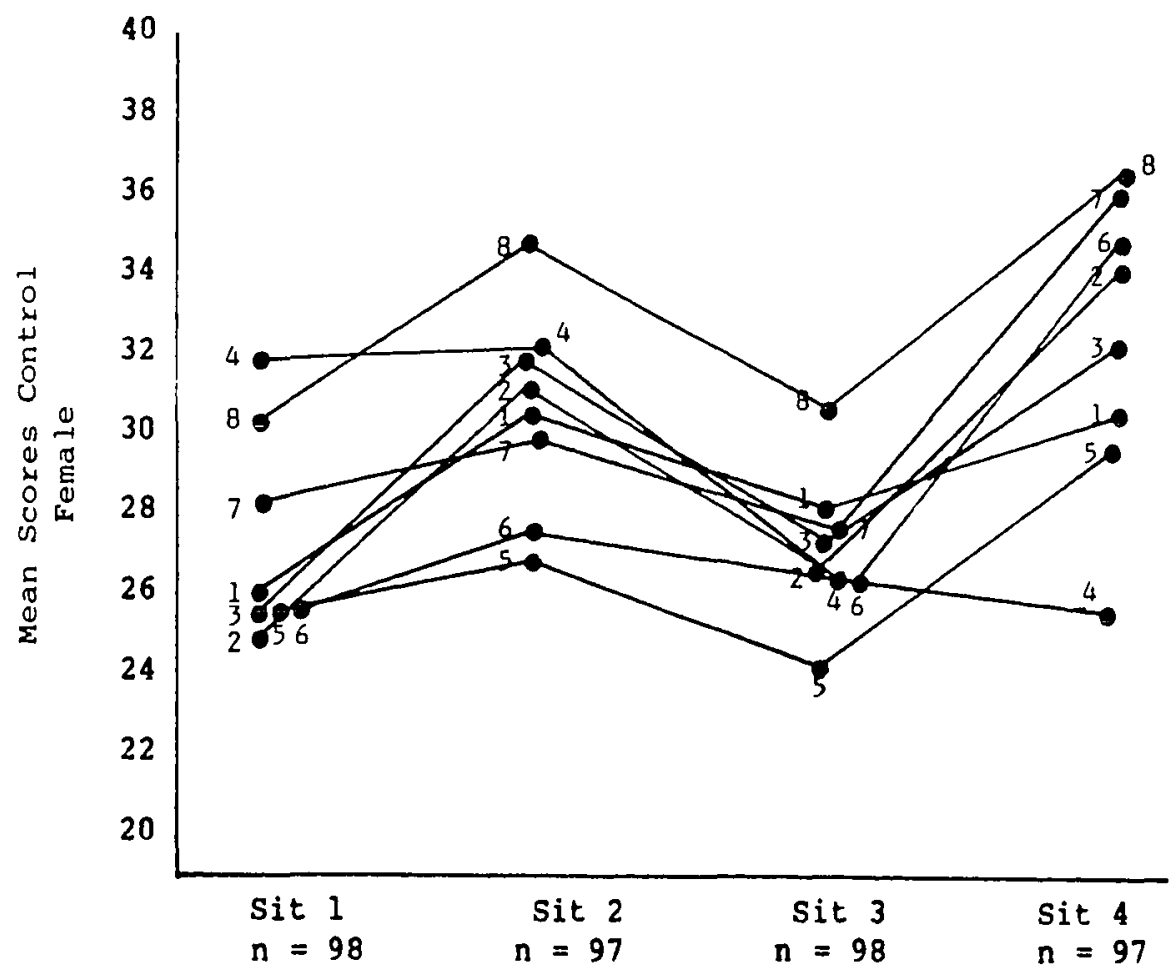

1 = LOP LOC LOI

21

21

21

20

$2=$ LOP LOC HiI

13

13

13

13

3 = LOP HiC LOI

13

13

13

13

$s=$ LOP HiC HiI

7

$\sigma$

7

7

$5=$ HiP LOC LOI

8

8

8

$6=$ HiP LOC HiI

8

8

8

7 = HiP HiC LOI

16

16

16

16

$8=$ HiP HiC RiI

12

12

12

12

$n$ of cases

Pigure 8. Mean scores control - female. 


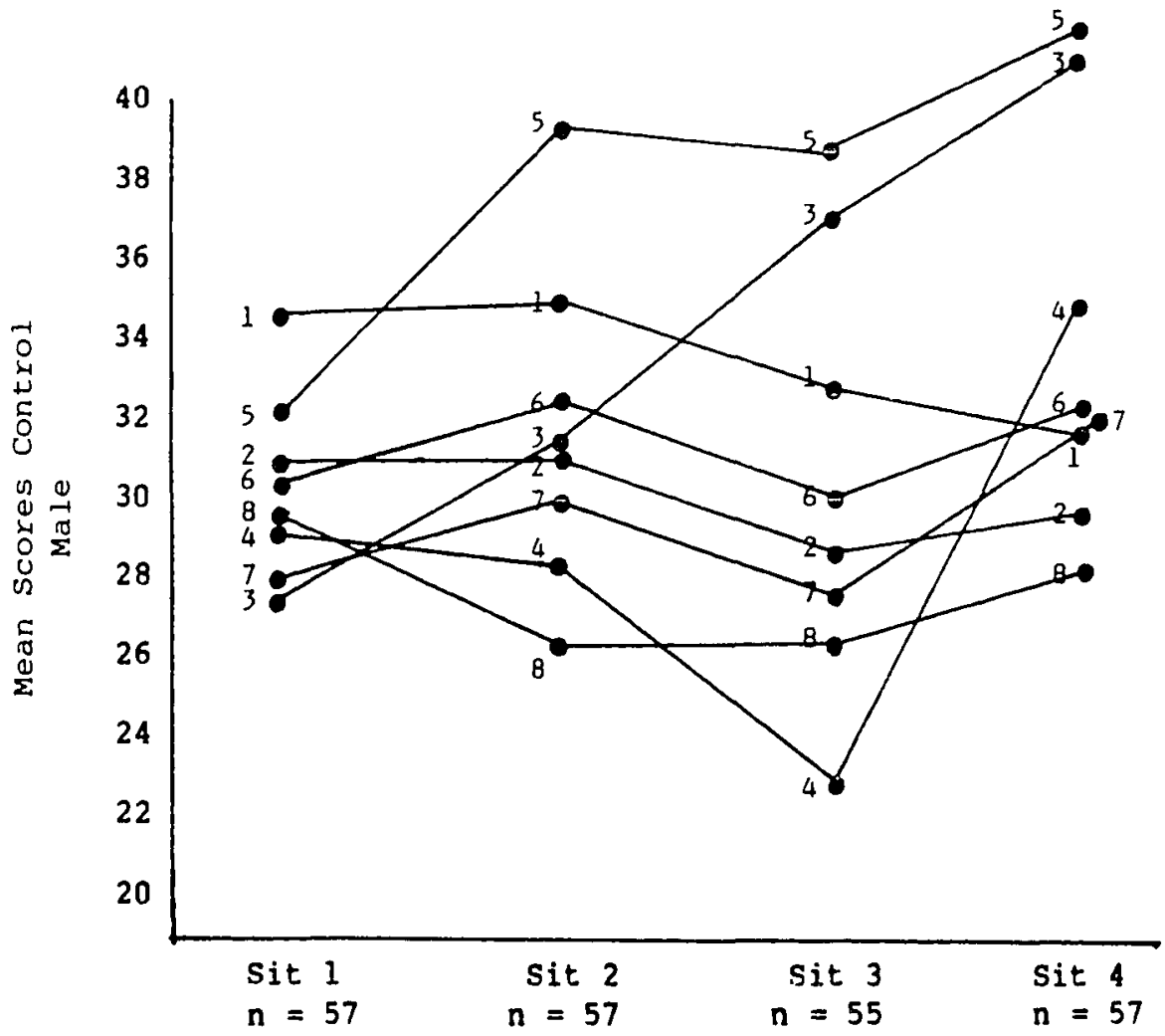

$1=$ LOP LOC LOI

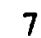

6

$2=$ LOP LOC HiI

10

10

10

10

$3=$ LOP HiC LOI

2

2

2

2

$4=$ LOP HIC HiI

7

7

7

5 = HiP LOC LOI

1

1

1

$6=$ HiP LOC HiI

7

7

7

$7=$ HiP HiC LOI

8

8

8

8

$8=$ HiP HiC HiI

15

15

14

15

$n$ of cases

Pigure 9. Mean scores control - male. 
TABLE XXI

NUMBER OP CASES LOCUS OP CONTROL BY SEX

\begin{tabular}{lcc}
\hline Locus of Control & Female & Male \\
\hline LOI & 58 & 18 \\
HiI & 40 & 39 \\
LOC & 50 & 25 \\
HiC & 48 & 32 \\
LOP & 54 & 26 \\
HiP & 44 & 31
\end{tabular}

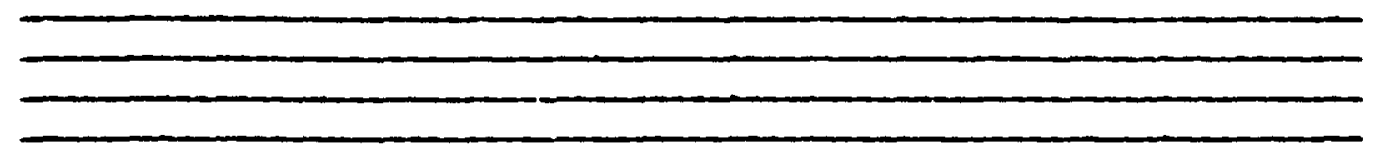

\begin{tabular}{|c|c|c|c|c|c|}
\hline & LOC & $\mathrm{HiC}$ & & LoC & $\mathrm{HiC}$ \\
\hline HiP & 8 & 12 & nip & 7 & 15 \\
\hline \multicolumn{6}{|c|}{ HiI } \\
\hline LOP & 13 & 7 & LOP & 10 & 7 \\
\hline HiP & 8 & 16 & HiP & 1 & 8 \\
\hline \multicolumn{6}{|l|}{ LOI } \\
\hline LOP & 21 & 13 & LOP & 7 & 2 \\
\hline
\end{tabular}

Figure 10. Locus of control by sex with solution-orientation scores from situation 4 (155 cases). 


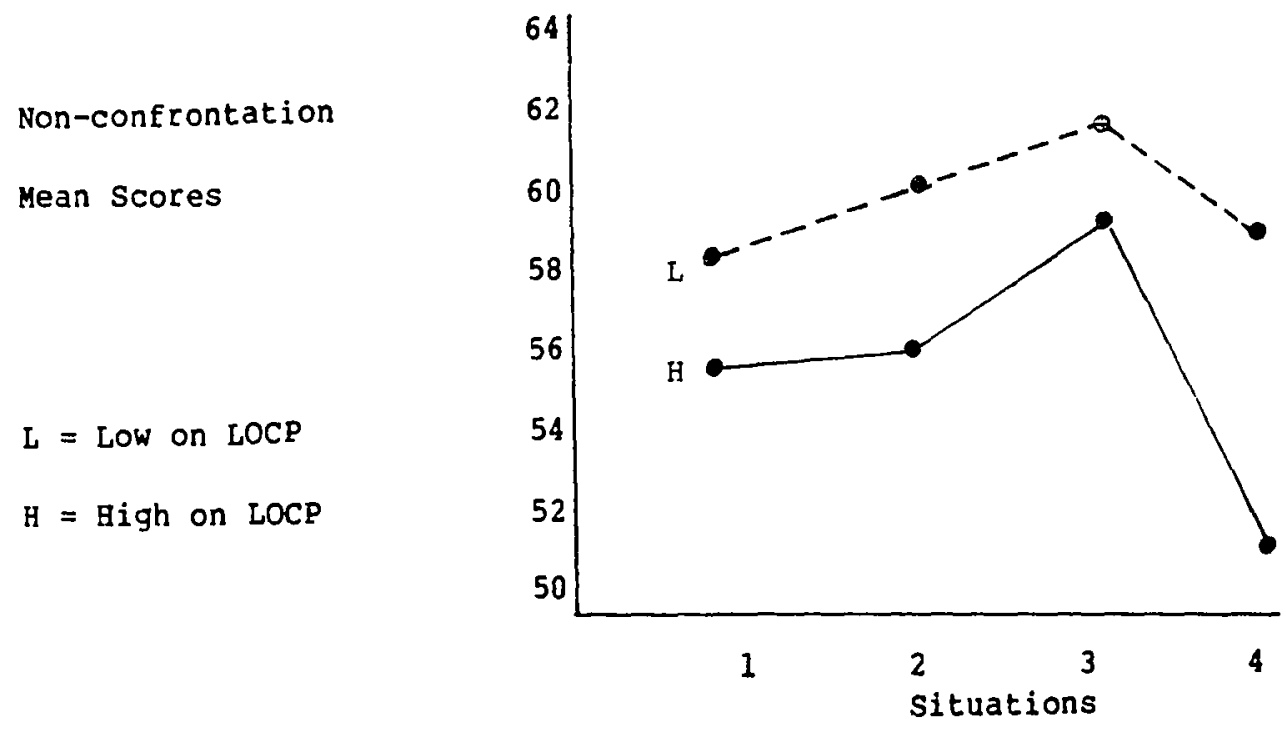

Figure 11. Relationship between LOCP and non-confrontation behavior.

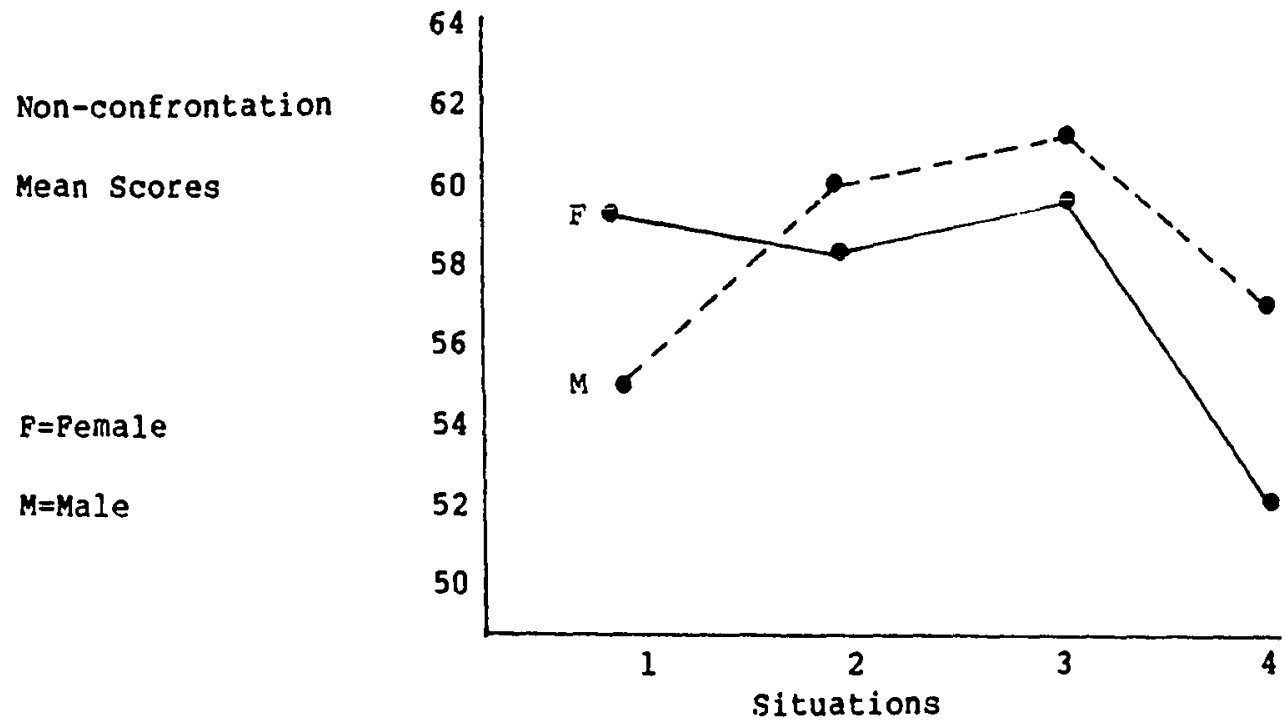

Pigure 12. Interaction of sex across situation and nonconfrontation behavior. 
Mean scores on

Solution-

Orientation

$\mathrm{F}=$ Pemale

$\mathbf{M}=$ Male

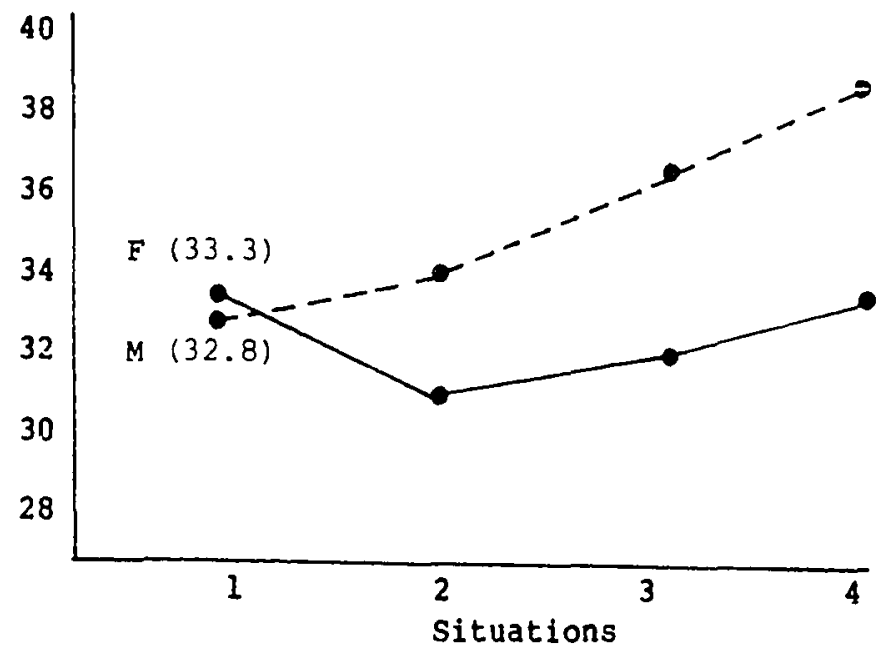

Figure 13. Relationship between sex and solution-orientation behavior.

In Situation 1 , males and females are choosing solutionorientation behavior within $1 / 2$ a point of each other, yet in the rest of the situations females choose solution-orientation behavior significantly more. Situation 2 represents the situation in which solution-orientation is regarded as the appropriate choice of behavior. The four-way interaction LOCP $X$ LOCC $X$ sex $x$ situation is reported in Figure 14, but because of the small number of cases in several cells, interpretation will not follow.

Control

The ANOVA for control contained several significant results. Some of the findings are more interpretable than others. Pigure 15 demonstrates the interaction of LOCI $x$ situation (which only became significant when sex was included in the analysis, see page 63).

In the first two situations the Lo $I$ is choosing control more than $\mathrm{Hi}$ I and then in situations $3 \& 4$ this reverses -- Hi I chooses control 
strategy more than Lo I. Situation 3 is the one which calls for that behavior, and yet both $\mathrm{Hi}$ and LO I are choosing control in situation 1 to a similar degree as the $\mathrm{HI} I$ is in situation 3.

The interaction of LOCI and sex for control behavior (Eigure 16) shows an interesting pattern that is also reflected in the LOCC $x$ sex interaction and the LOCP $\mathrm{x}$ LOCC $\times$ sex interaction (Pigures 17 and 18 respectively).

Being low on the Locus of Control orientation results in more use of the control strategy for females, while being high on the Locus of Control orientation results in the reverse, that is more use by males of the control strategy. As reported in Pigure 19, there is also the fourway interaction of LOCP $\times$ LOCC $\times$ Sex $\times$ situation.

ADDITIONAL RINDINGS

Since there was a significant main effect caused by situation in each of the ANOVAs, this is evidence that a significant portion of the variance in choice of conflict behavior can be attributed to the situation. However, individuals show some consistency in the approaches taken in the different conflict situations as well. For each conflict strategy the amount of between-subjects variance was significant (nonconfrontation $\mathrm{F}(145,435)=5.80, \mathrm{p}<.05$; solution-orientation $F(145,435)=6.32, p<.05$; control $F(145,435)=4.37, p<.05)$. In addition, intra-class correlations reflect a large proportion of the variance due to subjects (non-confrontation .62, solution-orientation .64, control $.53)$. 

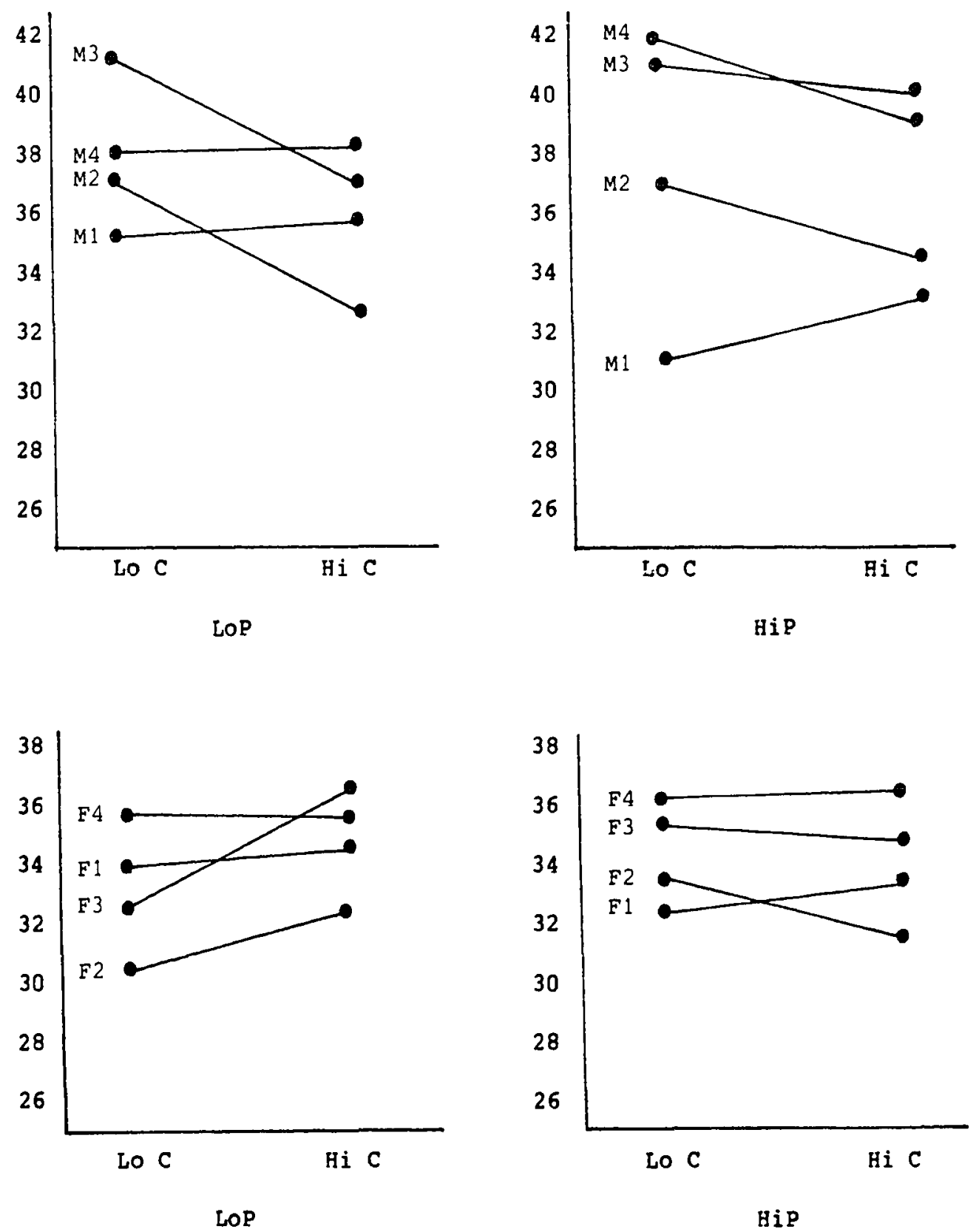

$$
\begin{array}{lll}
M=\text { Male } & 1=\operatorname{sit} 1 & 2=\text { sit } 2 \\
P=\text { Pemale } & 3=\operatorname{sit} 3 & 4=\operatorname{sit} 4
\end{array}
$$

Pigure 14. Four-way interaction: LOCP $x$ LOCC $x$ sex $x$ situation for solution-orientation behavior. 


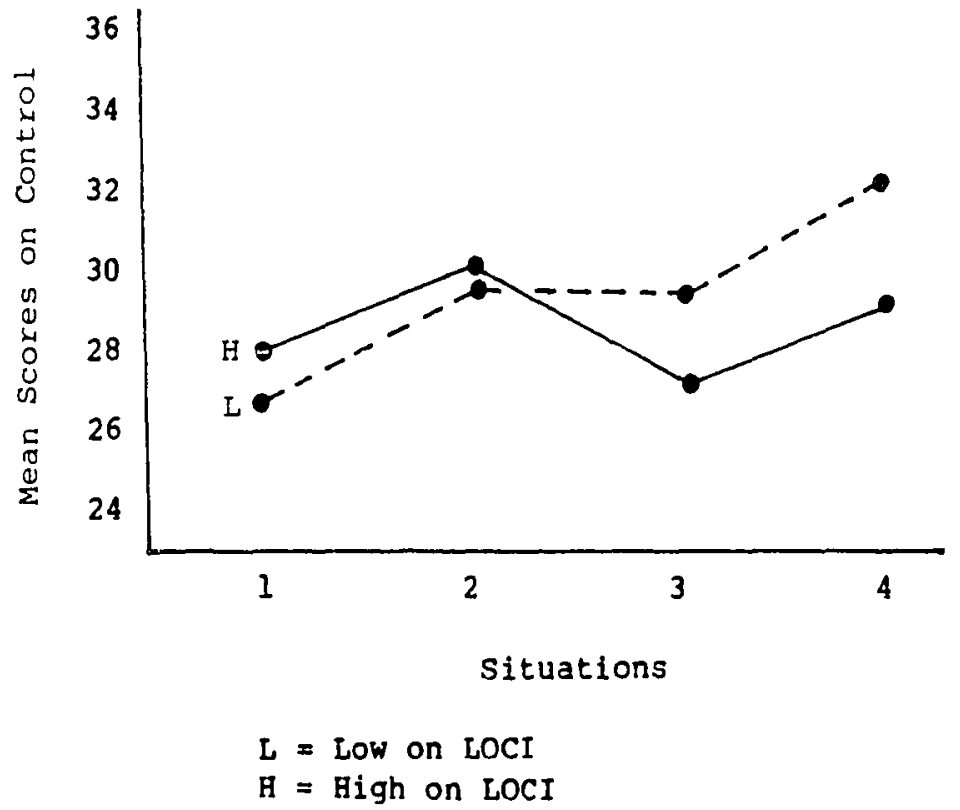

Figure 15. Interaction LOCI and situation for control behavior.

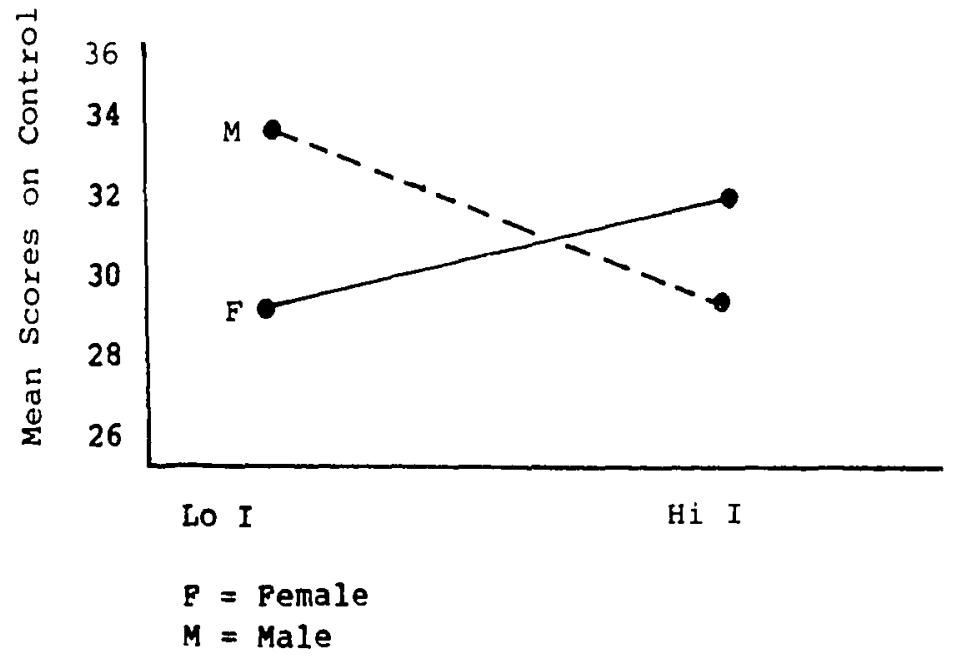

Pigure 16. Interaction of LOCI and sex for control behavior. 


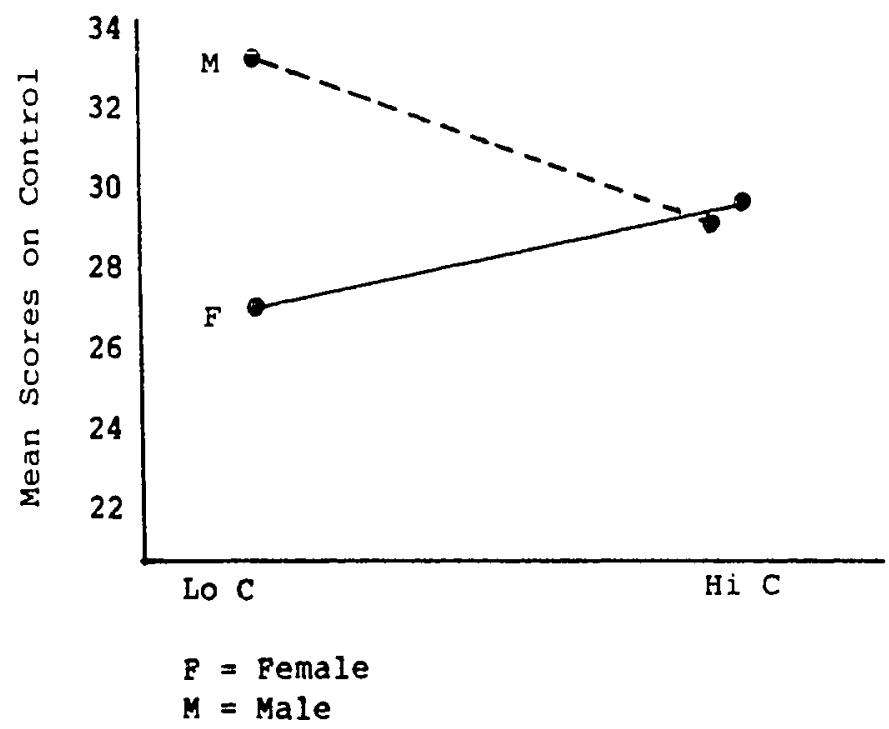

Pigure 17. Interaction of LOCC and sex for control behavior.
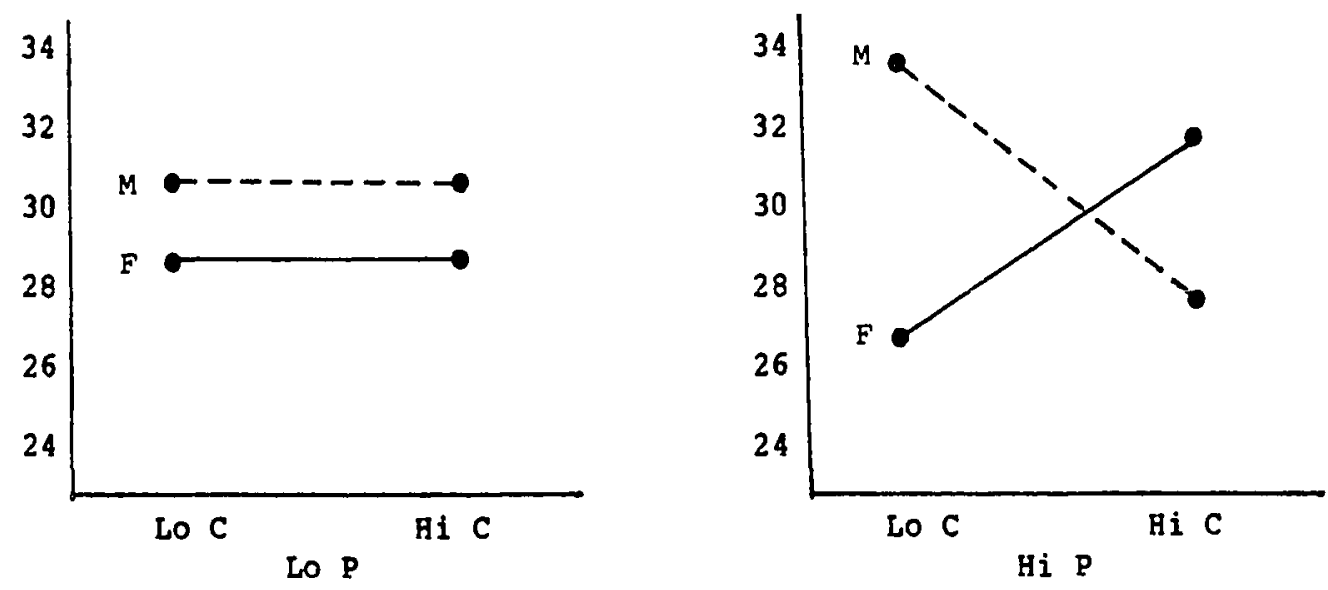

Mean scores on control

$F=$ Pemale $\quad M=$ Male

(This looks more like graph at right when cells with smallest (This pattern is consistent $n$ are removed from both $P$ and $M$, across situations.) but means for $B i$ and Lo $C$ Pemales don't differ.l

Figure 18. Interaction of LOCP and LOCC and sex for control behavior. 

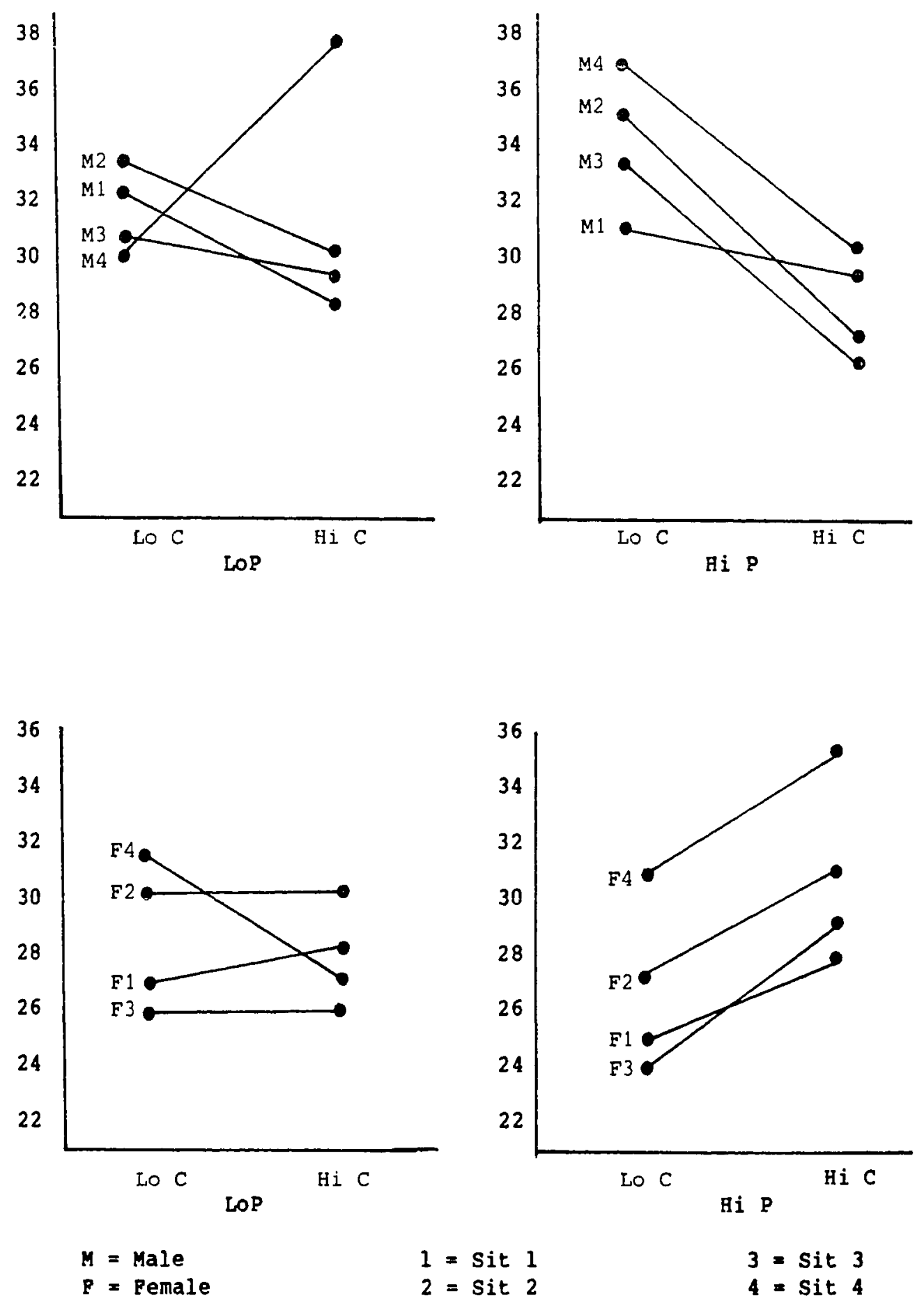

$1=$ sit 1

$2=$ sit 2

$3=$ sit 3

$4=$ sit 4

Pigure 19. Four-way interaction: LOCP $\times$ LOCC $\times$ sex $\times$ situation for control behavior. 
TABLE XXII

MEAN SCORES OF CONFLICT BEHAVIOR ACROSS SITUATIONS (LOWER MEAN IS HIGHER USE OR STRATEGY)

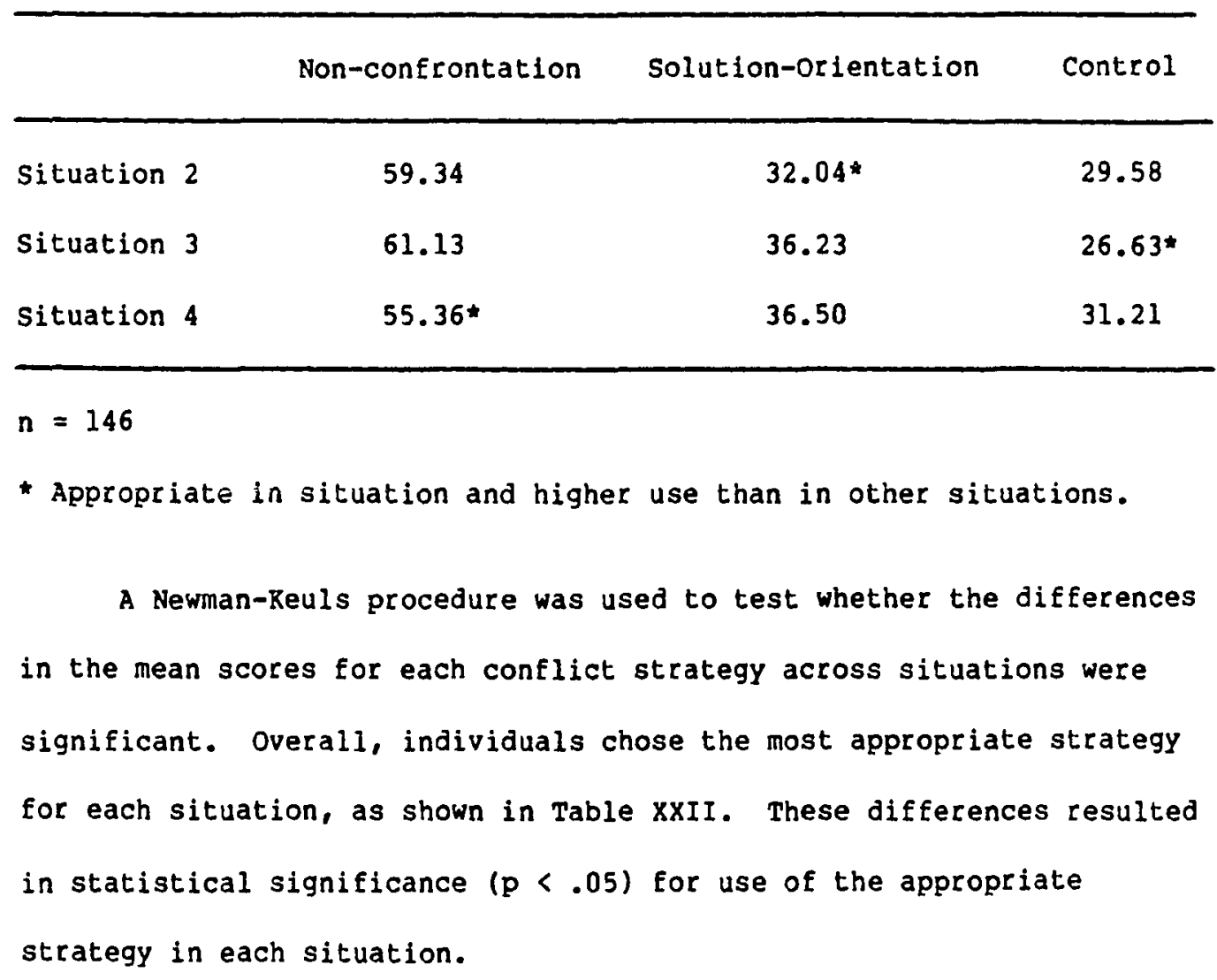


CHAPTER PIVE

DISCUSSION

RESPONSE TO HYPOTHESES

As restated from page 34-35, the first set of hypotheses were:

HI: Internal Locus of Control orientation would predict the choice of solution-orientation behavior.

H2: Powerful Others and Chance Locus of Control orientation would predict the choice of non-confrontation behavior.

H3: The Powerful others Locus of Control orientation would predict the choice of control behavior.

The canonical correlation results from situation 1 indicate some support for $\mathrm{H} 2$, but not for $\mathrm{Hl}$ nor H3. There was a statistically significant ( $p<.001)$ correlation due to the relationship between Powerful others Locus of Control and non-confrontation behavior. Being high powerful others locus of control orientation indicates more use of non-confrontation behavior. Upon further investigation, this same pattern of behavior was found in situations 2, 3, and 4, although not statistically significant in situation 3. This lends even stronger support for the hypothesis that Powerful others orientation predicts the choice of non-confrontation behavior. No other locus of control orientation was found to predict choice of conflict behavior strategy. The other set of hypotheses predicted the relatively pure types on Locus of Control (high on one dimension, low on the other two) would behave in the particular patterns as shown on page 38 . Since the 
results of the Multivariate Analysis of variance procedures did not reflect these predictions for the whole sample, it is inappropriate to reduce the number of cases for analysis by selecting out fust the relatively pure types (three of the eight cells). Refer to plots of the eight cells, for females and males, for each of the conflict strategies pages 66 to 71 for substantiation. The nain hypothesis, that subjects with an Internal Locus of Control orientation would be most flexible in choosing the effective conflict behavior in the particular situation was unsupported. However, the Powerful Others Locus of Control orientation did predict the use of non-confrontation behavior. And in situation 4 , where non-confrontation is the effective conflict strategy, having a high Powerful Others Locus of Control orientation seems to result in more ability to choose the effective conflict behavior. Before discussing the other findings it seems appropriate to offer some explanations for why several of the hypotheses were not supported. For each conflict strategy, the situation was a very strong significant main effect $(p<.001)$. It is possible that the strength of this relationship is masking other relationships, and/or individual differences. Another intervening factor may be that the Powerful others and Chance Locus of Control orientations are somewhat inter-correlated.

OTHER FINDINGS

Although these other results were unexpected, they nonetheless, offer a valuable contribution to the conflict behavior literature and theory development. 
Interaction - Sex $\times$ Situation in Non-confrontation

The interaction of sex and situation for non-confrontation behavior, reflected in Pigure 12, shows an interesting pattern of behavior. Sex role stereotypes of male and female behavior are supported by this finding. Pemales choose non-confrontation more than males in all situations except for the first situation. Male/female differences in choice of non-confrontation for situations 2,3 , and 4 are not significant statistically, hence there is no main effect for sex in the non-confrontation ANOVA. However, the fact that males choose non-confrontation more than females in the first situation is significant. In addition, males are choosing non-confrontation more in their intimate relationships than they are in the disagreement with their professor.

It seems that differences in female/male perception of power in relation to resolving conflicts are being reflected in this finding -if we can apply the finding of the link between Powerful others Locus of Control and non-confrontation behavior. That is, another way of explaining the Powerful others Locus of Control-non-confrontation behavior relationship is simply, that feeling powerless leads to nonconfrontation behavior. Therefore, females perceive themselves to be more powerless in resolving conflict situations than males except in intimate relationships.

This finding also seems consistent with the commonly held belief that males are less emotionally expressive than females, particularly in intimate relationships. Putnam and Wilson (1982) reported that males rely more than females on non-confrontation approaches when they are 
socialized in their place of employment. In other words, for males, the more involved personally, the more non-confrontation is chosen to deal with conflict.

Another possible explanation for males choosing non-confrontation more in the intimate relationship situation contradicts the previous discussion. While conducting a conflict management workshop not long ago, two men commented that they disagreed with my Table I (page 26) on characteristics of situations. They both said they thought nonconfrontation was effective in situations where they had more power (rather than less). In other words, confrontation wasn't necessary (and certainly not enjoyable) if one has more power. Perhaps the result I obtained is an indication of those perceptions. Because males feel in control and in power in their intimate relationships they can afford (and prefer) to choose a non-confrontation strategy.

\section{Main Effect - Sex and Solution-Orientation Behavior}

The only significant main effect for sex was found in the solution-orientation ANOVA (Refer to Figure 13). From the information available in the canonical correlation it is the relationship between sex and solution-orientation behavior in situations 2 and 3 that contribute significantly. Situation 2 was the one that called for using solution-orientation behavior, females choose it more than males. Pemales are also relatively consistent in their use of solutionorientation behavior with scores ranging from approximately $31-33$ across all situations.

These findings also contribute to commonly held beliefs regarding the differences between male/female conflict behavior. Females are 
considered more prone to cooperating and compromising rather than asserting their own needs, as reflected in the solution-orientation behavior. Interestingly, females chose this conflict strategy as often in their intimate relationships as they did in their disagreement with their professor.

This seems to indicate that whether or not solution-orientation is effective, females are choosing it, as in the disagreement with the professor. Direct confrontation -- the problem solving approach -- is not considered effective in situation 4.

This finding may be providing evidence of the socialization process for males and females. Females are socialized to integrate the needs of others into possible solutions, males are not. Females are socialized to be more expressive emotionally than males. Males are socialized to be more assertive about their needs. The impact of attempts to reduce sex-role stereotyping in the socialization process seems limited if these explanations are correct.

\section{Pour-Way Interactions}

The four-way interaction in the solution-orientation ANOVA as seen in Figure 14, LOCP $x \operatorname{LocC} x \operatorname{sex} x$ situation is difficult to interpret. In addition to being difficult it may not be particularly meaningful since in several of the subgroups a small number of cases are involved. The same is true for the four-way interaction of the control ANOVA (Pigure 19).

In looking at both of them together, it seems that there isn't much difference in the Lo P groups, whether they be Hi C or Lo $\mathrm{C}$. However, in the Hi $P$ groups there is some difference (particularly in 
the control ANOVA) between LO $\mathrm{C}$ and $\mathrm{Hi} \mathrm{C}$; and males and females are moving in opposite directions.

Locus of Control Internal and Situation in Control

The LOCI $X$ situation interaction in the control ANOVA (Figure 15) although quite unexpected offers a unique perspective that could increase our understanding of control behavior. In the first two situations, there is not much difference in choice of control behavior between Lo or $\mathrm{Hi} I$. Then in situations 3 and 4 , being $\mathrm{Hi} I$, or perceiving outcomes to be contingent on one's cwn behavior results in more use of control. Situations 3 and 4 both involve a power differential; in 3 the subject has more power, in 4 the subject has less power. In situations with a power differential, whether or not one believes outcomes are contingent on his/her behavior becomes relevant.

The control behavior is characterized simply as "I win, you lose", or being more assertive in meeting one's own needs than in cooperating to meet the other's needs. It seems plausible that the experience of using control behavior could lead one to get what one wants, and therefore feel that outcomes are contingent upon one's behavior. Both $\mathrm{Hi}$ and Lo I are using control approximately the same and as much in the first situation as $\mathrm{Hi}$ I does in the third situation where it is appropriate/effective. The canonical correlations indicate that the relevant factor in the first situation is sex; perhaps that explains why Locus of Control Internal orientation does not seem to differentiate usage. Again, $\mathrm{Hi}$ I is composed of a 50/50 male/female split; Lo I is disproportionate female to male. 
The high use of control by all subjects in the first situation seems to support in part the theory inherent in the initial hypotheses of this study. The first situation was designed to reflect one's natural response to conflict - hypothesized to develop from one's family experiences. The high use of control indicates, again, a lack of concern for the other's needs in resolving the disagreement. In the family, the modes of conflict resolution seem to be win-lose; rarely negotiation for mutual benefit between parent and child. The learned behavior becomes: assert your needs and whether you get what you want or not may or may not be contingent upon your behavior. The learned behavior also does not include a sensitivity to the other' $\mathrm{g}$ needs rather a survival behavior lacking confidence that being sensitive to other's needs is beneficial.

Locus of Control and Sex Interactions for Control

The Locus of control and sex interactions in the control ANOVA as seen in Figures 16,17 , and 18 , reflect a similar pattern - although with some variance in degrees. The basic relationship is that females and males respond in opposite manners as differentiated on the Hi or Lo Locus of Control orientation. Being Lo and female on I, C, and C within Hi P predicts more use of control than the males. However, being Hi I, C, and $C$ wthin Hi p predicts more male use of control. And the female and male choice of control as descrlbed above is at the same level; that is, Lo I females and Hi I males are choosing control to the same degree across all situations.

While the Lo I, $C$ and $C$ within $H i$ males and the $H i I, C$, and $C$ within Hi females reflect less choice of control, they are not at 
corresponding levels. That 1s, females choose control only slightly less on the $\mathrm{Hi}$ Locus of Control orientations and males choose control substantially less on the Lo Locus of Control orientations.

It seems plausible that this finding is affected by the number of cases of males to females on each of these dimensions.

\section{Choice of Effective Behavior}

'Table XXII reflects a very unexpected result; all subjects reflected a significant overall tendency to choose the effective conflict behavior strategy in the particular situation. The original hypotheses suggested that some individuals would reflect more ability than others to choose the appropriate/effective strategy. The question still remains as to whether or not an individual would actually behave in a conflict situation as $s /$ he indicated on the OCCI. Several researchers have investigated the difference between verbal behavior and performance (Lapierre, 1934; Wicker, 1969). However, the knowledge of what's appropriate seems well understood. This finding supports the concept that individuals do possess the desite to act appropriately in conflict and the intellectual understanding of skills that are required, and vary in ability to act accordingly. Another interpretation of this result is that there were indeed differences in ability to choose the effective conflict behavior strategy, but locus of control orientations and sex did not distinguish these differences significantly. There were obviously those that scored above the mean and those that scored below; and therein lies a difference in ability to choose the effective behavior. One can see from the Figures 4-9 (pages 66 to 71 ) that although not significant, 
there are differences between the eight combinations on Locus of Control.

What seems remarkable about this finding, is that the situation descriptions were only 3-4 sentences in length, with the characteristics being implied and not stated explicitly. And yet these situations conveyed quite significantly behavior that could be considered effective and most appropriate.

RESPONSE TO RELEVANT QUESTIONS

There was reference, on pages 19-20, to the relevant questions about conflict behavior that this study attempted to answer. How do the results of this study contribute to our understanding of conflict behavior?

Relationship Between Conflict Behavior and Personal Characteristics

Is there a relationship between an individual's conflict behavior style and personal characteristics such as feelings of power and control?

Yes. Having a Powerful others Locus of Control orientation, reflecting a belief that outcomes are contingent on powerful others is related to choosing non-confrontation conflict behavior. This holds true across situations. Extending personal characteristics to include sex differences, there is also a relationship between sex and solutionorientation behavior. In this case, however, this does not seem to relate to feelings of power and control, at least as defined by Locus of Control orientations. 
The sex and Locus of Control orientation interactions found in the control conflict behavior strategy are also evidence of the relationship between conflict behavior style and personal characteristics. It is curious that the sex and Locus of Control orientation interactions are more abundant in the control strategy, control behavior being that in which one use's his/her power to get the desired result.

\section{Effect Relationship has on Choice of Behayior}

If there is a relationship between personal traits and conflict behavior, does it affect one's choice of conflict behavior in particular situations? There are relationships, as discussed above; however, is there evidence that these relationships affect choice of conflict behavior in situations?

Two interactions of personal traits with situations provide support for an affirmative answer to this question. The sex and situation interaction in the non-confrontation strategy and the LOCI and situation interaction in the control strategy can be interpreted to say that these relationships are affecting choice of conflict behavior in situations. There was also a four-way interaction - including Locus of Control orientations, sex and situation - in two of the conflict behavior strategies (solution-orientation and control), which leads one to conclude that these relationships are affecting choices, even if it is not clear how they do so.

\section{Managing Conflict Effectively}

Can situations be defined so that a particular conflict behavior could be considered effective and therefore most appropriate? 
Situations were defined and validated as reflecting the desired characteristics for which there is support in the literature that a particular conflict strategy is considered effective. In some sense the result that all subjects chose the effective strategy lends some support for the appropriateness. Prior to this study, organizational settings have been used to help define effective conflict resolution modes. This study applied that research and developed it further by testing effective behavior in more interpersonal settings.

Equal Disposition to Choice of Appropriate Behavior Are all individuals equally disposed to choose the effective conflict behavior in the situation?

A contingency approach to conflict behavior states that there is no one best way to handle conflict; the idea that each approach is effective in the appropriate situation is supported by the literature and was a theoretical premise of this study. The unique enquiry made in this study was in relation to an individual's ability to choose the effective conflict behavior in the situation.

Pinding that the situation was a significant main effect for each conflict strategy lends support for the argument that the situation dictates the choice of strategy. However, there were also relationships between choice of conflict strategy and personal characteristics. In addition, there was a large proportion of variance due to subjects as indicated by the intra-class correlations (non-confrontation .62, solution-orientation .64, control .53). The significant betweensubjects variance also indicates that individuals show some consistency in the approaches taken in the different conflict situations. 
Therefore, there was support for both arguments. Bowever, the ability question was a bit more difficult to answer. The entire sample reflected, overall, the ability to choose the effective strategy, and individual differences were not as significant. Within each situation, however, there were some differences that could be considered due to varying abilities to choose correctly. Hi LOCP chose non-confrontation more than Lo LOCP, and particularly in the situation where non-confrontation was the appropriate strategy choice. Females chose solution-orientation behavior more than males, consistently and in the situation where that behavior was appropriate. Prom perusing the individual scores it seemed apparent that some scores remained the same across situations, and others seemed to vary. Even referring to Rigures 4-9 (pp. 66 to 71) one can see that some cells vary more than others. However, attempting to determine that individuals were not equally disposed to choosing the effective conflict behavior was not supported in any significant way by this study.

GENERAL DISCUSSION

This study offers a contribution in more general ways as well. This study provides additional support for separating the locus of control externality orientations into two dimensions: powerful others and chance. And as Levenson (1973) reports, several researchers agree that analyzing data separately for males and females is important. Although not predicted, sex turned out to be a significant independent variable. 
This study also further validates a relatively new measure for conflict behavior, the oCCI. An advantage of the OCCI is that it allows the researcher to describe situations and subsequently assess behavior choices. These situations, as in this study, can place the same subject in very different roles rather than try to obtain similar information by testing different people in those different roles. So that rather than study just a superior-subordinate relationship conflict, it is possible to study peer, superior-subordinate, and subordinate-superior relationship conflicts as well. Nost of the literature has produced results of superior-to-subordinate conflict handling behavior. Musser (1982) uniquely focused on the subordinate conflict handing behavior. The present study views the same individual in all three roles.

Rahim and Bonoma (1979) state that there are no clear guidelines for how conflict should be handled in different situations. The present study provides some guidelines that are clear and understandable that could be used to assess situation conditions and determine appropriate conflict behavior.

Lastly, the results of this study can be applied to existing thought in a unique way. The original hypotheses intended to support both of the major positions in explaining conflict behavior. The findings do this. More specifically, support was found both for the situation and the individual in determining choice of conflict behavior. 
CHAPTER SIK

CONCLUSION

This dissertation left me asking more questions than I feel satisfied that it answered. And so the curiosity that preceded this venture has not been satisfied, but rather still remains. However, as is the case with most research, this dissertation has provided me with a foundation from which to make new journeys.

I am still convinced that individuals are not equally disposed to choose effective conflict behavior in particular situations. Experience seems to provide the evidence for this belief. Conflict behavior and situations are so complex that in some ways it is not surprising that one construct could not distinguish the differences to a large degree. Perhaps those other complexities have interfered with the role played by locus of control, or the situation effects were so strong that they over-shadowed individual differences.

The sex differences discovered in this dissertation could fuel my research and explorations for years to come. I have felt that gender differences were caused only by soclalization; however, I am now more convinced that physiological or biological explanations have some credence.

Not only do the results of the data that were analyzed for this dissertation provide me with a desire for further investigation; I also have the additional data I collected that have barely been considered. Again, the data were collected to truly satisfy my inner need to substantiate what I deeply feel is true; that the family of origin 
where we initially learn conflict behavior (as well as everything else), does not prepare us to manage conflict effectively. That is, we learn to manage conflict from a "one-down" position, and that unless we consciously work to increase our skills in handling conflict, we will remain limited in our ability to assess a situation and act accordingly. And more importantly, that no matter what repertoire of skills we have, the emotional aspect of conflict interferes with our ability to act in ways we may want to or know would be effective.

In the introduction, I stated a pattern of beliefs that seems to affect our ability to manage conflict: I should not want something different than what my parent wants, ..... I don't know what I want. The relationship between the powerful others locus of control orientation and non-confrontation conflict behavior supports this idea. Belleving that powerful others are responsible for outcomes in one's life is related to nonconfrontation...avoiding or accommodating that powerful other. I want to explore that relationship further, to discover what may really be operating. Also, why didn't chance locus of control appear in any distinct form in any of the results?

After attending the Birst International Conference of the conflict Management Group it seems that the research conducted for this dissertation is on the cutting edge in the field. This conclusion was reached since the following issues raised in this dissertation were echoed by many at this conference as the direction for future research in the fleld:

1) the role of power in conflict behavior choices/strategies; 
2) the question of ability to act (skill) in a particular way as distinguished from intent or motivation;

3) the definition of situational characteristics to determine appropriate conflict behavior and provide guidelines;

4) the interaction of situation and personal characteristics; and,

5) the need to focus on actual conflict behavior to counter the limitation of self-report data.

Particlpants also discussed the need for further theoretical development to establish conflict management as a discipline in and of itself. There was no agreement that a separate discipline be established; however, there was agreement on integrating and refining the conflict theory.

As stated by Linda Putnam, a conference leader and author of the instrument used in this study to measure conflict behavior strategies, researchers in this field need to move away from attempts to categorize conflict behavior and progress toward developing a model that increases our understanding of the factors that affect choices of behavior. The rational, zero-sum game theory models have not really increased our understanding of conflict behavior. Putnam emphasized models that use situational factors. I'm interested in a particular situational factor - the emotions. Not just the emotional states of the participants, but the effect emotions have on abllity to act in conflict. Unlocking that door, I believe, would provide valuable information to increase effective conflict managenent. 
AFTERWORD

When this dissertation experience began, I was promised that at the end of the Chapter Pive rainbow I could write a Chapter Six in which I could put into words the heart and soul of this undertaking. That is, once I fulfilled the requirements for rigorous scientific research, I could discuss at last why I dedicated two intense years of my life to this work and what it all means to me now.

When I began this dissertation I was advised by one of my committee members to think of my 1 ife's work, and imagine the dissertation as the first chiseling away at the block of stone of my life's work. I realize that in a very real sense, my life's work involves dealing with conflict personally and professionally, and learning as well as teaching others that effective conflict management incorporates the emotional aspect of the conflict situation and the individuals involved.

The reason I have been so attracted to mediation as opposed to law for dispute resolution.... actually there are many reasons, and they are all related to my world view and my life's work. Mediation not only acknowledges the emotional aspect of conflict, it expects the parties to express their emotions during the process. Healthy "ventilation" can lead people to better solutions and more lasting settlements. Mediation empowers people to solve their own problems. Mediation approaches conflict from a non-adversarial, power-balancing perspective. This dissertation would not be complete, nor a real reflection of my heart and soul if Alice Miller was not mentioned. Her writings are brilliant and I believe she is one of the most advanced thinkers of my 
time. Among her many valuable insights, she asserts that it is not the fact that we experience trauma as children that causes us to be neurotic in adult life, but rather that we cannot express our feelings as we experience the trauma. The repression and denial of our emotional reality is what is at the root of our later difficulties and issues in life. In that vein, I believe that the repression of the emotional content in conflict, or the denial that it can play a vital, healthy role in reaching resolutions, is at the root of our difficulties in managing conflict effectively. She also analyzes the inherent power difference between parents and children which I believe shapes adult conflict behavior.

Referring back to the introduction (p. 7), I am still interested in further defining and understanding the actual behavior "what can do" and the intervening factors of style preference, previous experience, level of skill, feelings, and any other factors that play a role. 
REFERENCES

Austin, W., \& Worchel, S. (Eds.), (1979). The social psychology of intergroup relations. Monterey, CA: Brooks/Cole.

Axelrod, R. (1984). The evolution of cooperation. New York: Basic Books.

Baxter, L. A., shepherd, T. L. (1978). sex-role identity, sex of other, and affective relationship as determinants of interpersonal conflict management styles. Sex Roles, 4, 813-825.

Beck, P. (1979). Locus of control and task instruction effects upon creative problem solving. Unpublished doctoral dissertation. Pordham University.

Bell, E. C., \& Blakeny, R. N. (1977). Personality correlates of conflict resolution modes. Human Relations, 30, 849-857.

Blake, R. R., \& Mouton, J. S. (1964). The managerial grid. Houston: Gulf.

Brown, C. T., Yelsma, P., \& Reller, P. W. (1981). Communicationconflict predisposition: Development of a theory and an instrument. Human Relations, 34, 1103-1117.

Burger, J. M. (1979). Locus of control, motivation, and expectancy: Predicting hypnotic susceptibility from personality variables. Unpublished manuscript, Center for Research in Social Behavior, University of Missouri-Columbia, Columbia, Mo.

Burke, R. J. (1970). Methods of resolving superior-subordinate conflict: The constructive use of subordinate differences and disagreements. Organizational Behavior and Human Performance, $\underline{5}$, 393-411.

Caster, D. U., \& Parsons, O. A. (1977). Locus of control in alcoholics and treatment outcome. Journal of studies in Alcohol, 38, 20872095.

Chesler, M. A., Crowfoot, J. E., E Bryant, B. (1978). Power training: An alternative path to conflict management. California Management Review, 21, 84-90.

Coleman, J. S. (1957). Community conflict. New York: The Free Press. 
Coser, L. A. (1956). The functions of social conflict. New York: Free Press.

Coser, I. A. (1967). Continuities in the study of social conflict. New York: The Free Press.

decharms, R. (1981). Personal causation and locus of control: Two different traditions and two uncorrelated measures. In $H . M$. Lefcourt (Ed.), Research with the locus of control construct, Vol. 1 (pp. 337-358). New York: Academic Press.

Deci, E. L., \& Ryan, R. M. (1985). The general causality orientations scale: Self-determination in personality. Journal of Research in Personality, 19, 109-134.

deReuck, A., \& Rnight, J. (Eds.), (1966). Conflict in society: A Ciba Foundation volume. London: $J \& A$. Churchill.

Derr, B. (1978). Managing organizational conflict. California Management Review, 21, 76-83.

Deutsch, M. (1973). The resolution of conflict. New gaven, CT: Yale University Press.

Eisenman, R. (1972). Experience in experiments and change in internalexternal control scores. Journal of Consulting and Clinical Psychology, 39, 434-435.

Filley, A. C. (1975). Interpersonal conflict resolution. Glenview, IL: scott Roresman.

- (1978). Some normative issues in conflict management. California Management Review, 21, 61-66.

Fisher, B. A. (1974). Small group decision making: Communication and the group process. New York: McGraw-Hill Book Co.

Fisher, R., \& Ury, W. (1981). Getting to yes: Negotiating agreement without giving in. Boston, Mass.: Houghton Mifflin.

Pisher, R. S. (1972). Third party consultation: A method for the study and resolution of conflict. Journal of Conflict Resolution, 16, 67-94.

Folger, J. P., \& Poole, M. S. (1984). Working through conflict. Glenview, IL: Scott Poresman \& Co.

Follet, M. P. (1940). Constructive conflict. In H. C. Metcalf \& L. Orwick (Eds.), Dynamic administration: The collected papers of Mary Parker Pollet (pp. 30-49). New York: Harper Brothers. 
Garcia, C., \& Levenson, B. (1975). Differences between blacks' and whites' expectations of control by chance and powerful others. Psychological Reports, 37, 563-566.

Gibb, J. R. (1961). Defensive communication. Journal of Communtcation, September, 141-148.

Gricar, B. C., \& Brown, D. L. (1981). Conflict, power, and organization in a changing community. Human Relations, 34, 877-893.

Gulliver, P. H. (1979). Disputes and negotiations: A cross cultural perspective. New York: Academic Press.

Gurin, P., Gurin, G., Lao, R., \& Beattie, M. (1969). Internal-external control in the motivation dynamics of Negro youth. Journal of Social Issues, 25, 29-53.

Hocker, J. H., Wilmot, พ. พ. (1985). Interpersonal conflict. Iowa: Wm. C. Brown.

Jamieson, D. W., \& Thomas, K. W. (1974). Power and conflict in the student-teacher relationship. Journal of Applied Behavioral Science, 10, 321-336.

Jandt, F. E. (Ed.), (1973). Conflict resolution through communication. New York: Harper \& Row.

Joe, v. C. (1971). Review of the internal-external control construct as a personality variable. Psychological Reports, 28, 619-640.

Jones, R. E., \& Melcher, B. H. (1982). Personality and the preference for modes of conflict resolution. Human Relations, 35, 649-658.

Kahn, R. L., \& Boulding, E. (Eds.), (1964). Power and conflict in organizations. New York: Basic Books.

Rerlinger, F.N. (1973). Poundations of behavioral research. Holt, Rinehart, \&inston.

Rilmann, R. H., Thomas, R. W. (1975). Interpersonal conflicthandling behavior as reflections of Jungian personality dimensions. Psychological Reports, 37, 971-980.

- (1977). Developing forced-choice measure of conflict-handling behavior: The "MODE" instrument. Educational and Psychological Measurement, 37, 309-325.

Rindler, H. (1983). The art of managing differences. Training and Development Journal, 37, 26-32.

Romorita, S., \& Chertkoff, J. (1973). A bargaining theory of coalition formation. Psychological Review, 80, 149-162. 
Lapierre, R. T. (1934). Attitudes vs. actions. Social Porces, 13, 230237.

Lawrence, P. R., \& Lorsch, J. W. (1967). Organization and environment. Boston: Earvard University, Graduate School of Business Administration.

Lee, F. (1976). A study of sex differences in locus of control, tennis, expectancy for success and tennis achievement. Unpublisher? doctoral dissertation, University of Oregon.

Lefcourt, 月. (1981). The construction and development of the multidimensional-multi-attributional causality scales. In $\mathrm{H}$. M. Lefcourt (Ed.), Research with the locus of control construct, Vol 1 (pp. 245-277). New York: Academic Press.

Lefcourt, H. M. (1982). Locus of control. Laurence Erlbaum Assoc.

Levenson, B. (1981). Differentiating among internality, powerful others, and chance. In $B . M$. Lefcourt (Ed.), Research with the locus of control construct, Vol 1 (pp. 15-63). New York: Academic Press.

Levenson, H. L. (1973a). Multidimensional locus of control in psychiatric patients. Journal of Consulting and Clinical Psychology, 41, 397-404.

- (1973b). Perceived parental antecedents of internal, powerful others, and chance locus of control orientations. Developmental Psychology, 9, 260-265.

- (1974). Activism and powerful others: Distinctions within the concept of internal-external control. Journal of Personality Assessment, 38, 377-383.

Levenson, H. L., Mahler, I. (1975). Attitudes toward others and components of internal-external control. Journal of Personality Assessment, 38, 377-383.

Levenson, 月. L., \& Miller, J. (1976). Multidimensional locus of control in sociopolitical activists of conservative and liberal ideologies. Journal of Personality and Social Psychology, 33, 199-208.

MacDonald, A. P. (1971). Internal-external locus of control: Parental antecedents. Journal of Consulting and Clinical Psychology, 37, 141-147.

Marshall, P. S. (1979). Multidimensional locus of control and psychological adjustment in a semi-rural group of women. Unpublished doctoral dissertation, Colorado State University. 
Martin, D. (1979). Changes in locus of control in psychiatric patients as a regult of short term hospltalization. Unpublished Manuscript, P.O. Box 352, Madison, NJ 07940.

Miller, A. (1981). Drama of the gifted child. New York: Basic Books. - (1984). Ror your own good. New York: Parrar, Straus, \& Giroux. - (1984). Thou shalt not be aware. New York: Farrar, Straus, Giroux.

Minuchin, S. (1974). Families and family therapy. Cambridge: Harvard University Press.

Molinari, V. (1979). Locus of control. Unpublished doctoral dissertation, ohio state University.

Morelli, G., Rrotinger, B., \& Moore, S. (1979). Neuroticism and Levenson's locus of control scale. Psychological Reports, 44, 153-154.

Musser, S. J. (1982). A model for predicting the choice of conflict management strategies by subordinates in high-stakes conflicts. Organizational sehavior and Human Performance, 29, 257-269.

Napier, A. Y., \& Whitaker, C. A. (1978). The family crucible. New York: Harper \& Row.

Nowicki, S., \& Duke, M. P. (1974). A locus of control scale for noncollege as well as college adults. Journal of Personality Assessment, 38, 136-137.

Nunnally, J. C. (1978). Psychometric theory, (2nd ed.). New York: McGraw-Hill.

Oberschall, A. (1973). Social conflict and social movements. New Jersey: Prentice-hall.

Palenzuela, D. L. (1984). Critical evaluation of locus of control: Towards a reconceptualization of the construct and its measurement. Psychological Reports, 54, 683-709.

Paulhus, D. (1983). Sphere-specific measures of perceived control. Journal of Personal and Social Psychology, 44, 1253-1265.

Paulhus, D., \& Christie, R. (1981). Spheres of control: An interactionist approach to assessment of perceived control. In $\mathrm{H}$. M. Lefcourt (Ed.), Research with the locus of control construct, Vol 1 (pp. 161-188). New York: Academic Press.

Phillips, E., \& Cheston, R. (1979). Conflict resolution: What works? California Management Review, 21, 76-83. 
Prince, G. M. (1975). Creativity, self, and power. In Taylor, I. A., \& Getzels, J. H., Perspectives in creativicy (pp. 249-277). Chicago: Aldine.

Prociuk, T. J., \& Breen, L. J. (1975). Defensive externality and its relation to academic performance. Journal of Personality and Social Psychology, 31, 549-556.

- (1976). Machiavellianism and locus of control. Journal of Social Psychology, 98, 141-142.

Putnam, L. L. \& Wilson, C. E. (1982). Communicative strategies in organizational conflicts: Rellability and validity of a measurement scale. Communication Yearbook, 6, 629-652.

Rahim, M. A. (1983). A measure of styles of handling interpersonal conflicts. Academy of Management Journal, 26, 368-376.

- (1985). A strategy for managing confliet in a complex organization. Human Relations, 38, 81-89.

- (1985). Referent role and styles of handling interpersonal conflict. Journal of Social Psychology, 126, 79-86.

Rahim, M. A., \& Bonoma, T. V. (1979). Managing organizational conflict: A mode for diagnosis and intervention. Psychological Reports, 44, 1323-1344.

Raiffa, H. (1982). The art and science of negotiation. Cambridge, Mass.: The Belknap Press of farvard University Press.

Rapoport, A. (1974). Conflict in man-made environment. Baltimore, Maryland: Penguin Books.

Reid, D.H., \& Ziegler, M. (1981). The desired control measure and adjustment among the elderly. In H. M. Lefcourt (Ed.), Research with the locus of control Construct, Vol 1 (pp. 127-159). New York: Academic Press.

Reinsch, D. F. (1979). Locus of control, rigidity, and life satisfaction among elderly British subjects. Unpublished master's thesis. University of Calgary, Ontario.

Renwick, P. A. (1975). Impact of topic and source of disagreement on conflict management. Organizational Behavior and Human Performance, 14, 416-425. - (1977). Effects of sex-differences on the perception and management of conflict: An exploratory study. Organizational Behavior and Guman Performance, 19, 403-415. 
Robbins, S. P. (1978). Conflict management and conflict resolution are not synonymous terms, Califfornia Management Reyiay, 2르, 67-75.

Rotter, J. B. (1966). Generalized expectancies for internal versus external control of reinforcement. Psychological ironographs, 80, (1, Whole No. 609).

- (1975). Some problems and misconceptions related to the construct of internal versus external control of reinforcement. Journal of Consulting and Clinical Psychology, 43, 56-67.

Rubin, J. 2., \& Brown, B. (1975). The soclal psychology of bargaining and negotiation. New York: Academic Press.

Ryckman, R. M., \& Malikioski, M. (1975). Relationship between locus of control and chronological age. Psychological Reports, 36, 655658 .

Schelling, T. C. $(1960)$. The strategy of conflict. Cambridge, MA: Harvard University Press.

Sennet, R. (1970). The uses of disorder. Vintage Books.

Shearer, R. A., \& Moore, J. B. (1978). Personality dimensions of felonious probationers in Texas. Paper presented at the meeting of the American Society of Criminology, Dallas, November.

Simmel, G. (1955). Conflict and the web of group affiliations. Glencoe, IL: Rree Press.

Smith, P. (1980). Group processes and personal change. London: Harper $\&$ Row.

Strickland, B. R., \& Haley, W. E. (1980). Sex differences on the Rotter I-E scale. Journal of Personality and Social Psychology, 29, 930939.

Swingle, P. A. (Ed.), (1970). The structure of conflict. New York: Academic Press.

Terhune, R. W. (1970). The effects of personality in cooperation and conflict. In P. Swingle (Ed.), The strlicture of conflict (pp. 193234). New York: Academic Press.

Thomas, R. . (1976). Conflict and conflict management. In M. Dunnette (Ed.), Handbook of industrial and organizational psychology (pp. 889-935). Chicago: Rand MeNally.

- (1977). Toward multi-dimensional values in teaching: The example of conflict behaviors. Academy of Management Review, 2 , 484-490. 
Thomas, R. W., Jamieson, D. W., \& Moore, R. R. (1978). Conflict and collaboration: Some concluding observations. California Management Review, 21, 91-95.

Thomas, R. W., \& Rilmann, R. H. (1975). The social desirability variable in organizational research. Academy of Management Journal, 18, 741-752.

Thomas, R. W., \& Pondy, L. R. (1977). Toward an "intent" model of conflict management among principle parties. Human Relations, 30, 1089-1102.

Throop, W. F., \& MacDonald, A. P., Jr. (1971). Internal-external locus of control: A bibliography. Psychological Reports, 28, 175-190.

Trigg, L. J., Perlman, D., Perry, R. P., \& Janisse, M. P. (1976). Antipollution behavior: A function of perceived outcome and locus of control. Environment and Behavior, 8 , 307-313.

Wallston, R. A., Wallston, B. S. (1978). Health locus of control. Health Education Monographs, 6. San Francisco: Society for Public Health Education.

- (1981). Health locus of control scales. In H. M. Lefcourt (Ed.), Research with the locus of control construct, Vol I (pp. 189-243). New York: Academic Press.

Wicker, A. W. (1969). Attitudes versus action: The relationship of verbal and overt behavioral responses to attitude objects. Journal of Social Issues, 25, 41-78.

Worell, L., \& Tumilty, T. N. (1981). The measurement of locus of control among alcoholics. In $\mathrm{K}$. M. Lefcourt (Ed.), Research with the locus of control construct, yol 1 (pp. 321-333). New York: Academic Press.

Yelsma, P., Brown, C. T. (1985). Blological sex, and predisposition to conflict management. Sex Roles, 12, 731-747.

Zammuto, R. F., London, M.., \& Rowland, K. W. (1979). Effects of sex and commitment and conflict resolution. Journal of Applied Psychology, 64, 227-231.

Zukotynsii, G. E., \& Levenson, H. (1976). Perceptions of control by the elderly in a relocation environment. Unpublished manuscript. Murdoch Center, Butner, NC 27509. 
APPENDIX A

INFORMED CONSENT FORM 
I, , hereby agree to serve as

a subject in the research project investigating how people deal with conflict conducted by Mary zinkin.

I understand that the study involves completing six questionnaires. I understand that taking six questionnaires at one sitting may feel repetitive to me, and that it takes less than one hour. It has been explained to me that the purpose of the study is to learn more about choosing conflict behavior in different situations. I may not receive any direct benefit from participation in this study, but my participation may help to increase knowledge which may benefit others in the future.

Mary zinkin has offered to answer any questions I may have about the study and what is required of me in the study. I have been assured that all information I give will be kept confidential and that the identity of all subjects will remain anonymous.

I understand that I am free to withdraw from participation in this study without jeopardizing my course grade or my relationship with Portland State University.

I have read and understand the foregoing information.

Date: Signature: 
If you experience problems that are the result of your participation in this study, please contact Victor C. Dahl, office of Graduate studies and Research, 105 Neuberger Rall, Portland State University, 229-3423. 
APPENDIX B

LOCUS OF CONTROL SCALE 
PLEASE NOTE:

Copyrighted materiais in this document have not been filmed at the request of the author. They are available for consultation, however, in the author's university library.

These consist of pages:

APPENDIX B: pp. 111-114

APPENDIX C: pp. 116-129

\section{University}

Microfilms International

300 N. ZEEB RD. ANN ARBOR, MI 48106 (313) 761.4700 
APPENDIX C

CONFLICT INSTRUMENTS 
APPENDIX D

ADDITIONAL QUESTIONNAIRE 
1. Did you have any hunches about the purpose of the study? Yes No

2. If yes, what did you think it was investigating?

3. Do you have any suggestions for improving the study?

4. Were the questions in the first questionnaire clear? (You may refer to it again) Yes No

5. What did you think the first questionnaire was measuring?

6. What did you think the other four questionnaires, following the first, were measuring?

The following pages ask questions about the situations described in the four questionnalres. Please do not refer to them, but answer the questions as best you remember the situations. 
A. Please answer the following questions thinking of the situation describing a disagreement with your loyer-friend on where to go for vacation. Please circle the number that best reflects your response.

1. Was this situation real to you?

Not very real

Not sure

Very real

1

2

3

4

5

2. Did you feel you had a position of power over the other party? Less power

Equal power

More power

1

2

3

4

5

2. Which was more important; the goal you were trying to achieve, or maintaining the relationship with the other person?

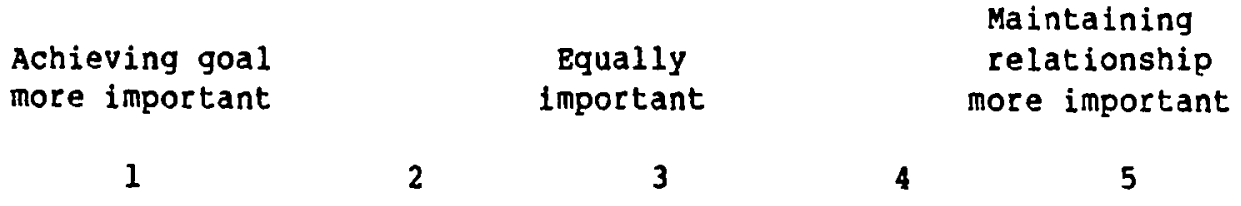

4. In this situation, did you feel you needed to make a decision to resolve the disagreement quickly?

Not quickly

Somewhat quickly

Very quickly

1

2

3

4

5

5. Is this the kind of situation in which both people's ideas would contribute to the resolution of the disagreement?

Only mine would
contribute

1
Both would

contribute only other's would contribute

2

3

4

5

6. Did you feel it was a temporary situation?

Not temporary

Somewhat temporary

Very temporary

1

2

3

4

5

7. What would you describe the cause of the conflict to be?
1. Value differences
2. Communication
3. Other 
B. Please answer the following questions thinking of the situation describing a disagreement with your assistant on covering a rally for the newspaper. Please circle the number that best reflects your response.

1. Was this situation real to you?

Not very real

Not sure

Very real

$\begin{array}{lllll}1 & 2 & 3 & 4 & 5\end{array}$

2. Did you feel you had a position of power over the other party? Less power Equal power

More power

1 2 3

4

5

2. Which was more important; the goal you were trying to achieve, or maintaining the relationship with the other person?

$\begin{array}{ccccc}\begin{array}{c}\text { Achieving goal } \\ \text { more important }\end{array} & 2 & \begin{array}{c}\text { Equally } \\ \text { important }\end{array} & \begin{array}{c}\text { Maintaining } \\ \text { relationship } \\ \text { more important }\end{array} \\ 1 & 2 & 3 & 4 & 5\end{array}$

4. In this situation, did you feel you needed to make a decision to resolve the disagreement quickly?

Not quickly

Somewhat quickly

very quickly

1

2

3

4

5

5. Is this the kind of situation in which both people's ideas would contribute to the resolution of the disagreement?
Only mine would
contribute

1

2

Both would

contribute

3

6. Did you feel it was a temporary situation?

Not temporary

Somewhat temporary

1

2

3
Only other's would contribute

4

5 
c. Please answer the following questions thinking of the situation describing a disagreement with your co-worker on the presentation format for a class project. Please circle the number that best reflects your response.

1. Was this situation real to you?

Not very real

1
Not sure

3
Very real

4

2. Did you feel you had a position of power over the other party?

Less power

1
Equal power

3

More power

2

5

2. Which was more important; the goal you were trying to achieve, or maintaining the relationship with the other person?

Âchieving goal

more important

1
Equally important

Maintaining relationship more important

4

5

4. In this situation, did you feel you needed to make a decision to resolve the disagreement quickly?

Not quickly

1
Somewhat quickly

3
Very quickly

4

5

5. Is this the kind of situation in which both people's ideas would contribute to the resolution of the disagreement?

only mine would contribute
Both would

contribute only other's would contribute

1 2

3

4

5

6. Did you feel it was a temporary situation?

Not temporary

Somewhat temporary

1

2

3

4

Very temporary

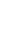

5

7. What would you describe the cause of the conflict to be?
1. Value differences
2. Communication
3. Other 
D. Please answer the following questions thinking of the situation describing a disagreement with your professor on the requirement of a particular assignment. Please circle the number that best reflects your response.

1. Was this situation real to you?

Not very real

Not sure

Very real

1

2

3

4

5

2. Did you feel you had a position of power over the other party?

Less power

1

2

Equal power

More power

3

4

5

2. Which was more important; the goal you were trying to achieve, or maintainirg the relationship with the other person?

$\begin{array}{cccc}\begin{array}{l}\text { Achieving goal } \\ \text { more important }\end{array} & \begin{array}{c}\text { Bqually } \\ \text { important }\end{array} & 3 & \begin{array}{c}\text { Maintaining } \\ \text { relationship }\end{array} \\ 1 & 2 & 4 & 5\end{array}$

4. In this situation, did you feel you needed to make a decision to resolve the disagreenent quickly?

Not quickly

Somewhat quickly

Very quickly

1

2

3

4

5

5. Is this the kind of situation in which both people's ideas would contribute to the resolution of the disagreement?

Only mine would contribute
Both would contribute
Only other's would contribute

4

5

2

3

6. Did you feel it was a temporary situation?

Not temporary

Somewhat temporary

Very temporary

1

2

3

4

5

7. What would you describe the cause of the conflict to be?
1. Value differences
2. Communication
3. Other 


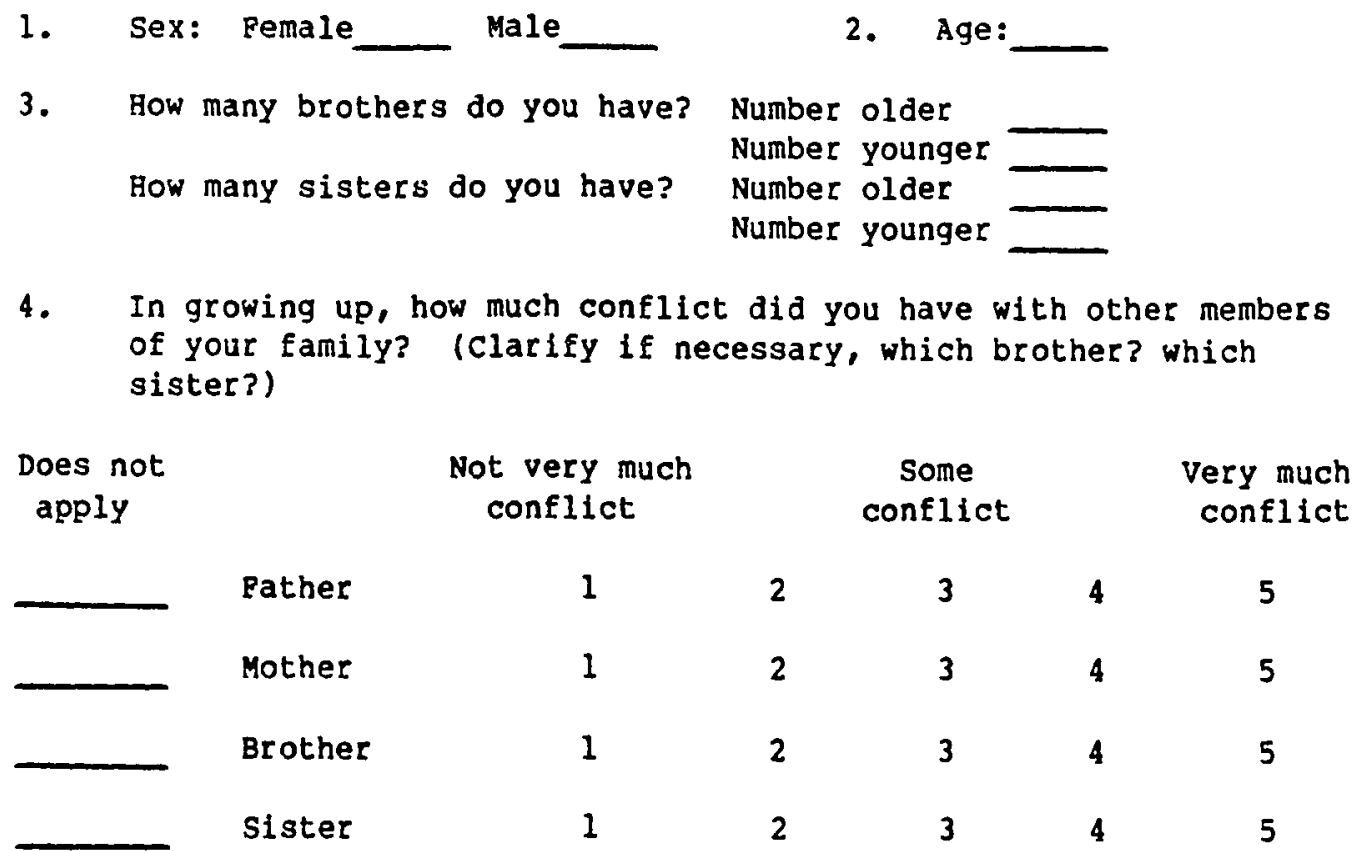

5. How much did children participate in decision-making in your family?

Not at al1

sometimes

Very often

1

2

3

4

5

6. In growing up, how much influence did you feel in relationships with your brothers/sisters? Does not apply

Not very much

influence

Some influence

Very much

1

2

3

4

5

7. How effective do others see you as being in dealing with conflict?

Much less effective than others

1
About the same

as others
Much more effective than others

2

3

4

5 
8. In general, in dealing with conflict with others, how much do you feel you get what you want?

I get what I want most often
We each get

what we want
They get what they want most often

\section{1}

2
4

5

9. In general, in dealing with conflict, do you put more value on the relationship with the other person, or on the goal you are trying to achieve?
Goal more
Equally
Important
Relationship
important 2 3 more important
1 4 5

10. Do you have any comments you'd like to make about your experience participating in this researcin? 